\title{
THREE ESSAYS ON EDUCATOR LABOR MARKETS: EVIDENCE FROM MISSOURI PUBLIC SCHOOLS
}

\author{
A Dissertation presented to
}

the Faculty of the Graduate School

at the University of Missouri

In Partial Fulfillment

of the Requirements for the Degree

Doctor of Philosophy

by

SHISHAN SHI

Dr. Michael Podgursky, Dissertation Supervisor

MAY 2013 
(C) Copyright by Shishan Shi 2013

All Rights Reserved 
The undersigned, appointed by the dean of the Graduate School, have examined the dissertation entitled

\title{
THREE ESSAYS ON EDUCATOR LABOR MARKETS: \\ EVIDENCE FROM MISSOURI PUBLIC SCHOOLS
}

presented by Shishan Shi, a candidate for the degree of Doctor of Philosophy and hereby certify that, in their opinion, it is worthy of acceptance.

\section{Professor Michael Podgursky}

\author{
Professor Cory Koedel
}

Professor J. Isaac Miller

Professor Shawn Ni

Professor Dana Weston 
I dedicate this dissertation to my grandma. 


\section{ACKNOWLEDGMENTS}

I would like to express my appreciation to my dissertation advisor, Dr. Michael Podgursky, for his academic and financial support, guidance and help throughout this research. I am also deeply grateful to my dissertation committee member, Dr. Cory Koedel, who introduced me into the research in Economics of Education, generously shared his knowledge with me on so many aspects, and patiently spent his precious time editing my paper. Without his tolerance of my ignorance and occasionally greatly appreciated pushes, I would not have been able to be on current stage. I also want to express my thanks to my committee members, Dr. J. Isaac Miller and Dr. Shawn Ni, who helped me build my foundation of Econometrics knowledge and writing skills. I highly look up to their intelligence and research attitude. I would like to extend my appreciation to my outside committee member, Dr. Dana Weston from the Department of Mathematics, who generously shared her knowledge in Mathematics and warmly encouraged me throughout my graduate study. Appreciation is extended to Dr. Chris Wikle from the Department of Statistics, who introduced me to the world of Spatial Analysis and is always willing to arrange extra meetings to discuss my questions. My gratitude also goes to Dr. Mark Ehlert, who trained me to use data from DESE and SAS programming in Linux. In addition, I want to thank Dr. Douglas Miller, from whom I had my initial training on Econometrics. Without his excellence in teaching, I might be intimidated from the beginning and would not have been able to discover my passion for Applied Econometrics.

I would like to give my deep appreciation to my family, most importantly, my beloved grandma, Biyun He, to whom I owe everything. She was the first teacher in my 
life journey and raised me to be the person I am today. Without her unconditional love and ever-lasting support, I would not have been able to finish my Ph.D. and go through difficult periods of my life. She deserves all the credits and will share all my accomplishments. Many thanks go to my parents for giving me life, and my aunts for their dedication and love.

I have been blessed with lots of friends. I would like to thank Lynne Riddell, Sheila Akers, JoAnn Kunza and Linda Dyer who are staff from the Department of Economics, not only for their kind help throughout my graduate study, but also for their friendship. I am also grateful to Dianne Boone, who never hesitated introducing me to American culture and different cuisines. As for Amy Schmid, I really enjoy our conversations on things outside the academic world which always enlighten me. Last but not least, I am grateful to Yanyan Huang, Bo Liang, Tingli Kang, Jing Han and Guodong Liang. Thank you for being part of my life and creating good memories in Columbia with me. 


\section{TABLE OF CONTENTS}

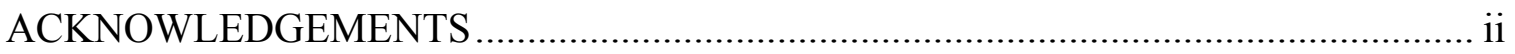

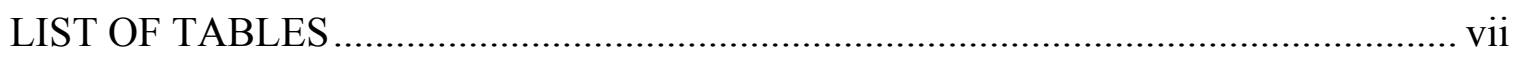

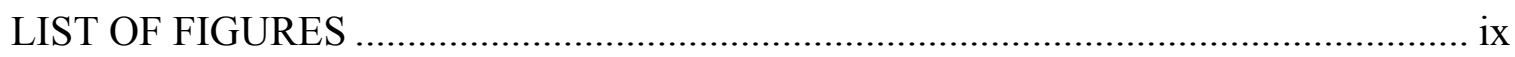

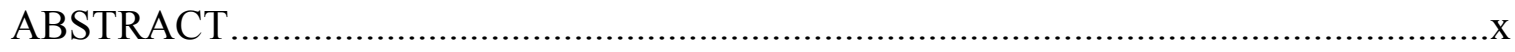

Chapter

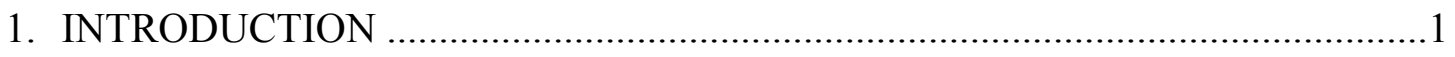

2. MOTIVATION/LITERATURE REVIEW .....................................................

2.1 Teacher Turnover and Mobility

2.2 Principal Turnover

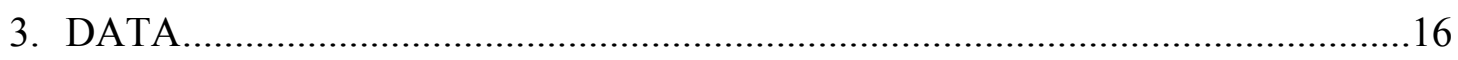

3.1 Teacher Mobility Dataset

3.2 Principal Turnover Dataset

4. The Patterns of Teacher Mobility between High-income Schools and Low- income

Schools 21

4.1 Empirical Strategy

4.1.1 Teacher-Level Models

4.1.2 School-Level Models

4.2 Analysis

4.2.1 Teacher-Level Models

4.2.2 School-Level Models

4.3 Limitation

4.4 Discussions and Policy Implications

5. INTRA-DISTRICT MOBILITY AND INTER-DISTRICT MOBILITY .44

5.1 Teacher Single Salary Schedule and Teacher Tenure 
5.2 Empirical Strategy

5.3 Analysis

5.4 Other Issues

5.4.1 Salary Differentials

5.4.2 Clustering of Schools by Type

5.5 Discussions and Conclusion

6. PRINCIPAL TURNOVER ON STUDENT OUTCOME .68

6.1 Empirical Strategy

6.1.1 Pooled OLS

6.1.2 IV Strategy

6.1.3 Supplemental Analysis

6.1.3.1 Robustness Check for the IV

6.1.3.2 Five-Year Analysis

6.2 Analysis

6.2.1 Main Results

6.2.2 Robustness Check for the IV

6.2.3 Time Trend

6.2.4 High-income and Low-income Schools

6.3 Limitation

6.4 Discussions and Conclusion

APPENDIX

A. CREATING NEIGHBORING SCHOOL VARIABLES .85

B. ORDERED PROBIT ESTIMATION RESULTS FOR ELEMENTARY SCHOOL

TRANSFERS. RADIUS: 5, 10, AND 20 MILES..

C. ORDERED PROBIT ESTIMATION RESULTS FOR MJH SCHOOL

TRANSFERS. RADIUS: 5, 10, AND 20 MILES 
D. CROSS-TABULATION FOR TRANSFERS WITH RANDOMLY ASSIGNED SCHOOL TYPES.

E. PERCENTAGES OF CORRECTLY PREDICTED TEACHER MOVES BASED ON ORDERED PROBIT ESTIMATES .....................................................90

F. DISTANCE BETWEEN TWO SCHOOLS FOR INTER-DISTRICT TRANSFERS (MILE) .91

G. ORDERED PROBIT ESTIMATION RESULTS FOR INTRA-DISTRICT ELEMENTARY SCHOOL TRANSFERS. RADIUS: 5, 10, AND 20 MILES 92

H. ORDERED PROBIT ESTIMATION RESULTS FOR INTER-DISTRICT ELEMENTARY SCHOOL TRANSFERS. RADIUS: 5, 10, AND 20 MILES 93

I. ORDERED PROBIT ESTIMATION RESULTS FOR INTRA-DISTRICT MJH SCHOOL TRANSFERS. RADIUS: 5, 10, AND 20 MILES.

J. ORDERED PROBIT ESTIMATION RESULTS FOR INTER-DISTRICT MJH SCHOOL TRANSFERS. RADIUS: 5, 10, AND 20 MILES...............................95

K. PERCENTAGES OF CORRECTLY PREDICTED TEACHER MOVES BASED ON ORDERED PROBIT ESTIMATES

L. AVAILABLE DATA FOR ESTIMATING PRINCIPAL TURNOVER AT DIFFERENT TIMING FOR EACH COHORT IN THE ANALYTICAL SAMPLE

M. ESTIMATES FOR THE OTHER COEFFICIENTS FROM EQUATION (10)

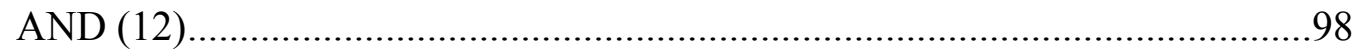

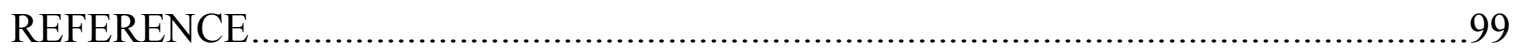

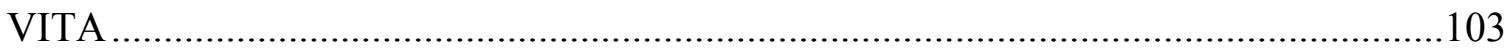




\section{LIST OF TABLES}

Table

Page

3.1 Five-year average percentages by school type: school year 2005-2006 to 20092010 19

3.2 Missouri longitudinal student data file: school year 2007-2008 to 2009-2010 .....20

4.1 Cross-tabulation for transfers by exporting school and importing school types.....37

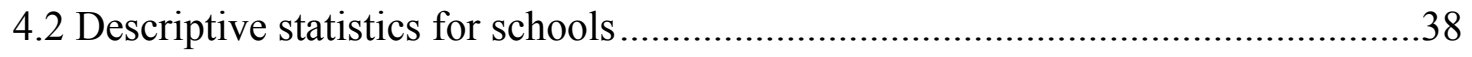

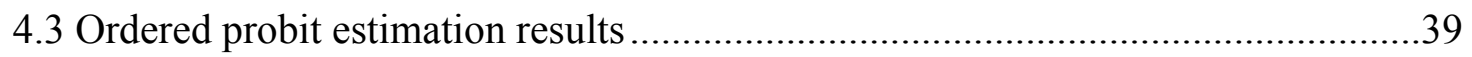

4.4 Probabilities of two representative transfers going to a high-income, or lowincome school evaluated at selected values of covariates ...............................40

4.5 Changes in probabilities of a transfer going to a high-income, or low-income school.

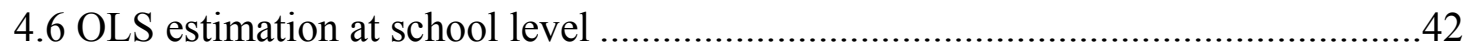

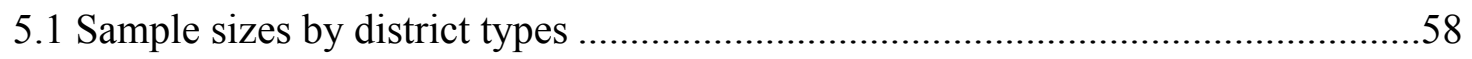

5.2 Cross-tabulation for elementary school transfers by exporting school and importing school types

5.3 Cross-tabulation for MJH school transfers by exporting school and importing school types

5.4 Distance between exporting schools and importing schools (mile)

5.5 Ordered probit estimation results

5.6 Probabilities of two representative transfers going to a high-income, or lowincome school evaluated at the mean value of covariates

5.7 Changes in probabilities of a transfer going to a high-income or low-income school.

5.8 Change in salary (dollar) 
5.9 Cross-tabulation for elementary and MJH school transfers by exporting school and importing school types (randomized within district).......................................66

5.10 Ordered probit estimation results (randomized within district) ........................67

6.1 Regression results of math and reading test scores on principal turnover ..............80

6.2 T-statistics and p-values of $\widehat{\alpha_{1}}$ from the first stage of 2SLS ..............................81

6.3 Regression results of math and reading test scores on principal leaving the

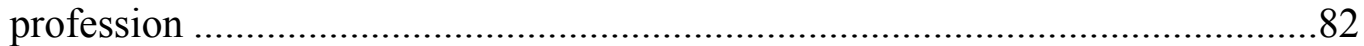

6.4 Regressions of math and reading test scores on principal turnover for low-income

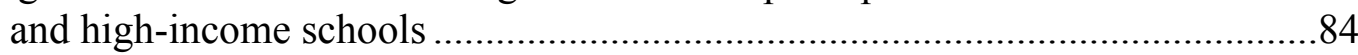




\section{LIST OF FIGURES}

Figure

Page

4.1 Probability of a teacher transfer going to a high-income, middle-income, or low-

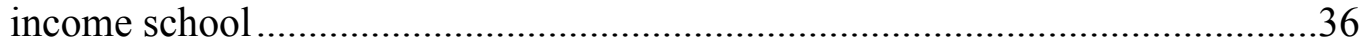

4.2 Map of all schools in Charlotte-Mecklenburg School District .............................43

6.1 Time trends for OLS estimates and IV estimates from main models ....................83 


\title{
THREE ESSAYS ON EDUCATOR LABOR MARKETS: EVIDENCE FROM MISSOURI PUBLIC SCHOOLS
}

\author{
Shishan Shi \\ Dr. Michael Podgursky, Dissertation Supervisor
}

\begin{abstract}
This dissertation consists of three essays. The first essay investigates the feasibility of moving high-performing teachers to low-performing schools using administrative micro data from Missouri. I define teacher labor markets concentrically and construct models to allow teachers' local labor markets, within teaching, to influence their mobility outcomes. I find when a teacher changes schools, other things being equal, this teacher is more likely to go to a socioeconomically similar school in close proximity. Correspondingly, the socioeconomic status of students enrolled in neighboring schools plays a significant role in teachers' transfer decisions. Teachers who move to schools that meaningfully differ along socioeconomic dimensions travel, on average, to schools that are more than 20 miles away from the current schools, although such moves are rare. Conditional on a school's own characteristics, the characteristics of neighboring schools have a small impact on teacher mobility. However, contrary to popular perception, I find no evidence to suggest that disadvantaged schools in close proximity to advantaged schools are at greater risk of "pull" or "push" induced teacher mobility. The reason is that teacher labor markets appear to be strongly segregated by the socioeconomic status of students. In summary, my findings suggest that teacher labor markets are narrow geographically and segregated in terms of the socioeconomic status of students, which raises questions about whether policies designed to encourage teachers to move into substantively different socioeconomic environments can be successful.
\end{abstract}


The second essay studies the differences in the mobility pattern between intradistrict transfers and inter-district transfers. I highlight four main differences. The first is, other things being equal; intra-district transfers are more likely to move to socioeconomically similar schools. This pattern is not evident for inter-district transfers. The second is though all movers are mid-career teachers; intra-district transfers are approximately 5 years older and have approximately 5 more years of experience than inter-district transfers. The third is intra-district transfers move to schools that are less than 5 miles away from the current schools, while inter-district transfers move to schools that are more than 20 miles away from the current schools. The fourth is conditional on a school's own characteristics, the socioeconomic status of students enrolled in neighboring schools within the same district plays a significant role for intra-district transfers. But for inter-district transfers, the socioeconomic status of students enrolled in neighboring schools outside the district doesn't play a significant role for MJH interdistrict transfers.

The third essay utilizes IV strategy and value-added modeling to estimate the impact of principal turnover on student academic achievement. We use the distance from peak-value pension wealth as an IV for the endogenous principal turnover variable. We find that, principal turnover has no significant impact on student academic achievement if a principal turns over at the end of previous school year, or at the end of current school year, or at the end of next school year. We find weak evidence from IV regression that principal turnover has a negative impact on student academic achievement if a principal left two years ago. 


\section{Chapter 1: Introduction}

The large and persistent gap in students' academic performance between advantaged schools (schools serving high-income and high-performing students and a lower percentage of minority students) and disadvantaged schools (schools serving lowincome and low-performing students and a higher percentage of minority students) has been observed for decades and continues to draw much attention from researchers and policymakers. Many factors, such as student, parental, school, neighborhood, principal, and teacher characteristics, affect students' academic performance and contribute to the divergence in academic performance between students at advantaged schools and disadvantaged schools. Recent studies indicate that teacher quality is among the most important factors affecting students' academic performance (Aaronson et al., 2007; Hanushek et al., 2005; Kane et al., 2006; Koedel and Betts, 2011; Rockoff, 2004; Rivkin et al., 2005). Previous research also suggests that teachers in general have a strong preference to teach in advantaged schools, and correspondingly, that disadvantaged schools face challenges in hiring and retaining teachers (Education Week, 2003; Jacob, 2007). Thus, the difference in teacher quality could be an important factor driving the gap between the academic performance of students at advantaged schools and those at disadvantaged schools. Sass et al. (2012) used data from Florida and North Carolina to show that teachers in advantaged schools are, on average, performing better than teachers in disadvantaged schools. This has led researchers to examine the extent to which differences in teacher quality can account for this large and persistent gap in student academic performance. 
As mandated in the No Child Left Behind Act (NCLB), states are required to provide high-quality teachers to all students. Policymakers concerned with existing inequities in access to high-quality teachers for students of differing socioeconomic status have pushed for policies and programs designed to help disadvantaged schools attract and retain effective teachers. However, most of the existing policy pursuits focus on increasing the overall supply of high-quality teachers, and only a very few have targeted an increase in access to high-quality teachers for disadvantaged schools (Education Week, 2003). In addition, the general lack of success of these programs has fueled additional research on alternative approaches aimed at encouraging effective teachers to work in low-performing schools. For example, in 2008 the U.S. Department of Education funded an \$11 million, ten-district experimental study entitled the Talent Transfer Initiative (TTI) that compensates high-quality teachers for being willing to transfer to lowperforming schools (Glazerman et al., 2012). ${ }^{1}$

One key element in the success of the TTI program is the ability to identify highquality teachers who are willing to transfer. To provide more insights for this program, it is important to know the current teacher mobility patterns, in particular, the factors driving teachers moving from high-income schools to low-income schools. I assume teachers take two sequential steps when they change jobs. First, they decide to move and second, they search for job openings in the job market. The analyses in chapters 4 and 5 focus on the second step. In chapter 4, I use administrative datasets from Missouri to study teacher mobility patterns. In particular, I address two questions. First of all, when a teacher is observed changing schools, is this teacher more likely to go to a school with a

\footnotetext{
${ }^{1}$ A brief description of this project can be found here: http://ies.ed.gov/ncee/projects/evaluation/tq_recruitment.asp.
} 
similar or different student body, and how do the characteristics of nearby schools influence mobility? Second, conditional on a school's own characteristics, do the characteristics of neighboring schools affect teacher labor markets?

To address the first question I estimate teacher-level ordered probit models that predict teacher moves using data about the exporting schools and the local choice set of alternative schools. For the second question, I estimate school-level regression models where I regress the percentage of teachers who change schools on the school's own characteristics and the characteristics of neighboring schools.

Similar to other studies in the literature, a limitation of my analysis is that I only observe the equilibrium outcomes from teachers' job searches. Supply and demand factors that influence these outcomes cannot be identified separately (Podgursky et al., 2004). ${ }^{2}$ Another limitation of this study is that I focus on the teacher labor market for transfers as opposed to the general teacher labor market. Thus, teachers' choice sets are more limited and findings are conditional on moving. However, available data still allow for the study of observed teacher mobility patterns and can help to inform current policy discussions.

I highlight two key findings from the analysis. First, teacher labor markets are narrow geographically and socioeconomically homogeneous. If a teacher is leaving a high-income school, she or he is much more likely to move into another high-income school as opposed to a low-income school. Due to the socioeconomic segregation in the

\footnotetext{
${ }^{2}$ Some researchers have been able to study supply or demand separately. For example, Boyd et al. (2011) studied the supply side using applications-to-transfer data from New York State.
} 
labor market, I find no evidence to suggest that disadvantaged schools in close proximity to advantaged schools are at greater risk of "push" or "pull" induced transfers.

My finding that teacher labor markets in Missouri are geographically and socioeconomically narrow is consistent with previous research by Feng and Sass (2010). It is also consistent with Glazerman et al. (2012), who required "A large pool of candidates...to yield the desired number of successful transfers" in their experimental evaluation of a program that induced teacher mobility using pecuniary incentives in ten large school districts. The geographic and socioeconomic narrowness of the current teacher labor market merits careful consideration from policymakers looking to move teachers to geographically distant and socioeconomically different schools. It suggests that such moves are highly abnormal, and consequently, to encourage such moves using pecuniary rewards alone may be costly.

The second key finding from this study is that conditional on moving, teacher who move into schools with different socioeconomic status do not seem to be driven by salary differentials. This result has implications for the design of policies with pecuniary incentives aimed at inducing teacher mobility in the teacher labor markets. In particular, the analysis suggests that teachers are not responsive to pecuniary incentives concerning where they are moving once they decide to move. Thus, it seems reasonable to conjecture that the compensation offered in the TTI program mainly encourages teachers to make the decision to move, which is the first step of teacher changing jobs.

In chapter 5, I separate the analytical sample in chapter 4 into two groups: intradistrict transfers and inter-district transfers. Given that the single salary schedule is 
universally adopted in public school districts (Podgursky, 2007), it is reasonable to investigate these two groups separately. I use ordered probit models to study the intradistrict and inter-district mobility. To differentiate the within-district local labor market and outside-district local labor market, I separate neighboring schools into two groups: within district and outside district.

I highlight four main differences between the two mobility patterns. The first is, other things being equal that intra-district transfers are more likely to move to socioeconomically similar schools. This pattern is not evident for inter-district transfers. The second is that although all movers are mid-career teachers, intra-district transfers are approximately five years older and have approximately five more years of experience than inter-district transfers. The third is that intra-district transfers move to schools that are less than 5 miles away from the current schools, whereas inter-district transfers move to schools that are more than 20 miles away from the current schools. The fourth is conditional on a school's own characteristics, the socioeconomic status of students enrolled in neighboring schools within the same district plays a significant role for intradistrict transfers. For inter-district transfers, the socioeconomic status of students enrolled in neighboring schools outside the district does not play a significant role.

Chapter 6 focuses on another group of educators: principals. As institutional leaders, principals bear more administrative responsibilities, such as supervising the operation of schools, establishing and conducting teacher evaluations, and managing budgets. Studies have shown that good principal leadership is critical for school performance (Edmonds, 1979; Purkey and Smith, 1983), and differences in principal experience may exaggerate the existing academic gap between advantaged schools and 
disadvantaged schools (Clark et al., 2009). Therefore, improving principal quality is of great interest with regard to school reform policies, especially for those that are designed to improve low-performing schools. For example, under the American Recovery and Reinvestment Act of 2009, in fiscal year 2009, the Department of Education allocated \$3.5 billion in Title I School Improvement Grants (SIGs) to reform the nation's lowest performing schools. SIG-awarded schools must implement one of the four models (two of which include replacing principals) to turn around schools.

The popular perception of principal turnover is that replacing ineffective principals would help improve school outcome such as student academic achievement. However, there is not much evidence for that argument mainly because estimating the causal impact of principal turnover on student academic achievement faces two issues. One issue is the definition of the impact of principal turnover. Unlike teachers, who generally affect students directly in the classroom, principals affect student learning in so many indirect ways that it is unclear in the existing literature how independent the measure of the impact of principal turnover should be. For example, when an ineffective principal is replaced with an effective principal, this new principal provides more professional development to help teachers improve, which improves student academic achievement. It is reasonable to assume that different teachers would gain differently from the same professional development. Thus, it is difficult to decide the portion of student gain due to the principal replacement (which provides the professional development), versus teacher quality improvement (which depends on teachers' different leaning ability). Our analysis does not provide more insights on this issue. The other issue, which is related to the first one, is that principal turnover is endogenous in the 
sense that it is correlated with unobserved factors that affect student academic achievement. For example, school district administrators could decide to implement a new policy or a new program that would impact student academic achievement. At the same time, principal could decide to leave the current school because this principal does not agree with this new policy or program.

Our analysis mainly contributes to the second issue by using instrumental variable (IV) strategy to mitigate the bias caused by the endogenous principal turnover variable. In particular, we introduce the distance from peak-value pension wealth for the principal as an IV for principal turnover variable. Two conditions are required for a variable to be a strong IV candidate: (1) the IV is exogenous in the sense that it has to be uncorrelated with unobservable factors in the model and (2) the IV has to be strongly correlated with the endogenous variable. The distance from peak-value pension wealth for the principal is not very likely to be correlated with unobserved factors that affect student academic performance so that it is an exogenous variable. We also expect the closer this distance, the more likely a principal turns over, so that the IV strongly predicts the likelihood a principal turns over. Thus, it is a strong IV candidate for principal turnover variable. We also include school fixed effects to control time-invariant school factors that affect student academic achievement and compare the impact of principal turnover within school.

We identify principals who turnover and compare principal effectiveness as measured by value-added for principals who turn over at the end of a school year to others who do not turn over. In addition, we identify two types of turnovers: (1) leaving from the current school and (2) leaving the profession. To compare the different impacts 
associated with turnover at different times, we identify five turnover times: (1) at the end of the school year three years ago, (2) at the end of the school year two years ago, (3) at the end of previous school year, (4) at the end of current school year and (5) at the end of next school year.

We estimate the impact of principal turnover using longitudinal administrative data from Missouri public schools. Contrary to prior research that finds principal turnover has negative effects on average student academic achievement, conditional on principal characteristics, student characteristics and school characteristics, we find principal turnover has no significant impact on student academic achievement if a principal turns over at the end of previous school year, at the end of current school year, or at the end of next school year. But we find weak evidence from the IV regression that principal turnover has a negative impact on student math scores if a principal left two years ago. One possible explanation is that when a principal leaves a school, this principal has provided management plans for the next few years based on his or her vision. However, lots of changes occurred after this principal's departure, and the original management plan is no longer effective for the new school environment after two years. We also compare the ordinary least-squares (OLS) estimates with IV estimates to measure the magnitude of the bias caused by the endogenous problem. We find that the discrepancy between OLS estimates and IV estimates decreases as the complexity of model increases. It provides evidence to suggest that a sufficiently complex model reduces the endogenous bias problem to be statistical insignificant. 


\section{Chapter 2: Motivation/Literature Review}

\subsection{Teacher Turnover and Mobility}

Teachers have been shown to be the most important schooling factor contributing to student academic achievement (Aaronson et al., 2007; Hanushek et al., 2005; Kane et al., 2006; Koedel and Betts, 2011; Rivkin et al., 2005; Rockoff, 2004). Therefore, the distribution of teacher quality across schools has been of great interest to researchers and policymakers. Teacher quality is usually measured either by teacher qualifications or teacher value-added estimates. Recent studies show that teacher qualifications vary tremendously across schools, especially between advantaged and disadvantaged schools (Clotfelter et al., 2005; Goldhaber et al., 2007; Lankford et al., 2002), although the link between qualifications and classroom performance is weak. ${ }^{3}$ Only a few studies have directly investigated between-school variation in teacher value-added estimates, and in particular, the variation in teacher value-added estimates between advantaged and disadvantaged schools. Using data from Florida and North Carolina, Sass et al. (2012) demonstrated that teachers in high-income schools, on average, outperform teachers in low-income schools. They reported that particularly low-performing teachers in lowincome schools largely drive this difference.

Whether measured by teacher qualifications or teacher value-added estimates, it is clear that gaps exist in the quality of teachers at advantaged and disadvantaged schools. In order to design policies that can shrink these gaps, it is important to understand the

\footnotetext{
${ }^{3}$ Clotfelter et al. $(2006,2007)$ provided some evidence that teacher qualifications matter, but the majority of the variation in teacher quality cannot be linked to teacher qualifications (e.g., see Aaronson et al., 2007; Koedel and Betts, 2007).
} 
mechanism of teacher labor markets, such as the characteristics of teachers who are more likely to turn over. Previous research shows that teachers' own demographic characteristics are strongly correlated with their decisions to transfer or to exit teaching. Research consistently shows that attrition is more common among young teachers relative to older and more experienced teachers, at least until they become eligible for retirement (Adams, 1996; Hanushek et al., 2004; Ingersoll, 2001; Kirby et al., 1999; Koedel et al., 2012). Female teachers are more likely to quit than their male counterparts (Gritz and Theobald, 1996; Ingersoll and Alsalam, 1997; Kirby et al., 1999; exceptions include Podgursky et al., 1999), and white teachers are more likely to quit than minorities (Adams, 1996; Ingersoll, 2001; Kirby et al., 1999). In terms of skills and qualifications, most studies report that teachers with more qualifications tend to have higher attrition rates (Henke et al., 2000; Lankford et al., 2002; Podgursky et al., 2004; exceptions include Goldhaber et al., 2007), ${ }^{4}$ especially when these highly qualified teachers are teaching low-performing students (Boyd et al., 2005b). In contrast, studies using teacher value-added estimates to measure teacher effectiveness indicate a positive correlation between tendency to stay in teaching and teacher effectiveness (Hanushek et al., 2005; Krieg, 2006; exceptions include West and Chingos, 2009). Across schooling levels, secondary education teachers are more likely to turn over than elementary teachers (Henke et al., 2001; Kirby et al., 1999).

\footnotetext{
${ }^{4}$ Henke et al. (2000) demonstrated that teachers with higher college entrance examination scores are more likely to quit teaching. Podgursky et al. (2004) reported that teachers with higher ACT scores or with an undergraduate degree from highly selective institutions are more likely to quit teaching. Similarly, Lankford et al. (2002) showed that New York State teachers with undergraduate degrees from highly competitive colleges are more likely to transfer to another district. Goldhaber et al. (2007) stated that teachers with higher SAT scores are more likely to leave teaching, but they also reported that teachers with more advanced degrees tend to stay in the system.
} 
Schools also vary in their ability to attract teachers. Schools with a higher percentage of minority, low-income, and low-performing students tend to experience greater attrition (Boyd et al., 2005a; Clotfelter et al., 2005; Hanushek et al., 2004; Lankford et al., 2002). Hanushek et al. (2004) also reported that a difficulty faced by lowperforming schools is that white teachers move to other schools with fewer minorities and higher-income students. According to Boyd et al. (2005a) and Reininger (2012), teachers prefer placements close to their homes, which are typically in more-advantaged areas.

Motivated by existing inequities between advantaged and disadvantaged schools regarding access to high-quality teachers, policymakers are increasingly advocating for interventions designed to improve teacher quality for low-income students. The federal government is also interested in policy alternatives to address this issue, as evidenced by the recent funding of a large-scale national experiment through the Institute for Education Sciences (IES). The IES-funded study is examining the success of an incentive program that provides financial rewards to encourage effective teachers to relocate from advantaged to disadvantaged schools (Glazerman et al., 2012). However, the research base on labor-market mixing between advantaged and disadvantaged schools in the absence of financial incentives to move is thin. A better understanding of current labormarket dynamics seems important for designing effective mobility-inducing policies.

This study adds to the minimal literature on teacher labor-market mixing by studying teacher mobility patterns across school poverty levels. Due to the strong positive correlation between the income level the schools serve and their students' academic performance, results from this study can be applied to teacher transfers between high- 
performing and low-performing schools. This technique avoids potential data issues, ${ }^{5}$ yet still allows study of the teacher mobility patterns to inform policy discussions. Another contribution of this study is to add to the current literature on teacher labor markets by incorporating the characteristics of neighboring schools into models that explain teacher mobility. I define teacher labor market concentrically and determine the best approach for constructing the teacher labor market empirically. Recent research indicates that the distance between work and home plays an important role in teacher turnover (Boyd et al., 2005a, 2005b; Reininger, 2012) - herein I examine the role of distance between schools, which are alternative employment locations (within education). Given evidence from previous research that teachers have strong preferences for schools in advantaged areas, as well as the strong policy push to reallocate teachers across schools (Glazerman et al., 2012), it is important to improve general understanding of teacher mobility. For example, are disadvantaged schools in close proximity to advantaged schools at greater risk of pull- and push-induced teacher mobility? And to what degree do these effects change when the distance between two schools changes?

\subsection{Principal Turnover}

Principal turnover is similar to teacher turnover in many ways. For example, principal turnover includes both involuntary and voluntary turnover, is disproportionately borne by disadvantaged schools mainly due to principals' preference for advantaged schools, and could be either beneficial or harmful. In other types of organizations, managers may voluntarily or involuntarily be forced to resign after a dip in business

\footnotetext{
${ }^{5}$ As pointed out later in the main text, students' test scores are not available for some schools in my sample. Therefore, I use slightly different models for those schools.
} 
performance, especially when the stock price drops dramatically (the most recent example is the resignation of former Groupon CEO, Andrew Mason). However, unlike the publicly traded companies in the private sector, involuntary principal turnover usually happens when principals from low-performing schools are reassigned or fired by school districts due to educational reform, though districts sometimes reassign principals for other reasons (Beteille et al., 2011). Voluntary principal turnover usually happens when principals move to advantaged schools based on the principals' preferences. Advantaged schools usually have a better socioeconomic environment, such as high-performing students, high-income students, and a lower percentage of minority students. Prior research has shown that, similar to teachers, non-pecuniary school characteristics affect principals' decision to transfer (Loeb et al., 2010).

Though prior research on the impact of principal turnover on student academic achievement is very limited, studies on the impact of leadership turnover in other types of institutions provide mixed results. Some show that leadership turnover is beneficial for institutions if inefficient managers are replaced with more efficient managers (Denis and Denis, 1995), but it can also be harmful when too-frequent turnovers cause instability to the institutions (Audas et al., 2002). There are also studies arguing that leadership turnover has no impact on institution performance because managers are typically dismissed due to poor stock performance, which is very likely caused by other factors.

Schools are not publicly traded as companies in the private sector, so principals could turn over for different reasons. For example, it is unlikely principals are dismissed in order to please certain stockholders. However, it is reasonable to make analogous arguments that principal turnover can be either beneficial or harmful. If new principals 
bring in innovative ideas, or if ineffective principals are more likely to turn over and are replaced with more effective principals, then principal turnover will have beneficial effects on schools. However, frequent principal turnover can also cause negative consequences, such as instability, more teacher turnover, and lower teacher commitment.

There exists a group of studies that investigate the correlations between certain characteristics of principals and school performance, such as raw test scores (Eberts and Stone, 1988; Brewer, 1993), student attendance (Blank, 1987), teachers' assessments of school principal performance (Ballou and Podgursky, 1993), and teacher mobility and attrition (Gates et al., 2006). However, they show mixed evidence regarding the relationship between principal characteristics and school performance. For example, some studies find a positive correlation between principal teaching experience and school performance (Eberts and Stone, 1988; Ballou and Podgursky, 1993), whereas others do not (Brewer, 1993). The differences in research findings could reveal differences in data availability, analytical samples, empirical methods, and measurements.

With the more detailed administrative student-principal linked panel data becoming available, researchers have started to conduct more careful examinations with the help of more rigorous empirical strategies. Clark et al. (2009) closely studied the correlation between principal experience and student performance. They showed that more experienced principals are observed at schools with higher student performance. Given that principals' preference to work at advantaged schools and less frequent principal turnover is observed at advantaged schools, it is not surprising to see the positive correlation between principal experience and student performance, which is similar to what is observed within teacher labor markets. 
Only a few studies directly estimate the impact of principal turnover on student academic outcome. Miller (2009) conducted analysis at the school level using North Carolina administrative data and found that principals leave after schools show poor academic performance. Beteille et al. (2011) conducted panel data empirical studies at the student level from a large urban school district and showed that principal turnover is harmful to school performance. Our empirical study on Missouri principals contributes to this limited literature. Similarly to Beteille et al. (2011), we conduct empirical analysis using student-level test scores. In addition, we use the IV strategy to directly untangle the endogenous problem of principal turnover, which has not been explicitly studied before. 


\section{Chapter 3: Data}

\subsection{Teacher Mobility Dataset}

I use statewide administrative data from the Missouri Department of Elementary and Secondary Education (DESE). The data include teacher employment histories in Missouri public schools from the academic years 2005-2006 through 2010-2011, including transfer information, which allows me to construct annual teacher mobility variables. For example, a teacher is coded as a transfer if I observe that teacher in a different school in the subsequent school year. The data also include standard district, school, teacher, and student information.

I focus on teacher mobility, which means only teacher transfers are included in the analytical sample. However, there are two other groups of teachers in teacher labor markets: stayers and leavers. Stayers are teachers who stay at the current school, and leavers are teachers who leave the teaching profession. Table 3.1 shows the crosstabulations for teachers (stayers, leavers, and transfers) by their current school type. Yearly variation is negligible so that all the percentages in this table are five-year average for simplicity. It is clear that regardless of schooling level, more than 80 percent of teachers are stayers in teacher labor markets. Around 7 percent of teachers are transfers, who compose the analytical sample in this study.

I retrieved schools' neighborhood information from the 2000 U.S. Census and link it to schools by ZIP code. ${ }^{6}$ To construct schools' neighborhoods, I retrieved each school's longitude and latitude from the Common Core of Data (CCD), then calculated

\footnotetext{
${ }^{6} \mathrm{http} / /$ factfinder2.census.gov/faces/nav/jsf/pages/index.xhtml.
} 
the distance in miles between all schools in my sample. ${ }^{7}$ For each school, I generated a list of neighboring schools within radii of 5, 10, and 20 miles. Using enrollment information from Missouri administrative data, I calculated the enrollment-weightedaverage neighboring-school characteristics for each school.

To construct the teacher-level panel I first found all transfers in each school and then added teachers' demographic, own-school, and neighboring-school information. I tracked all transfers and created a binary variable indicating the poverty level of their importing and exporting schools. Enrollment-weighted variables were generated for neighboring schools. ${ }^{8}$ Then I combined all teacher records in a given year and pooled across all five years of data to construct the final dataset, which contains one record per move. To construct the school-level data panel I first created school-level variables so that each school has only one record in a given year. Then, I pooled all five years of school records.

\subsection{Principal Turnover Dataset}

We use administrative panel data from DESE. Students and principals are linked through schools. Student test scores in math and reading from grade 3 to grade 8 are taken from the statewide Missouri Assessment Program (MAP) from school year 2005-2006 to school year 2008-2009. Each student has to have a prior score to be

\footnotetext{
${ }^{7}$ Distance is calculated using the Great Circle Distance Formula (http://support.sas.com/kb/24/897.html), which calculates the shortest distance between two points on the surface of a sphere. Therefore, I neglected any natural boundaries, such as forests, rivers, and mountains. There are other ways to calculate distance, however. Boyd et al. (2005a) calculated distance as a straight line and checked estimates' sensitivity to the algorithm used for distance calculation. They stated that choice of algorithm changed magnitude of the estimates but not significantly. In view of their work, I did not do a robustness check on sensitivity to algorithm. However, it can be done upon request.

${ }^{8}$ See Appendix A for details.
} 
included in our analytical sample. Thus, the analytical sample includes three cohorts of students: (1) cohort 0708 (i.e., students in school year 2007-2008), (2) cohort 0809, and (3) cohort 0910. We standardize student test scores by subject, year and grade.

Principal turnover variables were created in a similar fashion to teacher transfer variables. To construct the key IV: the distance from peak-value pension wealth for the principal, we calculated the peak-value pension wealth and the pension wealth associated with the timing when we observe the principal turnover in the dataset. We then take the difference of these two pension values to construct the IV. Basic descriptive statistics for the analytical sample used in the main regression are reported in Table 3.2. The analytical sample includes 1,606 unique schools, 1,974 unique principals, and 427,471 unique students. 
Table 3.1 Five-year average percentages by school type: school year 2005-2006 to 2009-2010

\begin{tabular}{|c|c|c|c|c|}
\hline \multirow{2}{*}{\multicolumn{2}{|c|}{$\begin{array}{c}\text { High-income (\%) } \\
\text { Elementary School teachers }\end{array}$}} & \multirow{2}{*}{ Middle-income (\%) } & \multirow{2}{*}{ Low-income (\%) } & \multirow[t]{2}{*}{$\overline{\text { Total }(\%)}$} \\
\hline & & & & \\
\hline Stayer & 85.70 & 83.97 & 76.63 & 82.88 \\
\hline Leaver & 8.30 & 9.17 & 12.97 & 9.74 \\
\hline Transfer & 6.00 & 6.86 & 10.39 & 7.38 \\
\hline Total (N) & 47,728 & 82,236 & 36,042 & 166,006 \\
\hline \multicolumn{5}{|c|}{ MJH School teachers } \\
\hline Stayer & 86.59 & 81.71 & 74.13 & 82.46 \\
\hline Leaver & 8.24 & 10.17 & 15.68 & 10.27 \\
\hline Transfer & 5.18 & 8.13 & 10.19 & 7.27 \\
\hline Total $(\mathrm{N})$ & 60,631 & 66,824 & 23,954 & 151,409 \\
\hline
\end{tabular}


Table 3.2 Missouri longitudinal student date file: school year 2007-2008 to 20092010

Data for main model:

Schools

Unique principals

Unique students

Total student test-score-gain records $\mathrm{N}$

1,606

1,974

427,471

816,493 (math) / 816,493 (com arts)

Share of principals classified as:

$\%$

Turnover

18

System exiter

7 


\section{Chapter 4: The Patterns of Teacher Mobility between High- income Schools and Low-income Schools}

\subsection{Empirical Strategy}

\subsubsection{Teacher-Level Models}

I begin with teacher-level models of teacher mobility patterns. If a teacher at school $j$ in year $t$ is observed in year $t+1$ at school $m, j \neq m$, I define this teacher as a transfer. I define the school that the teacher is leaving as the teacher's exporting school and the school this teacher is moving to as the importing school. I examine the labor markets across schooling levels separately (elementary and MJH [middle, junior high, and high] schools) because most teachers who change schools move to another school at the same schooling level. To investigate the degree to which both own-school and neighboring-school characteristics influence placement outcomes for teacher transfers, I use an ordered probit model to predict teacher moves as a function of own-school and neighboring-school characteristics. For expositional purposes I divide all schools in the sample into three groups based on their shares of free or reduced-price lunch-eligible students (FRL). I define low-income schools as schools in the top quartile in terms of their FRL shares, middle-income schools as schools in the middle two quartiles, and high-income schools as schools in the bottom quartile. The data are constructed to fit into an ordered-response-model framework, as illustrated by Wooldridge (2002). Each school 
in the model is coded as city, suburb, or rural, following the National Center for Education Statistics urban-centric locale code in the CCD. ${ }^{9}$

Briefly, let

$y_{i}=X^{\prime} \beta+\varepsilon_{i}=\beta_{1} X_{i}+\beta_{2} S_{j, t}+\beta_{3} N_{j}+\beta_{4} N S_{j, t, r}+\beta_{5} T+\beta_{6}$ Urbanicity $+\varepsilon_{i}$,

where $y_{i}$ is a latent variable for teacher $i$, based on which teacher $i$ chooses which school to move to. $X_{i}$ is a vector of demographic characteristics of teacher $i$, including gender, race, education, experience, and salary premium. The salary premium variable is the residual from an auxiliary regression of teacher salaries on experience and education levels and indicates the extent to which the teacher is currently compensated above or below the level of teachers with other similar characteristics in Missouri. $S_{j, t}$ is a vector of indicator variables indicating the school type (i.e., low-income, middle-income, or high-income). $N_{j}$ is a vector of general neighborhood characteristics of school $j$. These general neighborhood variables are from the 2000 U.S. Census and include demographic information for the exporting school $j$ 's neighborhood calculated by ZIP code. $N S_{j, t, r}$ is a vector of neighboring-school characteristics for the exporting school $j$ at year $t$ within radius $r$, which includes the percentage of high-income neighboring schools and the percentage of low-income neighboring schools. $T$ is a vector of indicator variables for years. Urbanicity is a vector of indicator variables for the urbanicity of the current school.

${ }^{9}$ Common Core of Data: http://nces.ed.gov/ccd/pubschuniv.asp. Each school is coded as city, suburb, town, or rural in $\mathrm{CCD}$, which is different from the conventional coding system that contains city, suburb and rural. I combine suburb and town as "suburb" in this paper. 
I construct a set of neighboring schools for each school $j$ concentrically. I consider radii at 5,10, and 20 miles to determine the neighboring-school set. The neighboringschool characteristics are weighted by enrollment so they are reflective of the nearby labor-market options for teachers at school $j .{ }^{10}$ I perform the primary analysis using a 10mile radius because the models suggest this is the most appropriate measure of a local labor market. ${ }^{11}$ More important, my key findings are robust regarding the choice of radius. Results for the alternative radii are reported in Appendices B and C.

Assume teacher $i$ chooses $y_{i}$ that yields the highest utility of three choices: goes to a low-income school $(k=1)$, goes to a middle-income school $(k=2)$, and goes to a high-income school $(k=3)$. In other words, I define

$k=1$ if $y_{i} \leq c_{1}$

$k=2$ if $c_{1} \leq y_{i} \leq c_{2}$

$k=3$ if $y_{i} \geq c_{2}$

where $c_{1}$ and $c_{2}$ are two unknown cut points. Given the finding from previous studies that teachers prefer to teach in advantaged schools bersus disadvantaged schools, I employ an ordered probit model with individual specific variables but without alternative specific

\footnotetext{
${ }^{10}$ Assume a school $j$ in year $t$ has $l, l=1 \ldots r_{j}$ neighboring schools of the same type within radius $r$, then $N S_{j, t, r}=\frac{\sum_{l=1}^{r_{j}} \text { enroll }_{l *} * s_{l, t}}{\sum_{l=1}^{r_{j}} \text { enroll }_{l, t}}$, where enroll $_{l, t}$ is enrollment for a neighboring school $l$ in year $t, s_{l, t}$ is the list of school characteristics for this neighboring school $l$ in year $t$. See Appendix A for more details. I also try a different specification, which is the difference between average characteristic of neighboring schools and school $j$ 's characteristic. I simply subtract school $j$ 's characteristic from its neighbor schools' average characteristic, $N S_{j, t, r}=\left(\frac{\sum_{l=1}^{r_{j}} \text { enroll }_{l, t} * s_{l, t}}{r_{j}}\right)-s_{j, t}$. Results are available upon request. 11 The main reason is Missouri has large rural areas, and many schools do not have neighboring schools when the radius is smaller.
} 
variables. Assuming the error terms $\varepsilon_{i}$ conditional on all covariates follow standard normal distribution, the probabilities of a teacher transfer going to a low-income, middleincome, or high-income school can be presented as the following.

$p(k=1 \mid X)=\Phi\left(c_{1}-X^{\prime} \beta\right)$

$p(k=2 \mid X)=\Phi\left(c_{2}-X^{\prime} \beta\right)-\Phi\left(c_{1}-X^{\prime} \beta\right)$

$p(k=3 \mid X)=1-\Phi\left(c_{2}-X^{\prime} \beta\right)$

Figure 4.1 illustrates these three probabilities in a general setting where $c_{1}-X^{\prime} \beta$ and $c_{2}-X^{\prime} \beta$ are arbitrarily chosen to be -1 and 1 . After estimation, equations (5) through (7) can compute probabilities given any set of values of covariates.

\subsubsection{School-Level Models}

The second approach focuses on models that predict teacher mobility at the school level. Specifically, I regress the percentage of transfers from school $j$ on neighboringschool characteristics using pooled OLS regressions. As with the teacher-level models, I estimate separate models by schooling level. To investigate the degree of mixing within the teacher labor market, I include interaction terms between current school type and neighboring-school type (i.e., low-income, middle-income, or high-income), which allows me study pull- and push-induced teacher mobility.

$Y_{j, t}=\beta_{0}+\beta_{1} D_{j, t}+\beta_{2} S_{j, t}+\beta_{3} N_{j}+\beta_{4} T+\beta_{5} N S_{j, t, r}+\beta_{6} S_{j, t} * N S_{j, t, r}+\beta_{7}$ Urbanicity $+\varepsilon_{j, t}$

In equation (8), $Y_{j, t}$ is the percentage of transfers for school $j$ in year $t ; D_{j, t}$ is the total student enrollment for the school district where school $j$ is located in year $t ; S_{j, t}, N_{j}$, $T, N S_{j, t, r}$, and Urbanicity are the same covariates in the teacher-level models; $\varepsilon_{j, t}$ is the 
error term. The estimates of primary interests are the estimates of the interaction between the school type and the percentage of neighboring-school types. I use data for school years $2005-2006$ to $2010-2011$. I also perform the primary analysis using a 10-mile radius.

\subsection{Analysis}

\subsubsection{Teacher-Level Models}

Table 4.1 provides cross-tabulations for teacher transfers by exporting and importing school types, which are defined by the shares of students eligible for FRL. Panels (1) through (3) present the counts, average age and average experience for elementary school transfers, and panel (4) through (6) present the counts, average age, and average experience for MJH school transfers. In panels (1) and (4), the large percentages on the diagonal of each panel indicate that most teachers move to socioeconomically similar schools. ${ }^{12}$ For example, in panel (1), 68.88 percent of elementary school transfers leaving high-income schools move to high-income schools, 24.42 percent move to middle-income schools, and only 6.70 percent move to lowincome schools. The same pattern for MJH school transfers leaving high-income schools is observed in panel (4), with a slightly lower percentage of teacher transfers moving to high-income and low-income schools, but a higher percentage of teacher transfers moving to middle-income schools. Panels (2) and (3) show elementary school transfers

\footnotetext{
${ }^{12}$ By construction, high-income, middle-income, and low-income schools compose of $25 \%, 50 \%$, and $25 \%$ of schools, respectively. Therefore, if school type is randomly distributed with the $25 \%, 50 \%$, and $25 \%$ distribution, regardless of the exporting school type, the percentages of teachers move to middle-income schools are around 50\%. Please see Appendix D for more details.
} 
are mostly mid-career teachers regardless of how they transfer. The same pattern is observed for MJH school transfers in panels (5) and (6).

Panels (1) and (4) in Table 4.1 also suggest that sorting into socioeconomically similar schools is most evident for high-income school transfers, with almost 70 percent of teacher transfers moving regardless of schooling levels, as opposed to low-income school transfers, with 54.95 percent of MJH school transfers and 60.71 percent of elementary teacher transfers moving. The evident sorting pattern for high-income schools is also reflected in the off-diagonals. The off-diagonals suggest that there are more teachers (in percentage points) switching from low-income schools to high-income schools than vice versa, regardless of schooling level. Although these statistics imply that high-income schools have a broader labor market than low-income schools, moves across socioeconomic groupings are generally limited in all directions; only a small portion of teachers makes this move.

Comparing the diagonals in panels (1) and (4), more weight is on the diagonal for the elementary labor market. The difference in weight increases as the poverty level of schools increases. For example, 68.88 percent of elementary school transfers move between high-income schools, as opposed to 68.08 percent of MJH school transfers. The difference is almost 1 percentage point. For school transfers moving between middleincome schools, the difference increases to almost 6 percentage points. These statistics suggest that across school levels, the teacher labor market for transfers is less mixed for elementary teachers than for MJH teachers. The difference seems to be driven by the MJH school transfers leaving middle-income and low-income schools. 
Another interesting finding is that the distribution of transfers by the poverty level of the exporting school is different for elementary schools and MJH schools, as presented in the last column in panels (1) and (4). For example, there are more transfers from lowincome (32.29\%) than from high-income elementary schools (24.31\%). However, it is the opposite for MJH schools. One implication is that programs designed to induce educator mobility will require a larger pool of candidates in the lower grades.

In addition, Table 4.2 provides more detailed information about both exporting and importing schools, including the average distance between the importing and exporting school for observed transfers. An interesting finding is that teacher transfers who move across school types, on average, move to distant schools; whereas, teacher transfers who move within the same school type, on average, move to schools that are nearby. For example, row 3 shows that on average, an elementary school transfer leaving from a high-income school goes to another high-income school that is 10 miles away from the current school, but moves to a low-income school that is 25 miles away. Similarly, row 9 shows that on average, an elementary school transfer leaving from a low-income school goes to another low-income school that is 10 miles away from current school, but moves to another high-income school that is 26 miles away. The same pattern is observed for MJH school transfers. All distance statistics for MJH school transfers are larger than those for elementary school transfers, which suggests that in general, MJH school transfers move to a school that is farther from the exporting school than do elementary school transfers. If we assume teachers live close to where they work, all distance statistics imply that when teachers transfer to socioeconomically similar schools, they do not change where the live. However, when teaches transfer to socioeconomically 
different schools, they either have to drive farther to the new job or they move to a different residence.

Other statistics in Table 4.2 consistently indicate the strong correlation between the schools' poverty level and students' academic performance, as expected. For example, row 1 shows that when a teacher moves from a high-income school to a lowincome school, this teacher is also moving to a low-performing school. The same pattern is observed across school types and levels.

Overall, Tables 4.1 and 4.2 suggest that when teachers change schools, most teachers move to socioeconomically similar schools that are geographically close. A small fraction of observed moves are to substantively different schools farther away. All else being equal, the bigger the socioeconomic difference between the exporting and importing schools, the greater the physical distance between them, and possibly the farther teachers travel to make the change. This is consistent with major school-type changes coinciding with changing life events for teachers. The tables illustrate that without any intervention, teachers move naturally into schools with socioeconomic environments similar to those of their original school.

The regression results further confirm the evidence in Tables 4.1 and 4.2. Table 4.3 provides the main results for elementary and $\mathrm{MJH}$ teachers. It is hard to interpret the magnitude of ordered probit estimates, but a positive and significant estimate implies a higher probability of going to a high-income school, and a negative and significant estimate implies a higher probability of going to a low-income school. Estimates agree with the previously presented tabulations. For example, -0.266 on row 2 is negative and 
significant at 1 percent significance level. It suggests that if an elementary school transfer is leaving a low-income school, that teacher is significantly more likely to go to another low-income school than an elementary school transfer leaving a middle-income or highincome school. Similarly, 0.354 on row 3 suggests that if an elementary school transfer is leaving a high-income school, that teacher is significantly less likely to go to a lowincome school than one leaving a middle-income or low-income school. The same pattern is observed for MJH school transfers.

Table 4.3 provides strong evidence not only for transfers moving to similar schools, but also for neighboring schools' impact on mobility. For example, -0.452 on row 4 suggests that if an elementary school transfer is leaving an exporting school that is surrounded by more low-income neighboring schools, this teacher is much more likely to go to a low-income school. Estimates in row 1 show there is no evidence of salary premiums affecting transfers' moving destinations once they decide to move.

As stated previously, the magnitude of ordered probit estimates is difficult to interpret. Thus, I provide predicted probabilities by move-type to better illustrate teachers' mobility patterns in Table 4.4. Probabilities are calculated for two representative transfers. One is at the mean value of all other covariates, and the other is a female teacher, with eight years of experience and not having a master's degree or a doctorate. Probabilities are very similar for these two teachers. For example, row 1 indicates that if an elementary school teacher is leaving a high-income school, the probability of going to a high-income school is 0.332 , and the probability of going to a low-income school is 0.122 . The difference in probability is more evident for a MJH school transfer leaving a high-income school. That teacher's probability of going to a 
high-income school is 0.431 and to a low-income school is 0.085 . The big difference in probability further confirms that transfers move to socioeconomically similar schools.

Probabilities in Table 4.4 may seem subjective because they are calculated at arbitrarily chosen values of covariates. Thus, in Table 4.5 , I provide the changes in probabilities for a teacher to go to a high-income or low-income school when the exporting school type changes, conditional on holding all else equal. Results are consistent with Table 4.4. For example, the probabilities in row 1 indicate that if an elementary school transfer is leaving a high-income school, the probability of moving into a high-income school is 0.110 higher than an elementary school transfer leaving a middle-income or low-income school; the probability of moving into a low-income school is 0.094 lower than an elementary school transfer leaving a middle-income or lowincome school, holding all else equal. If a MJH school transfer is leaving a high-income school, this teacher's probability of moving into a high-income school is 0.112 higher than a MJH school transfer leaving a middle-income or low-income school; the probability of moving into a low-income school is 0.063 lower than a MJH school transfer leaving a middle-income or low-income school, holding all else equal.

Table 4.5 also shows the changes in probabilities for a teacher to go to a highincome or low-income school when the percentage of high-income or low-income neighboring schools changes, conditional on holding all else equal. For example, the probabilities in row 3 indicate that if the share of high-income neighboring schools within 10 miles increases by its full range (as observed in the Missouri data), the probability of a teacher going to a high-income school is predicted to increase by 0.271 , and the probability of going to a low-income school is predicted to decrease by 0.203 , holding all 
else equal. These results consistently show that, across different measures of change in average income level of neighboring schools, being surrounded by low-income schools will increase the likelihood of a transfer moving to a low-income school. Similarly, if surrounded by high-income schools, a transfer is more likely to go to a high-income school. I observed the same pattern for MJH school transfers. Thus, statistics in Table 4.5 suggest that transfers move to schools that are socioeconomically similar not only to their exporting schools, but also to the original neighboring schools, regardless of school level.

\subsubsection{School-Level Models}

The school-level models inform us about the correlations between neighboringschool characteristics and school-level transfer rates. Table 4.6 shows the main regression results for both elementary and $\mathrm{MJH}$ schools. If low-income schools in close proximity to high-income schools have higher school-level transfer rates, then there would be evidence for high-income schools inducing school transfers from low-income schools. The regression analysis did not provide this evidence. On the contrary, as seen in Table 4.6, a low-income school surrounded by high-income schools is predicted to have lower transfer rates. One reason is that teacher labor markets appear to be strongly segregated by the income level of schools. It is very difficult for a teacher in a low-income school to land a job in a high-income school. Being surrounded by high-income schools further decreases this possibility because teacher labor markets are also geographically narrow and teachers usually search for jobs near their current location. 


\subsection{Limitation}

As mentioned earlier, this study has some limitations. One limitation is I only observe the equilibrium outcomes from teachers' job searches. On the teacher labor supply side, my sample identifies the teachers who successfully transferred, but the portion of teachers who wanted to transfer but failed to do so cannot be identified. Similarly, on the teacher labor demand side, my sample identifies the schools that successfully receive transfers, but the total vacancies of teaching positions offered by schools cannot be identified. More detailed data would allow studying the supply and demand sides of the teacher movement separately. For example, if teachers' transfer application data were available, I could identify the characteristics of teachers by their school preferences. Comparing the teachers who successfully transferred with those who wanted to but failed to do so would provide empirical evidence for teacher mobility patterns and would permit researchers to gain more insights into the teacher labor market.

Another limitation is that I focus on the teacher labor market for transfers as opposed to the general teacher labor market. For example, I do not consider the case that teachers quit teaching for better paying jobs. I also do not consider the case that teachers move to schools outside of Missouri or to a private school in Missouri.

Finally, the predicting power of the ordered probit model varies for teachers making different choices, ranging from 45.80 percent (the minimum) to 76.71 percent (the maximum). Appendix E reports the percentages of correctly predicted teacher moves by groups of teachers (i.e., teachers moving to high-income, middle-income, or lowincome schools). The higher the percentage, the better the predicting power. For example, 
row 1 in the top panel shows 60.35 percent of elementary school teachers who move to high-income schools are correctly predicted. This model has the best predicting power for elementary school teachers who move to middle-income schools, with 76.71 percent correctly predicted. Though there is no universal standard for the strength of predicting power these numbers are all lower than 80 percent, which is unsatisfactory. One can compare the predicting power for the same group of teachers using different estimation strategies. For example, different models can be implemented, such as ordered logit models, or mixed logit models and competing risk models if data fail the Hausman test for independence from the irrelevant alternatives assumption. Another option is using different estimators, such as Bayesian estimators, instead of maximum likelihood estimators. However, it is very likely that the unsatisfactory predicting power is due to unobserved factors in the models. For example, if a teachers moves because his or her spouse has a job in a different location, the main model in this analysis would not be able to control that.

\subsection{Discussions and Policy Implications}

This paper investigates the feasibility of moving high-performing teachers to lowperforming schools by paying close attention to teacher mobility patterns in high-income and low-income schools. Using administrative data from Missouri, I find strong evidence that teachers move into socioeconomically similar schools regardless of grade level. In other words, if a teacher is leaving a high-income school, this teacher is much more likely to transfer to another high-income school than a low-income school, and vice versa. The MJH teacher labor market is more mixed than that for elementary school teachers. However, it is not clear which factors contributes to this pattern. 
I also find elementary and $\mathrm{MJH}$ school transfers do not respond to pecuniary incentives once they decide to move. It might be that a lot of teachers transfer for personal reasons other than pecuniary reasons. Perhaps salary differentials play a significant role when they make the initial decisions of transferring, but after they decide to transfer, salary differentials no longer matter.

As mentioned earlier, there is considerable interest in developing policies that encourage high-performing teachers to move to low-performing schools. For example, in a recent experimental study by Glazerman et al. (2012), high-performing teachers in advantaged schools were offered $\$ 20,000$ to move to a low-performing school within the same school district for two years. This experiment was conducted in ten large school districts, in both elementary schools and middle schools. My finding provides some insight into the likely efficacy of such programs. First, given evidence that most teachers move to schools that are fewer than 10 miles away when they change schools, moving teachers within geographically small school districts may be feasible, but long-distance moves may not be. For example, Figure 4.2 is the map of all schools in the CharlotteMecklenburg School District, one of the ten large participating school districts in the TTI program. My finding suggests that it may be feasible to move teachers between schools that are nearby, but it may not be feasible to move teachers from schools located in the south end of the district to the north end of the district.

Second, moving high-performing teachers to low-performing schools will be challenging because such moves appear quite uncommon in the absence of financial incentives. Glazerman et al. (2012) reported that a large pool of candidates was needed to 
achieve the desired number of successful transfers in the experiment. This result is unsurprising given the transfer dynamics in current labor markets.

Third, teachers do not seem to respond to pecuniary incentives and further analysis testing the responsiveness is needed. I think the optimal transfer-bonus program may (a) target specific grade levels and geographic areas where moves are more likely to occur naturally and/or (b) vary the level of the financial incentive across these dimensions depending on how far the program is pushing relative to what is observed in terms of transfer behavior in its absence.

Finally, a small portion of teachers move form high-income schools to lowincome schools without any intervention. Because it is challenging to move highperforming teachers to low-performing schools, a program that is designed to help retain teachers who naturally follow this move may be more efficient at increasing students' access to high-performing teachers. 
Figure 4.1 Probability of a teacher transfer going to a high-income, middle-income, or low-income school

\section{Standard Normal Distribution}

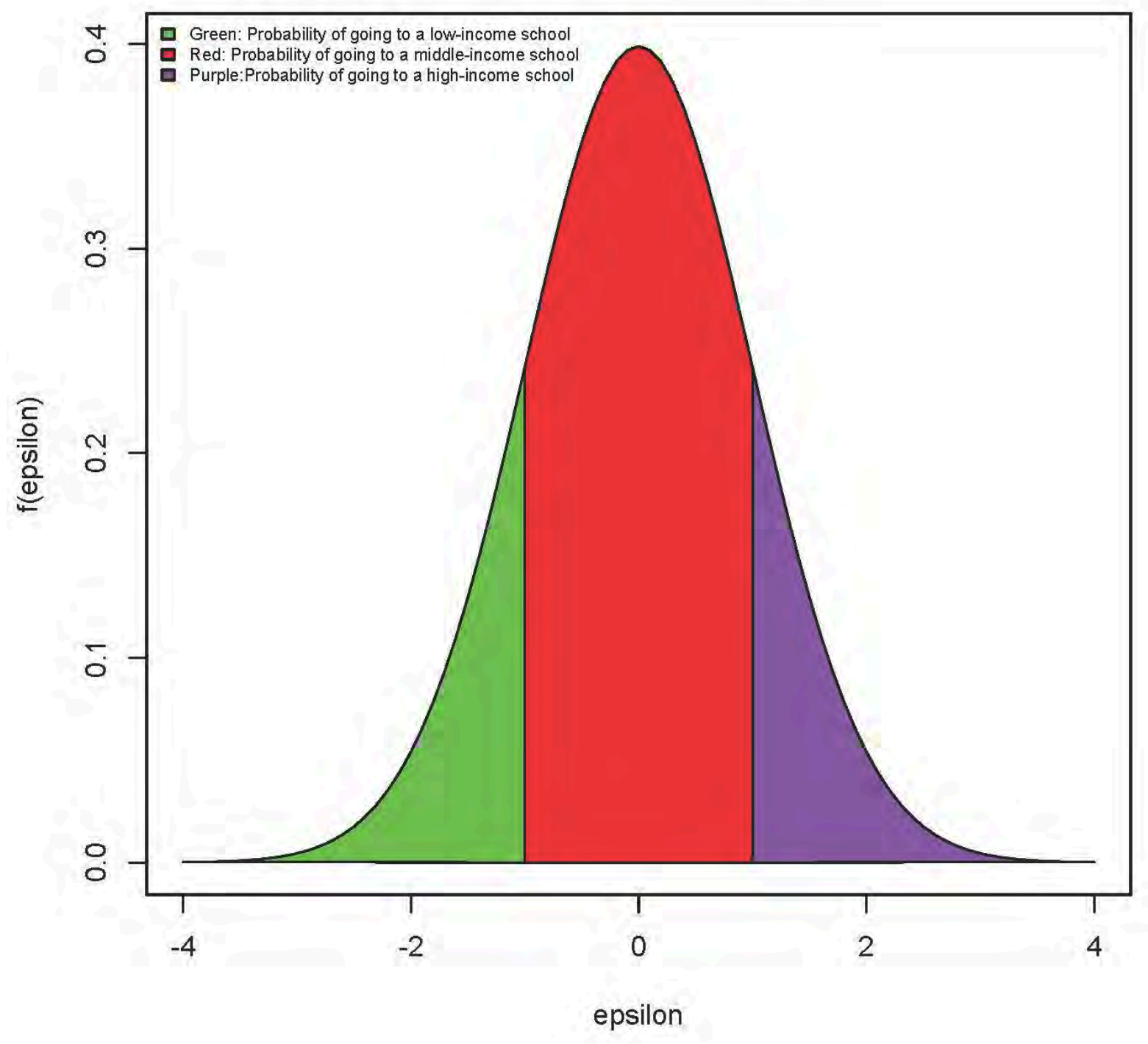




\section{Table 4.1 Cross-tabulation for transfers by exporting school and importing school}

types

\begin{tabular}{|c|c|c|c|c|}
\hline \multicolumn{5}{|c|}{ Elementary school transfers } \\
\hline \multirow{2}{*}{$\begin{array}{l}\text { (1) Count } \\
\text { Exporting school }\end{array}$} & \multicolumn{4}{|c|}{ Importing school } \\
\hline & $\begin{array}{c}\text { High-income } \\
(\%)\end{array}$ & $\begin{array}{c}\text { Middle-income } \\
(\%)\end{array}$ & $\begin{array}{c}\text { Low-income } \\
(\%)\end{array}$ & Total, N (\%) \\
\hline High-income & 68.88 & 24.42 & 6.70 & $2,330(24.31)$ \\
\hline Middle-income & 21.49 & 63.54 & 14.97 & $4,161(43.41)$ \\
\hline Low-income & 9.31 & 29.98 & 60.71 & $3,095(32.29)$ \\
\hline
\end{tabular}

(2) Average age (year)

Exporting school High-income Middle-income Low-income

\begin{tabular}{llll}
\hline High-income & 37 & 37 & 40 \\
Middle-income & 35 & 37 & 39 \\
Low-income & 35 & 38 & 44
\end{tabular}

(3) Average experience (year)

\begin{tabular}{lccc} 
Exporting school & High-income & Middle-income & Low-income \\
\hline High-income & 9 & 9 & 10 \\
Middle-income & 8 & 8 & 9 \\
Low-income & 8 & 9 & 11
\end{tabular}

MJH school transfers

\begin{tabular}{lcccc}
\hline (4) Count & \multicolumn{4}{c}{ Importing School } \\
Exporting school & $\begin{array}{c}\text { High-income } \\
(\%)\end{array}$ & $\begin{array}{c}\text { Middle-income } \\
(\%)\end{array}$ & $\begin{array}{c}\text { Low-income } \\
(\%)\end{array}$ & Total, N (\%) \\
\hline High-income & 68.08 & 26.66 & 5.27 & $2,506(30.73)$ \\
Middle-income & 29.74 & 57.76 & 12.50 & $3,783(46.38)$ \\
Low-income & 11.57 & 33.48 & 54.95 & $1,867(22.89)$
\end{tabular}

(5) Average age (year)

\begin{tabular}{lccc} 
Exporting school & High-income & Middle-income & Low-income \\
\hline High-income & 37 & 37 & 39 \\
Middle-income & 35 & 37 & 38 \\
Low-income & 35 & 40 & 44
\end{tabular}

(6) Average experience (year)

\begin{tabular}{lccc} 
Exporting school & High-income & Middle-income & Low-income \\
\hline High-income & 8 & 8 & 8 \\
Middle-income & 7 & 8 & 8 \\
Low-income & 6 & 9 & 11 \\
\hline
\end{tabular}

Note: MJH schools are middle, junior high, and high schools. Percentages in columns 1-3 are calculated in terms of row total, and percentages in column 4 are calculated in terms of column total. All schools in the sample are divided into three groups based on their shares of free or reduced-price lunch-eligible students (FRL). Low-income schools are schools in the top quartile in terms of their FRL shares, middle-income schools are schools in the middle two quartiles, and high-income schools are schools in the bottom quartile. 
Table 4.2 Descriptive statistics for schools

Elementary school

\begin{tabular}{|c|c|c|c|c|}
\hline \multirow{2}{*}{ Exporting school } & & \multicolumn{3}{|c|}{ Importing school } \\
\hline & & High-income & Middle-income & Low-income \\
\hline \multirow[t]{3}{*}{ High-income } & $\begin{array}{l}\text { Average standardized } \\
\text { composite score in importing } \\
\text { school }\end{array}$ & 0.318 & -0.005 & -0.433 \\
\hline & $\begin{array}{l}\text { Difference in average } \\
\text { standardized composite score }\end{array}$ & 0.018 & -0.266 & -0.732 \\
\hline & Average distance (mile) & 10 & 26 & 25 \\
\hline \multirow[t]{3}{*}{ Middle-income } & $\begin{array}{l}\text { Average standardized } \\
\text { composite score in importing } \\
\text { school }\end{array}$ & 0.259 & 0.001 & -0.299 \\
\hline & $\begin{array}{l}\text { Difference in average } \\
\text { standardized composite score }\end{array}$ & 0.268 & 0.005 & -0.210 \\
\hline & Average distance (mile) & 28 & 23 & 26 \\
\hline \multirow[t]{3}{*}{ Low-income } & $\begin{array}{l}\text { Average standardized } \\
\text { composite score in importing } \\
\text { school }\end{array}$ & 0.280 & -0.092 & -0.632 \\
\hline & $\begin{array}{l}\text { Difference in average } \\
\text { standardized composite score }\end{array}$ & 0.663 & 0.270 & -0.031 \\
\hline & Average distance (mile) & 26 & 20 & 10 \\
\hline \multicolumn{5}{|l|}{ MJH school } \\
\hline & & & Importing school & \\
\hline Exporting school & & High-income & Middle-income & Low-income \\
\hline High-income & Average distance (mile) & 17 & 36 & 34 \\
\hline Middle-income & Average distance (mile) & 36 & 34 & 35 \\
\hline Low-income & Average distance (mile) & 33 & 22 & 8 \\
\hline
\end{tabular}

Note: MJH schools are middle, junior high, and high schools. Composite score $=$ the average of math score and reading score. Difference in average standardized composite score $=$ average standardized composite score of the importing school minus the average standardized composite score of the exporting school. All schools in the sample are divided into three groups based on their shares of free or reduced-price luncheligible students (FRL). Low-income schools are schools in the top quartile in terms of their FRL shares, middle-income schools are schools in the middle two quartiles, and high-income schools are schools in the bottom quartile. 
Table 4.3 Ordered probit estimation results

\begin{tabular}{lcc}
\hline \multicolumn{2}{c}{ Elementary school transfers } & MJH school transfers \\
\hline \multicolumn{1}{c}{ Teacher } & & \\
Salary premium & -0.086 & 0.275 \\
Exporting school & $(0.187)$ & $(0.225)$ \\
Low-income & -0.266 & -0.314 \\
& $(0.058)^{* *}$ & $(0.078)^{* *}$ \\
High-income & 0.354 & 0.304 \\
& $(0.077)^{* *}$ & $(0.072)^{* *}$ \\
Neighboring schools & & \\
Low-income & -0.452 & -0.301 \\
High-income & $(0.089)^{* *}$ & $(0.114)^{* *}$ \\
& 0.833 & 0.408 \\
Neighborhood covariates & $(0.121)^{* *}$ & $(0.086)^{* *}$ \\
Urbanicity & & $\mathrm{X}$ \\
Log pseudolikelihood & $\mathrm{X}$ & $\mathrm{X}$ \\
$\mathrm{N}$ & $\mathrm{X}$ & $-6,764.181$ \\
P-value & -7732.234 & 8,156 \\
\hline
\end{tabular}

Note: Positive estimates imply higher probability of moving into a high-income school. Negative estimates imply higher probability of moving into a low-income school. Standard errors are in parentheses and clustered at the school level. All schools in the sample are divided into three groups based on their shares of free or reduced-price lunch-eligible students (FRL). Low-income schools are schools in the top quartile in terms of their FRL shares, middle-income schools are schools in the middle two quartiles, and high-income schools are schools in the bottom quartile.

** Indicates statistical significance at the $1 \%$ level.

* Indicates statistical significance at the 5\% level.

$\dagger$ Indicates statistical significance at the $10 \%$ level. 
Table 4.4 Probabilities of two representative transfers going to a high-income, or low-income school evaluated at selected values of covariates

\begin{tabular}{lcccc}
\hline & \multicolumn{2}{c}{$\begin{array}{c}\text { Elementary school transfers } \\
\text { Importing school }\end{array}$} & \multicolumn{2}{c}{$\begin{array}{c}\text { MJH school transfers } \\
\text { Importing school }\end{array}$} \\
Exporting school & High-income & Low-income & High-income & Low-income \\
\hline High-income & 0.332 & 0.122 & 0.431 & 0.085 \\
Low-income & 0.146 & 0.292 & 0.214 & 0.225 \\
& & & \\
Experience: 8years; female; does not have a master's degree or doctorate & 0.083 \\
High-income & 0.349 & 0.112 & 0.435 & 0.222 \\
Low-income & 0.157 & 0.276 & 0.217 & \\
\hline Note: Probabilities are calculated at the mean value of all other covariates. All schools in the sample are \\
divided into three groups based on their shares of free or reduced-price lunch-eligible students (FRL). Low- \\
income schools are schools in the top quartile in terms of their FRL shares, middle-income schools are
\end{tabular}


Table 4.5 Changes in probabilities of a transfer going to a high-income, or lowincome school

\begin{tabular}{lcccc}
\hline & \multicolumn{2}{c}{$\begin{array}{c}\text { Elementary school transfers } \\
\text { Importing school }\end{array}$} & \multicolumn{2}{c}{$\begin{array}{c}\text { MJH school transfers } \\
\text { Importing school }\end{array}$} \\
Exporting schools & High-income & Low-income & High-income & Low-income \\
\hline High-income & 0.110 & -0.094 & 0.112 & -0.063 \\
Low-income & -0.075 & 0.079 & -0.108 & 0.075 \\
& & & & \\
& & & & \\
Neighboring & High-income & Low-income & High-income & Low-income \\
schools & & & & \\
\hline High-income & & & & \\
Min $\rightarrow$ Max & 0.271 & -0.203 & 0.149 & -0.085 \\
\pm 0.5 & 0.241 & -0.236 & 0.146 & -0.090 \\
\pm SD/2 & 0.070 & -0.069 & 0.050 & -0.031 \\
Marginal effect & 0.244 & -0.239 & 0.146 & -0.090 \\
& & & & \\
Low-income & & & & 0.073 \\
Min $\rightarrow$ Max & -0.121 & 0.140 & -0.103 & 0.066 \\
\pm 0.5 & -0.132 & 0.129 & -0.108 & 0.015 \\
\pm SD/2 & -0.035 & 0.034 & -0.025 & 0.066 \\
Marginal effect & -0.132 & 0.129 & -0.108 & \\
\hline
\end{tabular}

Note: Min $\rightarrow$ Max: variable changes from its minimum to its maximum.

\pm 0.5 : from its mean value minus 0.5 units to its specified value plus 0.5 .

$\pm \mathrm{SD} / 2$ : from its mean value minus 0.5 standard deviations to its value plus 0.5 standard deviations. Marginal effect: partial derivative of the predicted probability with respect to the independent variables. All schools in the sample are divided into three groups based on their shares of free or reduced-price luncheligible students (FRL). Low-income schools are schools in the top quartile in terms of their FRL shares, middle-income schools are schools in the middle two quartiles, and high-income schools are schools in the bottom quartile. 
Table 4.6 OLS estimation at school level

\begin{tabular}{|c|c|c|}
\hline & Elementary schools & MJH schools \\
\hline \multicolumn{3}{|l|}{ School is low-income* } \\
\hline Neighboring schools are low-income & $\begin{array}{c}0.015 \\
(0.010)\end{array}$ & $\begin{array}{l}-0.004 \\
(0.012)\end{array}$ \\
\hline Neighboring schools are high-income & $\begin{array}{l}-0.032 \\
(0.017) \dagger\end{array}$ & $\begin{array}{c}0.002 \\
(0.019)\end{array}$ \\
\hline \multicolumn{3}{|l|}{ School is high-income* } \\
\hline Neighboring schools are low-income & $\begin{array}{l}-0.007 \\
(0.010)\end{array}$ & $\begin{array}{c}0.011 \\
(0.008)\end{array}$ \\
\hline Neighboring schools are high-income & $\begin{array}{l}-0.042 \\
(0.015)\end{array}$ & $\begin{array}{c}0.006 \\
(0.023)\end{array}$ \\
\hline School covariates & $\mathrm{X}$ & $\mathrm{X}$ \\
\hline Neighborhood covariates & $\mathrm{X}$ & $\mathrm{X}$ \\
\hline Neighboring school covariates & $\mathrm{X}$ & $\mathrm{X}$ \\
\hline $\mathrm{N}$ & 5,684 & 3,958 \\
\hline Adj R-squared & 0.085 & 0.085 \\
\hline $\begin{array}{l}\text { Note: All schools in the sample are divided in } \\
\text { lunch-eligible students (FRL). Low-incomes } \\
\text { shares, middle-income schools are schools in } \\
\text { schools in the bottom quartile. } \\
* * \text { Indicates statistical significance at the } 1 \% \\
* \text { Indicates statistical significance at the } 5 \% 1 \\
\dagger \text { Indicates statistical significance at the } 10 \%\end{array}$ & $\begin{array}{l}\text { ups based on their sh } \\
\text { chools in the top quar } \\
\text { two quartiles, and hig }\end{array}$ & $\begin{array}{l}\text { or reduced-pric } \\
\text { ms of their FRL } \\
\text { schools are }\end{array}$ \\
\hline
\end{tabular}


Figure 4.2 Map of all schools in Charlotte-Mecklenburg School District

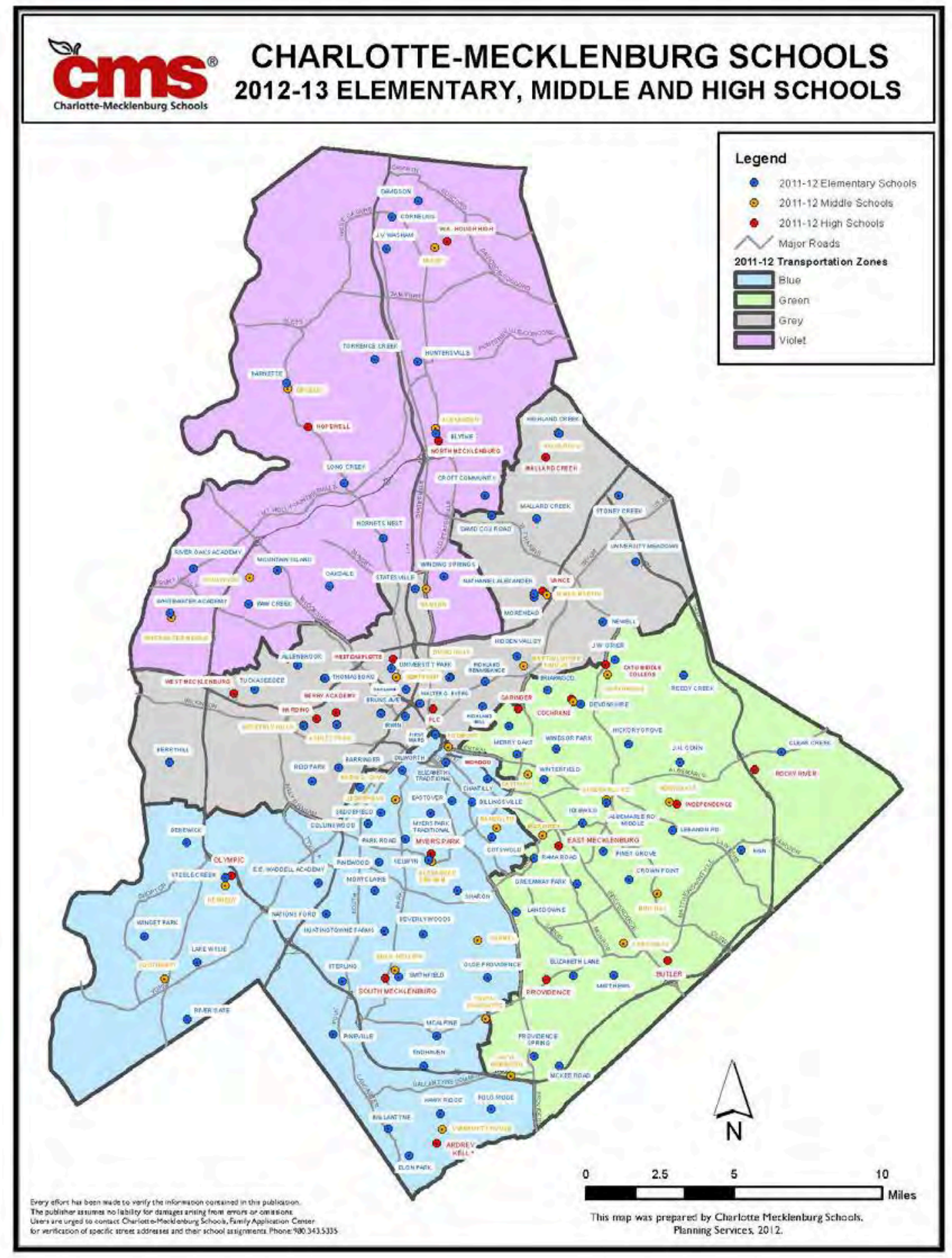

Source: http://www.cms.k12.nc.us/cmsdepartments/StudentPlacement/Documents/2012-

13\%20All\%20Schools\%20Map.pdf 


\section{Chapter 5: Intra-district Mobility and Inter-district Mobility}

\subsection{Teacher Single Salary Schedule and Teacher Tenure}

The single salary schedule is a method of setting salary rates, and it has been universally adopted in public school districts (Podgursky, 2007), including those in Missouri. It means that within the same school district, a teacher's salary is determined only by experience and degree, regardless of other factors, such as the subject taught, race, and gender. In the teacher mobility context, it implies that if a teacher transfers to a school within the same school district, the transfer will not affect the teacher's salary. Thus, salary differential is not expected to be a reason for intra-district moves.

Alternatively, a teacher who moves to a school in a different school district will be on a different salary schedule and may have a higher salary. It is possible, then, that salary differential is one of the reasons for inter-district moves. In other words, the single salary schedule creates an incentive for teachers to transfer to a school in a different school district.

In Missouri, a teacher who works full-time within the same public school district for five consecutive years will automatically gain tenure or permanent-teacher status. A district pays senior teachers more than junior teachers because the former have more years of experience than the latter. The teacher tenure system protects senior teachers from being replaced by junior teachers. When a teacher transfers to a school in a different school district, whether this teacher can carry tenure depends on the hiring school district. It may seem at first that the teacher tenure system creates a disincentive for teachers to transfer to a school in a different school district because it is not guaranteed that this 
teacher would be tenured after transferring. However, this disincentive is not binding because in reality, it is rare that a district does not renew a teacher's contract.

Given these two features, it seems reasonable to analyze intra-district transfers and inter-district transfers separately. I first provide descriptive statistics for key teacher characteristics and then use regressions to estimate the effects of neighboring school on intra-district and inter-district transfers.

\subsection{Empirical Strategy}

I conduct analyses separately for intra-district transfers and inter-district transfers. There is one sample issue in the intra-district analysis. If there is only one type of school (i.e., low-income, middle-income, or high-income) in a district, then the finding that teachers move into socioeconomically similar schools will not be driven by teachers' own choices, but are driven by forced choices. This is not a concern for big districts, such as New York School District and Chicago School District. However, Missouri has many small districts so that it is important to investigate this issue and to exclude those districts from being included in the analysis. Table 5.1 shows the sample sizes by district types (i.e., districts having three types of schools, districts having two types of schools, and districts having only one type of schools). Column 1 shows that 89.3 percent of districts have only one type of elementary school and 81.1 percent of districts have only one type of MJH schools. However, because all of them are small districts, the actual decrease in the sample size for the main analysis is 26 percent for elementary school transfers and 38.1 percent for MJH school transfers, as shown in column 5. For the main analysis, there 
are 4,190 intra-district elementary school transfers and 2,071 intra-district MJH school transfers in the analytical samples.

There is also one sample issue for inter-district analysis. It is reasonable to assume that if a teacher moves to a school that is 100 miles away, this teacher is making a lifechanging decision and are motivated differently than other inter-district transfers who move to schools that are 30 miles away. I cannot model unobservable factors that motivate these long-distance movers. Thus, it is reasonable to identify this group of teachers and restrict them from being included in the analysis. I arbitrarily pick 82 mile ( $85^{\text {th }}$ percentile) and 85 mile $\left(85^{\text {th }}\right.$ percentile) as the cut off distances for elementary school transfers and MJH school transfers, respectively. Distances at more detailed percentiles are reported in Appendix F.

For each group, I use an ordered probit model to predict teacher moves as a function of own-school, within-school-district neighboring-school, and outside-schooldistrict neighboring-school characteristics. Let

$$
\begin{aligned}
& y_{i}=X^{\prime} \beta+\varepsilon_{i}
\end{aligned}
$$

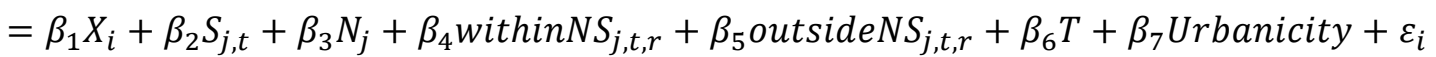

where $y_{i}, X_{i}, S_{j, t}, N_{j}, T$, and Urbanicity are the same as described in chapter 4.

withinN $_{j, t, r}$ is a vector of within-school-district neighboring-school characteristics for the exporting school $j$ at year $t$ within radius $r$, which includes the percentages of highincome and low-income neighboring schools that are within the same school district as the exporting school $j$. Similarly, outsideN $S_{j, t, r}$ is a vector of outside-school-district 
neighboring-school characteristics for the exporting school $j$ at year $t$ within radius $r$, which includes the percentages of high-income and low-income neighboring schools that are outside the school district where exporting school $j$ is located. I perform the primary analysis using a 10-mile radius. Results for the alternative radii are reported in Appendices G, H, I, and J.

\subsection{Analysis}

Table 5.2 provides cross-tabulations for elementary school transfers by exporting and importing school types. Panels (1) through (3) present the counts, average age, and average experience for intra-district transfers, and panels (4) through (6) present the same data for inter-district transfers. In panel (1), the large percentages on the diagonal indicate that most intra-district transfers move to socioeconomically similar schools. However, in panel (4), I do not observe this pattern for all inter-district transfers. Though most interdistrict transfers leaving high-income or middle-income schools still move to socioeconomically similar schools, most inter-district transfers from low-income schools move to middle-income schools. In addition, the distribution of teacher move by exporting school type is different for intra-district and inter-district transfers. For example, row 1 shows 63.41 percent, 30.39 percent, and 6.19 percent of intra-district transfers leaving high-income schools move to high-income, middle-income and lowincome schools, respectively. However, the distribution is more even for inter-district transfers with 49.81 percent, 35.31 percent, and 14.89 percent, respectively. This implies that the segregation of teacher labor markets by the socioeconomic status of the exporting school is more evident for intra-district than inter-district transfers. 
In particular, column (3) in panel (1) show that only 6.19 percent of intra-district transfers leaving high-income schools move to low-income schools, whereas the same is true of 14.89 percent of inter-district transfers in panel (4). This implies that it is more challenging to encourage teachers to move from high-income schools to low-income schools within the same school district than in different school districts.

As seen in panels (2), (3), (5), and (6) in Table 5.2, most of the intra-district and inter-district elementary school transfers are mid-career teachers. However, intra-district transfers are on average five years older and have five more years of experience than inter-district transfers regardless of the exporting school and importing school type.

Table 5.3 provides cross-tabulations for $\mathrm{MJH}$ school transfers by exporting and importing school types. Similar to elementary school transfers, most intra-district MJH school transfers move to socioeconomically similar schools. Most inter-district MJH school transfers leaving high-income or middle-income schools still move to socioeconomically similar schools, but most inter-district transfers from low-income schools move to middle-income schools.

One striking point in Table 5.3 is there are only 1.43 percent of intra-district MJH school transfers leaving high-income schools move to low-income schools within the same school district, whereas the same is true of 6.19 percent for intra-district elementary school transfers in Table 5.2. It implies that programs designed to encourage teachers to move from high-income schools to low-income schools within the same school district would require a larger pool of candidates in the higher grades. 
Tables 5.2 and 5.3 indicate several other different patterns in teacher mobility across schooling levels. The first difference is that there are more intra-district than interdistrict elementary school transfers, whereas it is the opposite for MJH school transfers. The second is that the distribution of intra-district transfers by exporting school type differs across schooling level. For example, the last column of panel (4) in Table 5.2 shows that 15.73 percent and 27.31 percent of inter-district elementary school transfers are leaving from high-income schools and from low-income schools, respectively. It means there are more inter-district elementary school transfers leaving low-income schools than high-income schools. However, the last column of panel (4) in Table 5.3 shows that there are more inter-district MJH school transfers leaving high-income schools than low-income schools.

Table 5.4 provides the mean and median of the distance between exporting schools and importing schools. Across schooling levels, intra-district transfers move to schools that are on average less than 5 miles from the current schools, but inter-district transfers move to schools that are on average more than 20 miles from the current schools. This finding suggests that inter-district transfers do travel farther than intradistrict transfers. If a teacher lives at the border of two school districts, this teacher could work in a different school district without traveling farther. But the finding that interdistricts transfers travel farther than intra-district transfers suggests this scenario is not very likely. The finding in chapter 4 that teachers who move to socioeconomically different schools usually travel farther is not evident for intra-district transfers, but it is still evident for inter-district transfers based on the median. 
It is also interesting to compare the mean and median for inter-district transfers across the schooling level. The median is always smaller than the mean in all cells of Table 5.4, which implies some inter-district transfers move to schools that are much farther from their current schools than the schools to which other inter-district transfers move.

Table 5.5 provides the main regression results for intra-district and inter-district transfers across schooling levels. Similar to Table 4.3 in chapter 4, positive estimates imply a higher probability of moving into a high-income school. Negative estimates imply a higher probability of moving into a low-income school. Estimates agree with the previously presented tabulations in Tables 5.2 and 5.3. They show that intra-district transfers move into socioeconomically similar schools regardless of the schooling level. For example, -0.191 in row 2 is negative and significant at a 1 percent significance level. This suggests if an intra-district elementary transfer leaves a low-income school, this teacher is much more likely to move to a low-income school within the same school district.

For inter-district transfers, there is strong evidence to suggest that inter-district transfers leaving low-income schools move into low-income schools, but not for those leaving high-income schools. The -0.076 in row 3 is negative and not significant. This suggests if an inter-district elementary transfer leaves a high-income school, there is no evidence that this teacher is more likely to move to a high-income school in a different school district. 
Table 5.5 also provides strong evidence for neighboring schools' impact on mobility. Estimates in columns 1 and 2 show high-income neighboring schools have a significant impact on mobility for elementary school transfers regardless of the location of high-income neighboring schools, i.e., within the same district or outside the district. However, only the low-income neighboring schools within the same school district have a significant impact on mobility for intra-district transfers. For example, -2.161 in row 4 means that if an elementary teacher leaves a school that is surrounded by more lowincome schools that are within the same school district, this teacher is significantly more likely to move to a low-income school within the same school district. The 3.264 in row 5 and the 0.685 in the last row mean if an elementary teacher leaves a school that is surrounded by more high-income schools, regardless of the location, this teacher is more likely to move to a high-income school within the same school district.

For elementary school transfers, it seems counterintuitive that high-income neighboring schools outside the school district are found to have a significant impact on intra-district mobility and that high-income neighboring schools within the same school district are found to have a significant impact on inter-district mobility. But the fact that a similar pattern is not observed in low-income schools implies that high-income schools have a much greater influence on teacher labor markets than low-income schools have.

Estimates in columns 3 provide strong evidence that neighboring schools within the same district have a significant impact for intra-district MJH school transfers and some evidence that high-income neighboring schools outside the same district have an impact. This is expected. Estimates in column 4 suggest that neighboring schools within the same district have a significant impact for inter-district MJH school transfers. Though 
the estimates of the neighboring schools outside the same district are insignificant, it does not necessarily imply that they have no impact for inter-district MJH school transfers. The reason is the primary analysis using a 10-mile radius which may be too small for analyzing inter-district MJH school transfers. The analysis using a 20-mile radius can be found in Appendix J. It is clear that neighboring schools outside the same district have a significant impact for inter-district transfers.

The estimates in row 1 in Table 5.5 allow one to detect whether transfers respond to salary differentials once they decide to move. Estimates for elementary school transfers are insignificant, which suggests elementary school transfers do not respond to salary differentials.

In Table 5.6, I provide predicted probabilities by move-type for two representative transfers to better illustrate teachers' mobility patterns. I assign the mean value of all covariates for one representative transfer, and select I select a female transfer with eight years of experience and no master's degree or doctorate as another representative transfer. Probabilities are very similar for these two teachers. For example, if both representative intra-district elementary transfers leave from a high-income school, the probability of transfer to a high-income school is 0.214 for one and 0.218 for the other. Similarly, if both representative intra-district elementary transfers leave from a low-income school, the probability of transfer to a low-income school is 0.375 for one and 0.369 for the other.

Furthermore, in row 2 , the probability in column $1(0.095)$ is smaller than that in column $2(0.375)$, which implies that if an intra-district elementary transfer leaves from a 
low-income school, this teacher has a higher probability to move to a low-income school than a high-income school within the same school district. The difference in probabilities if more evident for transfers leaving low-income schools than high-income schools. A similar pattern can be observed for intra-district MJH school transfers. As can be seen from the Table 5.6, the difference in probabilities is more dramatic for MJH intra-district transfers. For example, in row 6 , the probability in column $1(0.044)$ is much smaller than that in column $2(0.407)$.

Probabilities for inter-district transfers show different results across schooling levels. Though they still show that inter-district elementary transfers are more likely to move to socioeconomically similar schools, this is not the case for inter-district MJH school transfers, which is consistent with the estimates presented in Table 5.5.

Table 5.7 provides the changes in probabilities of a transfer going to a highincome or a low-income school when exporting school type changes. Results are consistent with the estimates in Table 5.5. For example, the probabilities in row 1 indicate that if an intra-district elementary transfer is leaving a high-income school, the probability of moving into a high-income school is 0.076 higher than an intra-district elementary transfer leaving a middle-income or low-income school. For inter-district transfers, it may seem odd to see that the probability of moving into a high-income school is 0.023 lower for an elementary transfer leaving a high-income school, but this result is consistent with the insignificant estimate in Table 5.5.

Table 5.7 also provides the changes in probabilities of a transfer going to a highincome or a low-income school when the percentage of high-income and low-income 
neighboring schools changes. For simplicity, I only provide the changes in probabilities when the percentage of high-income and low-income neighboring schools increases by its full range (as observed in the data). For example, 0.814 in row 3 means that when the percentage of high-income neighboring schools within the same school district increases by its full range, the probability of an intra-district elementary transfer to move to a highincome school within the same school district will increase by 0.814 .

\subsection{Other Issues}

\subsubsection{Salary Differentials}

As stated earlier, one possible motivation for teachers to move across district is salary differentials. Table 5.8 shows the mean and the median change in salaries by exporting school and importing school type. ${ }^{13}$ If most teachers move across district for higher salary, then the mean or median for inter-district transfers should be higher than for stayers and intra-district transfers. However, I do not find evidence for that argument for elementary school transfers and MJH school transfers. This finding is consistent with the finding from 2008-2009 Teacher Follow Survey, which shows that stayers, movers and leavers are almost equally likely to be satisfied with their teaching salary. ${ }^{14}$ It suggests that inter-district transfers move for other reasons than higher salary.

\subsubsection{Clustering of Schools by Type}

Though there is strong evidence to suggest that intra-district transfers move into socioeconomically similar schools, it is not clear whether it is partially or mainly driven

\footnotetext{
${ }^{13}$ Median is reported with the mean because two cells have fewer than 30 teachers, which makes inference from the mean alone not reliable.

${ }^{14}$ See http://nces.ed.gov/surveys/sass/tables/tfs0809_023_cf1n.asp. 
by the clustering of schools by type. There is no existing literature on the clustering of Missouri public schools, but it is reasonable to think more low-income schools are clustered in downtown areas of big cities, such as Kansas City and St.Louis. I directly investigate the clustering issue by randomly assigning school types within each district based on the real distribution. For example, if a school district has ten low-income elementary schools, eight middle-income elementary schools, and five high-income elementary schools, I randomly pick ten elementary schools to be low-income, eight to be middle-income, and five to be high-income.

Table 5.9 replicates part of Tables 5.2 and 5.3. It presents cross-tabulations for elementary and $\mathrm{MJH}$ school transfers by randomly assigned exporting and importing school types. If clustering of schools plays a significant role in teachers' move, Table 5.9 should repeal different patterns than the reality presented in Tables 5.2 and 5.3. For elementary school transfers, I observe similar patterns. It suggests that clustering of elementary schools does not affect teachers' move. For MJH school transfers, I observe a different pattern for intra-district transfers leaving high-income schools and inter-district transfers leaving low-income schools. It suggests that part of reason why intra-district MJH school transfers move from high-income schools to high-income schools is due to clustering of high-income MJH schools.

Table 5.10 replicates Table 5.5. It presents the ordered probit estimation results using randomly assigned exporting and importing school types. Table 5.10 confirms my findings from Table 5.9. There is no evidence that clustering of elementary schools has an impact for elementary schools, but column 3 provides evidence that clustering of $\mathrm{MJH}$ high-income schools contributes to the teacher move between them. 


\subsection{Discussions and Conclusion}

This chapter studies the differences in the mobility pattern between intra-district transfers and inter-district transfers by schooling level. I find that other things being equal, intra-district transfers are more likely than inter-district transfers to move to socioeconomically similar schools, although the move between high-income MJH school transfers is partially due to the clustering of high-income MJH schools. I also find all movers are mid-career tenured teachers; intra-district transfers are approximately five years older and have approximately five more years of experience than inter-district transfers. As expected, intra-district transfers move to schools that are less than 5 miles from the current schools, whereas inter-district transfers move to schools that are more than 20 miles from the current schools.

Conditional on a school's own characteristics, the socioeconomic status of students enrolled in neighboring schools within the same district plays a significant role for intra-district transfers. For inter-district transfers, however, the socioeconomic status of students enrolled in close neighboring schools outside the district does not play a significant role, but that of farther neighboring schools outside the district plays a significant role.

Finally, the predictive power of the ordered probit model is higher in general for intra-district transfers than inter-district transfers. Appendix K reports the percentages of correctly predicted teacher moves by groups of teachers (i.e., teachers moving to highincome, middle-income, or low-income schools). The higher the percentage, the better the predictive power. The main model has the best predictive power for elementary 
teachers leaving middle-income schools, with 91.02 percent correctly predicted. In general, the main model does not have a satisfying predictive power for inter-district transfers. 
Table 5.1 Sample sizes by district types

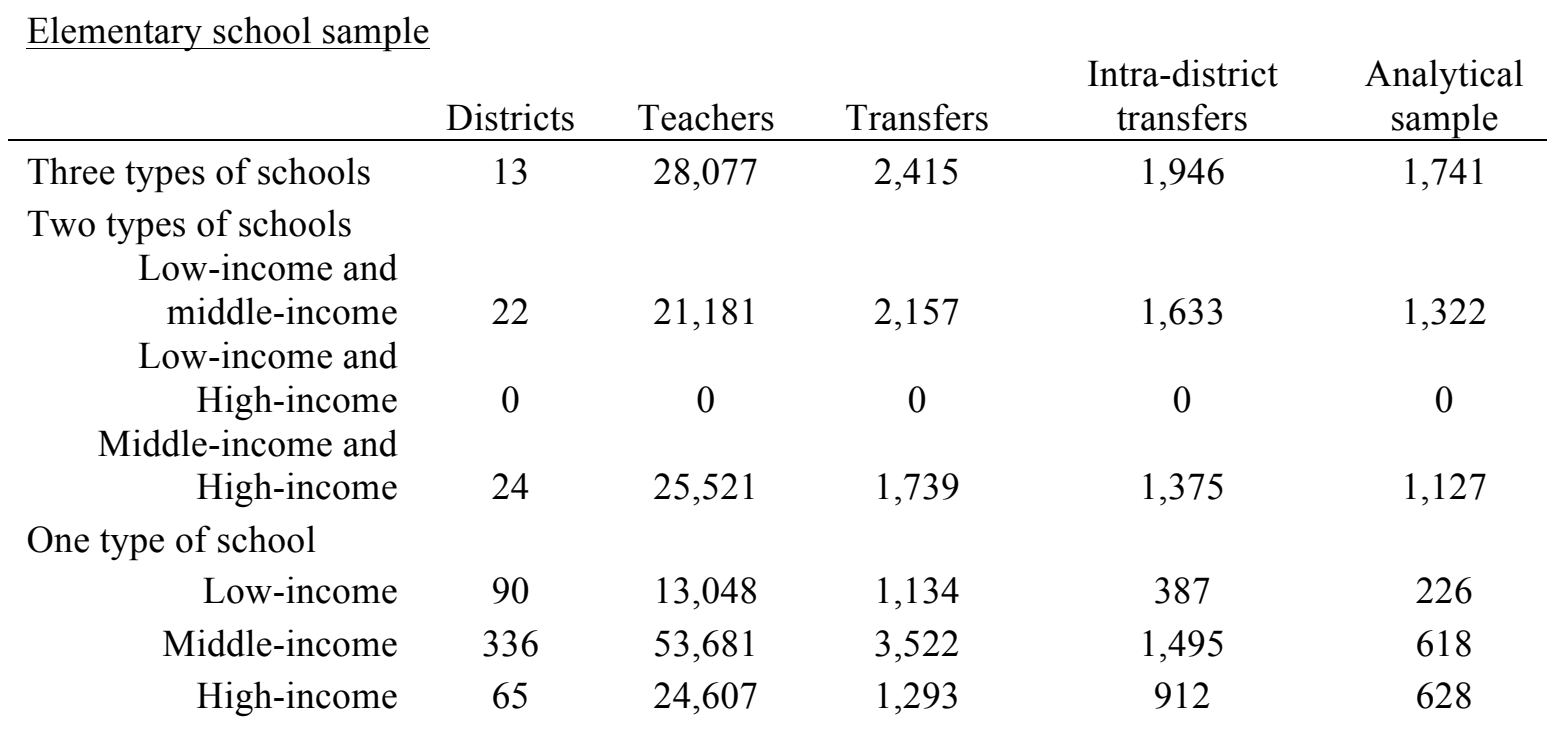

MJH school sample

\begin{tabular}{cccccc} 
& Districts & Teachers & Transfers & $\begin{array}{c}\text { Intra-district } \\
\text { transfers }\end{array}$ & $\begin{array}{c}\text { Analytical } \\
\text { sample }\end{array}$ \\
\hline $\begin{array}{c}\text { Three types of schools } \\
\text { Two types of schools } \\
\text { Low-income and } \\
\text { middle-income }\end{array}$ & 3 & 8,998 & 604 & 444 & 374 \\
Low-income and & 39 & 24,961 & 2,266 & 1,463 & 1,094 \\
$\begin{array}{c}\text { High-income } \\
\text { Middle-income and }\end{array}$ & 0 & 0 & 0 & 0 & 0 \\
$\begin{array}{c}\text { High-income } \\
\text { One type of school }\end{array}$ & 47 & 28,377 & 1,798 & 980 & 603 \\
Low-income & 65 & 8,151 & 787 & 241 & 71 \\
Middle-income & 240 & 41,582 & 3,523 & 1,428 & 431 \\
High-income & 76 & 39,340 & 2,030 & 1,179 & 775 \\
\hline
\end{tabular}

Note: MJH schools are middle, junior high, and high schools. All schools in the sample are divided into three groups based on their shares of free or reduced-price lunch-eligible students (FRL). Low-income schools are schools in the top quartile in terms of their FRL shares, middle-income schools are schools in the middle two quartiles, and high-income schools are schools in the bottom quartile. 
Table 5.2 Cross-tabulation for elementary school transfers by exporting school and importing school types

\begin{tabular}{lcccc}
\hline Intra-district transfers & \multicolumn{5}{c}{ Importing School } \\
(1) Count & $\begin{array}{c}\text { High-income } \\
\text { Exporting school }\end{array}$ & $\begin{array}{c}\text { Middle-income } \\
(\%)\end{array}$ & $\begin{array}{c}\text { Low-income } \\
(\%)\end{array}$ & Total, N (\%) \\
\hline High-income & 63.41 & 30.39 & 6.19 & $1,066(25.44)$ \\
Middle-income & 25.69 & 51.77 & 22.54 & $1,300(31.03)$ \\
Low-income & 5.48 & 26.15 & 68.37 & $1,824(43.53)$
\end{tabular}

(2) Average age (year)

Exporting school

$\begin{array}{llll}\text { High-income } & 38 & 40 & 43 \\ \text { Middle-income } & 39 & 41 & 43 \\ \text { Low-income } & 39 & 42 & 46\end{array}$

(3) Average experience (year)

\begin{tabular}{lccc} 
Exporting school & High-income & Middle-income & Low-income \\
\hline High-income & 9 & 11 & 12 \\
Middle-income & 10 & 11 & 12 \\
Low-income & 11 & 12 & 13
\end{tabular}

Inter-district transfers

\begin{tabular}{lcccc}
\hline (4) Count & \multicolumn{4}{c}{ Importing School } \\
Exporting school & $\begin{array}{c}\text { High-income } \\
(\%)\end{array}$ & $\begin{array}{c}\text { Middle-income } \\
(\%)\end{array}$ & $\begin{array}{c}\text { Low-income } \\
(\%)\end{array}$ & Total, N (\%) \\
\hline High-income & 49.81 & 35.31 & 14.89 & $524(15.73)$ \\
Middle-income & 23.92 & 61.64 & 14.44 & $1,898(56.96)$ \\
Low-income & 18.13 & 42.09 & 39.78 & $910(27.31)$
\end{tabular}

(5) Average age (year)

\begin{tabular}{lccc} 
Exporting school & High-income & Middle-income & Low-income \\
\hline High-income & 33 & 34 & 38 \\
Middle-income & 33 & 35 & 36 \\
Low-income & 33 & 35 & 38
\end{tabular}

(6) Average experience (year)

\begin{tabular}{lccc} 
Exporting school & High-income & Middle-income & Low-income \\
\hline High-income & 6 & 7 & 8 \\
Middle-income & 6 & 7 & 7 \\
Low-income & 6 & 6 & 8
\end{tabular}

Note: MJH schools are middle, junior high, and high schools. Percentages in columns 1-3 are calculated in terms of row total, and percentages in column 4 are calculated in terms of column total. All schools in the sample are divided into three groups based on their shares of free or reduced-price lunch-eligible students (FRL). Low-income schools are schools in the top quartile in terms of their FRL shares, middle-income schools are schools in the middle two quartiles, and high-income schools are schools in the bottom quartile. 
Table 5.3 Cross-tabulation for MJH school transfers by exporting school and importing school types

\begin{tabular}{|c|c|c|c|c|}
\hline \multicolumn{5}{|c|}{ Intra-district transfers } \\
\hline \multirow{2}{*}{$\begin{array}{l}\text { (1) Count } \\
\text { Exporting school }\end{array}$} & \multicolumn{4}{|c|}{ Importing School } \\
\hline & $\begin{array}{c}\text { High-income } \\
(\%)\end{array}$ & $\begin{array}{c}\text { Middle-income } \\
(\%)\end{array}$ & $\begin{array}{c}\text { Low-income } \\
(\%)\end{array}$ & Total, N (\%) \\
\hline High- & 51.55 & 47.02 & 1.43 & $419(20.23)$ \\
\hline Middle-income & 34.33 & 43.45 & 22.22 & 702(33.90) \\
\hline Low-income & 1.89 & 28.42 & 69.68 & $950(45.87)$ \\
\hline
\end{tabular}

(2) Average age (year)

Exporting school High-income Middle-income Low-income

$\begin{array}{llll}\text { High-income } & 39 & 40 & 46 \\ \text { Middle-income } & 40 & 40 & 42 \\ \text { Low-income } & 40 & 43 & 47\end{array}$

(3) Average experience (year)

\begin{tabular}{lccc} 
Exporting school & High-income & Middle-income & Low-income \\
\hline High-income & 10 & 11 & 15 \\
Middle-income & 10 & 10 & 11 \\
Low-income & 13 & 12 & 12
\end{tabular}

$\underline{\text { Inter-district transfers }}$

\begin{tabular}{lcccc}
\cline { 1 - 2 } (4) Count & \multicolumn{4}{c}{ Importing School } \\
Exporting school & $\begin{array}{c}\text { High-income } \\
(\%)\end{array}$ & $\begin{array}{c}\text { Middle-income } \\
(\%)\end{array}$ & $\begin{array}{c}\text { Low-income } \\
(\%)\end{array}$ & Total, N (\%) \\
\hline High-income & 57.40 & 32.44 & 10.16 & $1,122(27.48)$ \\
Middle-income & 33.96 & 55.09 & 10.95 & $2,197(53.66)$ \\
Low-income & 23.25 & 40.78 & 35.97 & $770(18.86)$
\end{tabular}

(5) Average age (year)

\begin{tabular}{lccc} 
Exporting school & High-income & Middle-income & Low-income \\
\hline High-income & 34 & 35 & 39 \\
Middle-income & 34 & 35 & 36 \\
Low-income & 35 & 37 & 40
\end{tabular}

(6) Average experience (year)

\begin{tabular}{lccc} 
Exporting school & High-income & Middle-income & Low-income \\
\hline High-income & 7 & 7 & 8 \\
Middle-income & 6 & 7 & 7 \\
Low-income & 5 & 6 & 8
\end{tabular}

Note: MJH schools are middle, junior high, and high schools. Percentages in columns 1-3 are calculated in terms of row total, and percentages in column 4 are calculated in terms of column total. All schools in the sample are divided into three groups based on their shares of free or reduced-price lunch-eligible students (FRL). Low-income schools are schools in the top quartile in terms of their FRL shares, middle-income schools are schools in the middle two quartiles, and high-income schools are schools in the bottom quartile. 
Table 5.4 Distance between exporting schools and importing schools (mile)

\begin{tabular}{|c|c|c|c|c|c|c|}
\hline \multirow[t]{2}{*}{ Elementary school } & \multicolumn{2}{|c|}{ High-income } & \multicolumn{2}{|c|}{ Middle-income } & \multicolumn{2}{|c|}{ Low-income } \\
\hline & Mean & Median & Mean & Median & Mean & Median \\
\hline \multicolumn{7}{|c|}{ Intra-district transfers } \\
\hline High-income & 4 & 3 & 4 & 4 & 4 & 4 \\
\hline Middle-income & 4 & 3 & 3 & 3 & 4 & 3 \\
\hline Low-income & 5 & 5 & 4 & 3 & 3 & 3 \\
\hline \multicolumn{7}{|c|}{ Inter-district transfers } \\
\hline High-income & 17 & 14 & 25 & 21 & 23 & 17 \\
\hline Middle-income & 23 & 20 & 25 & 21 & 28 & 24 \\
\hline Low-income & 20 & 15 & 22 & 15 & 11 & 6 \\
\hline \multirow[t]{2}{*}{ MJH school } & \multicolumn{2}{|c|}{ High-income } & \multicolumn{2}{|c|}{ Middle-income } & \multicolumn{2}{|c|}{ Low-income } \\
\hline & Mean & Median & Mean & Median & Mean & Median \\
\hline \multicolumn{7}{|c|}{ Intra-district transfers } \\
\hline High-income & 4 & 3 & 3 & 3 & 4 & 4 \\
\hline Middle-income & 4 & 3 & 3 & 2 & 3 & 2 \\
\hline Low-income & 5 & 5 & 3 & 2 & 3 & 3 \\
\hline \multicolumn{7}{|c|}{ Inter-district transfers } \\
\hline High-income & 20 & 17 & 30 & 24 & 23 & 19 \\
\hline Middle-income & 28 & 23 & 30 & 26 & 29 & 25 \\
\hline Low-income & 21 & 18 & 23 & 16 & 11 & 7 \\
\hline
\end{tabular}

Note: MJH schools are middle, junior high, and high schools. All schools in the sample are divided into three groups based on their shares of free or reduced-price lunch-eligible students (FRL). Low-income schools are schools in the top quartile in terms of their FRL shares, middle-income schools are schools in the middle two quartiles, and high-income schools are schools in the bottom quartile. 
Table 5.5 Ordered probit estimation results

\begin{tabular}{|c|c|c|c|c|}
\hline & \multicolumn{2}{|c|}{ Elementary school transfers } & \multicolumn{2}{|c|}{ MJH school transfers } \\
\hline & Intra-district & Inter-district & Intra-district & Inter-district \\
\hline \multicolumn{5}{|l|}{ Teacher } \\
\hline Salary premium & $\begin{array}{l}-0.146 \\
(0.254)\end{array}$ & $\begin{array}{c}0.212 \\
(0.341)\end{array}$ & $\begin{array}{c}-0.700 \\
(0.395) \dagger\end{array}$ & $\begin{array}{c}0.561 \\
(0.349)\end{array}$ \\
\hline \multicolumn{5}{|l|}{ Exporting school } \\
\hline Low-income & $\begin{array}{c}-0.191 \\
(0.080)^{*}\end{array}$ & $\begin{array}{c}-0.213 \\
(0.082)^{* *}\end{array}$ & $\begin{array}{c}-0.340 \\
(0.169)^{*}\end{array}$ & $\begin{array}{c}-0.345 \\
(0.078)^{* *}\end{array}$ \\
\hline High-income & $\begin{array}{c}0.325 \\
(0.100)^{* *}\end{array}$ & $\begin{array}{l}-0.076 \\
(0.093)\end{array}$ & $\begin{array}{c}0.416 \\
(0.169)^{*}\end{array}$ & $\begin{array}{c}0.096 \\
(0.071)\end{array}$ \\
\hline \multicolumn{5}{|l|}{ Neighboring schools } \\
\hline Within low-income & $\begin{array}{c}-2.161 \\
(0.323)^{* *}\end{array}$ & $\begin{array}{l}-0.026 \\
(0.309)\end{array}$ & $\begin{array}{c}-5.425 \\
(1.762)^{* *}\end{array}$ & $\begin{array}{c}-0.306 \\
(0.131)^{*}\end{array}$ \\
\hline Within high-income & $\begin{array}{c}3.264 \\
(0.344)^{* *}\end{array}$ & $\begin{array}{c}0.860 \\
(0.389)^{*}\end{array}$ & $\begin{array}{c}2.498 \\
(0.453)^{* *}\end{array}$ & $\begin{array}{c}0.354 \\
(0.152)^{*}\end{array}$ \\
\hline Outside low-income & $\begin{array}{c}0.114 \\
(0.269)\end{array}$ & $\begin{array}{c}-0.209 \\
(0.100)^{*}\end{array}$ & $\begin{array}{l}-0.087 \\
(0.601)\end{array}$ & $\begin{array}{c}-0.204 \\
(0.136)\end{array}$ \\
\hline Outside high-income & $\begin{array}{c}0.685 \\
(0.232)^{* *}\end{array}$ & $\begin{array}{c}0.347 \\
(0.118)^{* *}\end{array}$ & $\begin{array}{c}0.647 \\
(0.325)^{*}\end{array}$ & $\begin{array}{c}0.108 \\
(0.097)\end{array}$ \\
\hline Neighborhood & $\mathrm{X}$ & $\mathrm{X}$ & $\mathrm{X}$ & $\mathrm{X}$ \\
\hline Urbanicity & $\mathrm{X}$ & $\mathrm{X}$ & $\mathrm{X}$ & $\mathrm{X}$ \\
\hline Log pseudolikelihood & -2911.642 & -3053.960 & $-1,335.985$ & $-3,726.689$ \\
\hline $\mathrm{N}$ & 4,190 & 3,332 & 2,071 & 4,083 \\
\hline P-value & 0.000 & 0.000 & 0.000 & 0.000 \\
\hline \multicolumn{5}{|c|}{$\begin{array}{l}\text { Note: Positive estimates imply higher probability of n } \\
\text { imply higher probability of moving to a low-income } \\
\text { clustered at the school level. All schools in the sampl } \\
\text { free or reduced-price lunch-eligible students (FRL). I } \\
\text { terms of their FRL shares, middle-income schools are } \\
\text { schools are schools in the bottom quartile. } \\
* * \text { Indicates statistical significance at the } 1 \% \text { level. } \\
* \text { Indicates statistical significance at the } 5 \% \text { level. } \\
\uparrow \text { Indicates statistical significance at the } 10 \% \text { level. }\end{array}$} \\
\hline
\end{tabular}


Table 5.6 Probabilities of two representative transfers going to a high-income, or low-income school evaluated at the mean value of covariates

\begin{tabular}{|c|c|c|c|c|}
\hline \multicolumn{5}{|c|}{ Elementary school transfers } \\
\hline \multirow[b]{2}{*}{ Exporting school } & \multicolumn{2}{|c|}{$\begin{array}{c}\text { Intra-district } \\
\text { Importing school }\end{array}$} & \multicolumn{2}{|c|}{$\begin{array}{c}\text { Inter-district } \\
\text { Importing school }\end{array}$} \\
\hline & High-income & Low-income & High-income & Low-income \\
\hline High-income & 0.214 & 0.202 & 0.234 & 0.190 \\
\hline Low-income & 0.095 & 0.375 & 0.194 & 0.229 \\
\hline \multicolumn{5}{|c|}{ Experience: 8years; female; no master's degree or doctorate } \\
\hline High-income & 0.218 & 0.198 & 0.244 & 0.181 \\
\hline Low-income & 0.098 & 0.369 & 0.203 & 0.219 \\
\hline \multicolumn{5}{|c|}{ MJH school transfers } \\
\hline & \multirow{2}{*}{\multicolumn{2}{|c|}{$\begin{array}{c}\text { Intra-district } \\
\text { Importing school }\end{array}$}} & \multirow{2}{*}{\multicolumn{2}{|c|}{$\begin{array}{c}\text { Inter-district } \\
\text { Importing school }\end{array}$}} \\
\hline & & & & \\
\hline Exporting school & High-income & Low-income & High-income & Low-income \\
\hline High-income & 0.172 & 0.161 & 0.418 & 0.101 \\
\hline Low-income & 0.044 & 0.407 & 0.258 & 0.201 \\
\hline \multicolumn{5}{|c|}{ Experience: 8years; female; no master's degree or doctorate } \\
\hline High-income & 0.168 & 0.165 & 0.409 & 0.105 \\
\hline Low-income & 0.042 & 0.414 & 0.251 & 0.208 \\
\hline
\end{tabular}

Note: Probabilities are calculated at the mean value of all other covariates. All schools in the sample are divided into three groups based on their shares of free or reduced-price lunch-eligible students (FRL). Lowincome schools are schools in the top quartile in terms of their FRL shares, middle-income schools are schools in the middle two quartiles, and high-income schools are schools in the bottom quartile. 
Table 5.7 Changes in probabilities of a transfer going to a high-income or lowincome school

\begin{tabular}{|c|c|c|c|c|}
\hline \multicolumn{5}{|c|}{ Elementary school transfers } \\
\hline \multirow[b]{2}{*}{ Exporting schools } & \multicolumn{2}{|c|}{$\begin{array}{c}\text { Intra-district } \\
\text { Importing school }\end{array}$} & \multicolumn{2}{|c|}{$\begin{array}{c}\text { Inter-district } \\
\text { Importing school }\end{array}$} \\
\hline & High-income & Low-income & High-income & Low-income \\
\hline High-income & 0.076 & -0.109 & -0.023 & 0.021 \\
\hline Low-income & -0.040 & 0.067 & -0.063 & 0.060 \\
\hline $\begin{array}{l}\text { Neighboring schools } \\
\text { (Min->Max) }\end{array}$ & High-income & Low-income & High-income & Low-income \\
\hline Within high-income & 0.814 & -0.444 & 0.247 & -0.134 \\
\hline Within low-income & -0.213 & 0.706 & -0.008 & 0.007 \\
\hline Outside high-income & 0.146 & -0.185 & 0.114 & -0.084 \\
\hline Outside low-income & 0.025 & -0.039 & -0.061 & 0.059 \\
\hline \multicolumn{5}{|l|}{ MJH school transfers } \\
\hline & \multirow{2}{*}{\multicolumn{2}{|c|}{$\begin{array}{c}\text { Intra-district } \\
\text { Importing school }\end{array}$}} & \multirow{2}{*}{\multicolumn{2}{|c|}{$\begin{array}{c}\text { Inter-district } \\
\text { Importing school }\end{array}$}} \\
\hline & & & & \\
\hline Exporting schools & High-income & Low-income & High-income & Low-income \\
\hline High-income & 0.071 & -0.136 & 0.036 & -0.019 \\
\hline Low-income & -0.048 & 0.120 & -0.124 & 0.081 \\
\hline \multicolumn{5}{|l|}{ Neighboring schools } \\
\hline Within high-income & 0.741 & -0.407 & 0.138 & -0.061 \\
\hline Within low-income & -0.191 & 0.857 & -0.108 & 0.074 \\
\hline Outside high-income & 0.094 & -0.183 & 0.041 & -0.022 \\
\hline Outside low-income & -0.008 & 0.020 & -0.074 & 0.046 \\
\hline
\end{tabular}

Note: MJH schools are middle, junior high, and high schools. All schools in the sample are divided into three groups based on their shares of free or reduced-price lunch-eligible students (FRL). Low-income schools are schools in the top quartile in terms of their FRL shares, middle-income schools are schools in the middle two quartiles, and high-income schools are schools in the bottom quartile. 
Table 5.8 Change in salary (dollar)

Elementary school

Intra-district transfers

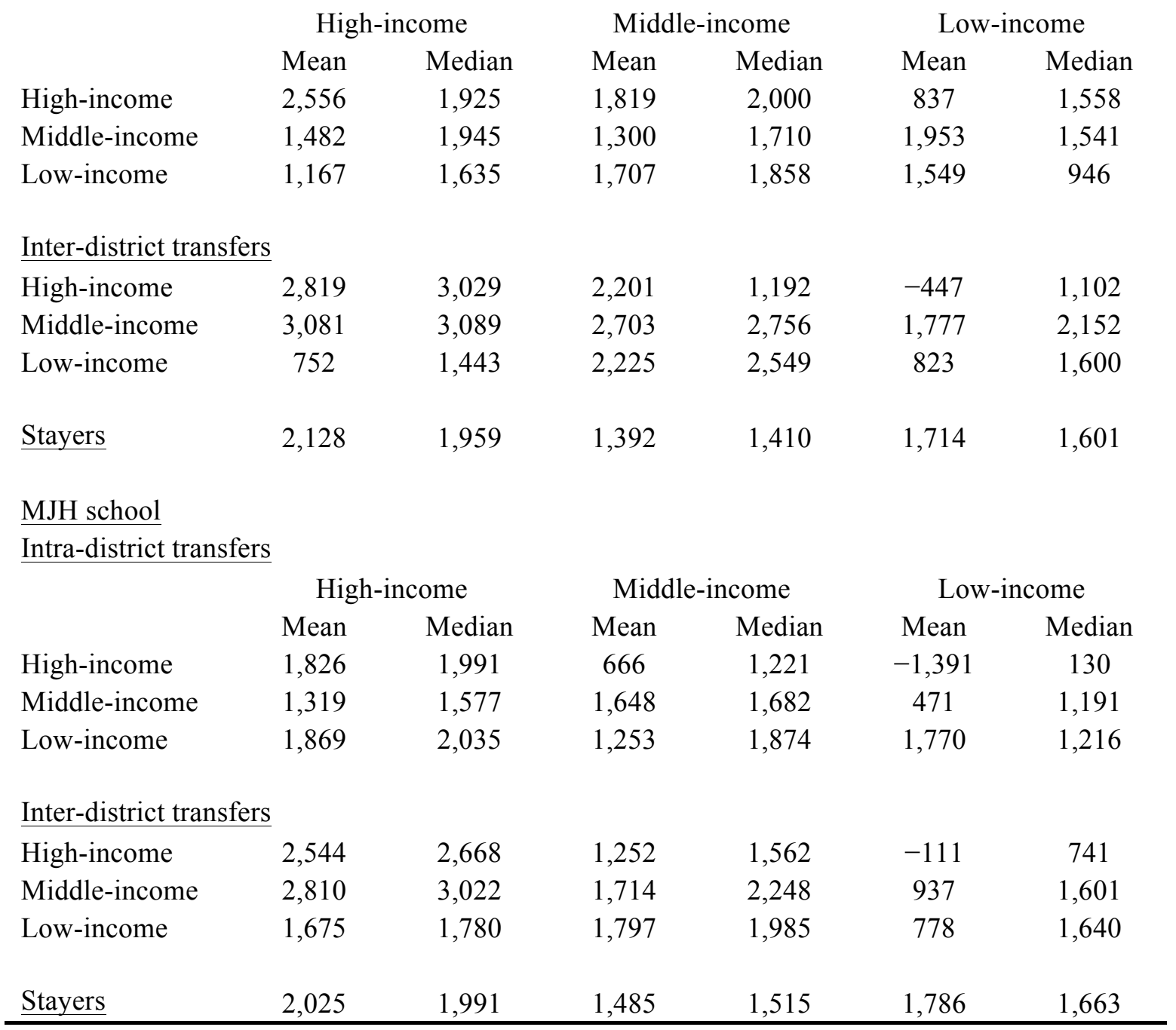

Note: MJH schools are middle, junior high, and high schools. All schools in the sample are divided into three groups based on their shares of free or reduced-price lunch-eligible students (FRL). Low-income schools are schools in the top quartile in terms of their FRL shares, middle-income schools are schools in the middle two quartiles, and high-income schools are schools in the bottom quartile. 
Table 5.9 Cross-tabulation for elementary and MJH school transfers by exporting school and importing school types (randomized within district)

\begin{tabular}{|c|c|c|c|}
\hline & & Importing school & \\
\hline & High-income (\%) & Middle-income (\%) & Low-income $(\%)$ \\
\hline Elementary scho & & & \\
\hline Intra-district tran & & & \\
\hline High-income & 61.36 & 29.86 & 8.78 \\
\hline Middle-income & 26.81 & 47.90 & 25.29 \\
\hline Low-income & 5.29 & 26.93 & 67.78 \\
\hline Inter-district trai & & & \\
\hline High-income & 46.49 & 38.90 & 14.61 \\
\hline Middle-income & 23.17 & 63.02 & 13.82 \\
\hline Low-income & 19.72 & 43.23 & 37.05 \\
\hline MJH school & & & \\
\hline Intra-district tral & & & \\
\hline High-income & 40.72 & 56.50 & 2.77 \\
\hline Middle-income & 34.05 & 35.11 & 30.84 \\
\hline Low-income & 2.34 & 29.19 & 68.46 \\
\hline Inter-district tra1 & & & \\
\hline High-income & 54.48 & 35.28 & 10.24 \\
\hline Middle-income & 31.26 & 56.14 & 12.60 \\
\hline Low-income & 23.11 & 41.51 & 35.38 \\
\hline
\end{tabular}


Table 5.10 Ordered probit estimation results (randomized within district)

\begin{tabular}{|c|c|c|c|c|}
\hline & \multicolumn{2}{|c|}{ Elementary school transfers } & \multicolumn{2}{|c|}{ MJH school transfers } \\
\hline & Intra-district & Inter-district & Intra-district & Inter-district \\
\hline \multicolumn{5}{|l|}{ Teacher } \\
\hline Salary premium & $\begin{array}{c}-0.214 \\
(0.244)\end{array}$ & $\begin{array}{c}0.616 \\
(0.364) \dagger\end{array}$ & $\begin{array}{c}-0.799 \\
(0.370)^{*}\end{array}$ & $\begin{array}{c}0.548 \\
(0.339)\end{array}$ \\
\hline \multicolumn{5}{|l|}{ Exporting school } \\
\hline Low-income & $\begin{array}{c}-0.157 \\
(0.081) \dagger\end{array}$ & $\begin{array}{c}-0.137 \\
(0.078) \dagger\end{array}$ & $\begin{array}{c}-0.380 \\
(0.160)^{*}\end{array}$ & $\begin{array}{c}-0.173 \\
(0.069)^{*}\end{array}$ \\
\hline High-income & $\begin{array}{c}0.428 \\
(0.084)^{* *}\end{array}$ & $\begin{array}{l}-0.138 \\
(0.085)\end{array}$ & $\begin{array}{c}-0.136 \\
(0.155)\end{array}$ & $\begin{array}{c}0.097 \\
(0.071)\end{array}$ \\
\hline \multicolumn{5}{|l|}{ Neighboring schools } \\
\hline Within low-income & $\begin{array}{c}-2.173 \\
(0.328)^{* *}\end{array}$ & $\begin{array}{l}-0.056 \\
(0.302)\end{array}$ & $\begin{array}{c}-4.625 \\
(1.040)^{* *}\end{array}$ & $\begin{array}{c}-0.674 \\
(0.172)^{* *}\end{array}$ \\
\hline Within high-income & $\begin{array}{c}3.689 \\
(0.373)^{* *}\end{array}$ & $\begin{array}{c}1.078 \\
(0.387)^{* *}\end{array}$ & $\begin{array}{c}3.564 \\
(0.828)^{* *}\end{array}$ & $\begin{array}{c}0.126 \\
(0.167)\end{array}$ \\
\hline Outside low-income & $\begin{array}{c}0.117 \\
(0.268)\end{array}$ & $\begin{array}{c}-0.168 \\
(0.095) \dagger\end{array}$ & $\begin{array}{l}-0.236 \\
(0.509)\end{array}$ & $\begin{array}{l}-0.271 \\
(0.117)^{*}\end{array}$ \\
\hline Outside high-income & $\begin{array}{c}0.640 \\
(0.243)^{* *}\end{array}$ & $\begin{array}{c}0.297 \\
(0.123)^{*}\end{array}$ & $\begin{array}{c}1.413 \\
(0.413)^{* *}\end{array}$ & $\begin{array}{c}0.182 \\
(0.106) \dagger\end{array}$ \\
\hline Neighborhood & $\mathrm{X}$ & $\mathrm{X}$ & $\mathrm{X}$ & $\mathrm{X}$ \\
\hline Urbanicity & $\mathrm{X}$ & $\mathrm{X}$ & $\mathrm{X}$ & $\mathrm{X}$ \\
\hline Log pseudolikelihood & $-2,916.533$ & -3038.475 & $-1,379.414$ & $-3,761.570$ \\
\hline $\mathrm{N}$ & 4,172 & 3,332 & 2,071 & 4,082 \\
\hline P-value & 0.000 & 0.000 & 0.000 & 0.000 \\
\hline $\begin{array}{l}\text { Note: Positive estimates in } \\
\text { imply higher probability o } \\
\text { clustered at the school leve } \\
\text { sample are randomly assig } \\
* * \text { Indicates statistical sign } \\
* \text { Indicates statistical signi } \\
\dagger \text { Indicates statistical signi }\end{array}$ & $\begin{array}{l}\text { y higher probabi } \\
\text { loving to a low-i } \\
\text { MJH schools are } \\
\text { d a type within d } \\
\text { cance at the } 1 \% \\
\text { ance at the } 5 \% 1 \\
\text { ance at the } 10 \%\end{array}$ & $\begin{array}{l}\text { moving to a } \\
\text { school. Star } \\
\text { le, junior hig } \\
\text { based on the }\end{array}$ & $\begin{array}{l}\text { trome school. } \\
\text { rrors are in par } \\
\text { igh schools. A } \\
\text { stribution. }\end{array}$ & $\begin{array}{l}\text { itive estimates } \\
\text { eses and } \\
\text { oools in the }\end{array}$ \\
\hline
\end{tabular}




\section{Chapter 6: Principal Turnover on Student Outcome}

\subsection{Empirical Strategy}

\subsubsection{Pooled OLS}

Equation (10) is a typical value-added model of student achievement. We identify students whose schools experience at least one principal turnover during the data panel of our analysis and estimate the following equation using OLS.

$$
Y_{i, t}=\beta_{0}+\beta_{1} Y_{i, t-1}+\beta_{2} Y_{i, t-1}^{\text {other }}+\beta_{3} X_{i, t}+\beta_{4} P_{i, t}+\beta_{5} S_{i, t}+\beta_{6} \gamma_{s}+\beta_{7} T U R N_{s, t-1}+\varepsilon_{i, t}
$$

In (10), $Y_{i, t-1}$ is a test score for student $i$ at year $t ; Y_{i, t-1}$ is a test score in the same subject for student $i$ at year $t-1 ; Y_{i, t-1}^{O t h e r}$ is a test score in another subject for student $i$ at year $t-1 ; X_{i, t}$ is a vector of observable covariates for student $i$ at year $t$, including race, gender, free-lunch status, and grade level; $P_{i, t}$ is a vector of observable time-variant and time-invariant characteristics for student $i$ 's principal at year $t$, including age, age squared, experience in Missouri schools, experience in Missouri schools squared, highest degree, race, gender, and salary in constant dollars; $S_{i, t}$ is a vector of time-varying school characteristics for student $i$ 's school, including percentage of black students, percentage of Hispanic students, and percentage of students enrolled in the free-lunch program, and school enrollment; $\gamma_{s}$ refers to school fixed effects; $T U R N_{s, t-1}$ is an indicator variable for principal turnover that is 1 if school s's principal left the school at the end of the year $t-1$ and 0 otherwise. 
$\beta_{7}$ is the parameter of primary interest. It shows the within-school difference in average student achievement gains when this school experiences principal turnover compared with times when this school does not. This basic model does not solve the endogenous principal turnover problem, so $\beta_{7}$ is biased. Because IV estimators are unbiased if other conditions are met, comparing the OLS estimate and the IV estimate will help us measure the bias caused by the endogenous problem.

\subsubsection{Strategy}

Though the IV strategy is a very typical solution for endogenous problems, it is not always available because it is difficult to find a strong IV candidate, and using a weak IV often not only makes the estimate more biased but also may cause other problems. Beteille et al. (2011) have tried other approaches to solve the endogenous problem when a strong IV is not available or has not been found yet, such as controlling for percentage of new teachers at a school or the year before the new principal takes the job. However, they find these two approaches do not make a difference in the estimates. To directly solve the problem, we introduce $P V \_D I S T_{s, t-1}$ as an IV for principal turnover and use two-stage least square (2SLS) estimation. The two stages are:

First stage:

$$
T U R N_{s, t-1}=\alpha_{1} P V_{-} D I S T_{s, t-1}+\mathrm{A}_{2}^{\prime} Q_{s, t}+u_{s, t}
$$

Second stage:

$$
Y_{i, t}=\beta_{0}+\beta_{1} Y_{i, t-1}+\beta_{2} Y_{i, t-1}^{\text {other }}+\beta_{3} X_{i, t}+\beta_{4} P_{i, t}+\beta_{5} S_{i, t}+\beta_{6} \gamma_{s}+\beta_{7} T U \widehat{R N_{s, t-1}}+\varepsilon_{i, t}
$$


In the first stage, $P V_{-} D I S T_{s, t-1}$ is the distance from peak-value pension wealth at time $t-1$ for the principal $p ; Q_{s, t}$ is a vector including all the covariates from the second stage equation besides $T U \widehat{R N_{s, t-1}}$. In the second stage, $T U R N_{s, t-1}$ is replaced by $T U \widehat{R N_{s, t-1}}$, which is estimated from the first stage.

\subsubsection{Supplemental Analysis}

\subsubsection{Robustness Check for the IV}

We expect that the shorter the distance from peak-value pension, the more likely a principal retires. $T U R N_{s, t-1}$ identifies principals who leave their current schools; the variable not only includes retirees but also includes those who voluntarily move to other schools or involuntarily are reassigned. Thus, if the majority of principals who are identified by $T U R N_{s, t-1}$ are not retirees, $P V_{-} D I S T_{s, t-1}$ would not be a strong IV for $T U R N_{s, t-1}$. Though our data and previous research have provided evidence that this is not the case, ${ }^{15}$ we directly check this issue by restricting principal turnovers to retirees. In other words, we create a variable SYSTEM_EXIT $T_{s, t-1}$ that is 1 if the school's principal left the profession at the end of the previous school year and 0 otherwise. We replace $T U R N_{s, t-1}$ with SYSTEM_EXIT $T_{s, t-1}$ and rerun OLS and IV regressions. We expect that $P V_{-} D I S T_{s, t-1}$ would be a stronger IV for SYSTEM_EXIT $T_{s, t-1}$ than for $T U R N_{s, t-1}$.

\footnotetext{
${ }^{15}$ Aud et al (2011) demonstrated that 12 percent of all principals left the profession and 6 percent of all principals moved to other schools nationally during the school year 2008-2009, based on data from the School and Staffing Survey (SPSS). Our data shows that 7 percent of all principals left the profession and 11 percent of all principals moved to other schools during the three-year panel.
} 


\subsubsection{Five-Year Analysis}

We create four more principal turnover variables and corresponding IVs that indicate different timings when a principal turns over in order to detect if principal turnover has any non immediate impact or if the impacts have a time trend. This analysis allows us to list the impacts of principal turnover on a timeline and graphically show any advanced or lagged impact as well as the time trend. Previous literature mostly focuses on the immediate impact when a principal turns over; however, it is reasonable to look at a longer time period due to the possibility of nonimmediate impact. For example, assume a principal is able to plan ahead for the school and the school is not affected right away when this principal turns over. However, after a period of time, the original plan cannot accommodate the current situation or the new principal starts to implement new plans that may be more or less effective than the original. If we just focused on principal turnover at the end of previous school year, we would draw a conclusion that principal turnover has no impact on student outcome. However, this is not the whole picture. Although it is still a short panel, our five-year analysis helps complete that picture. Hence, we created the following four additional variables: (1)TURN $N_{s, t-3}, 1$ if a principal turned over at the end of the school year three years ago, (2) $T U R N_{s, t-2}, 1$ if a principal turned over at the end of the school year two years ago, (3) $T U R N_{s, t}, 1$ if a principal turns

over at the end of current school year, and (4) $T U R N_{s, t+1}, 1$ if a principal turns over at the end of the school year next school year.

We only looked back three years due to concerns about the decay and persistence of principal impact. There is no extant literature on the decay of principal impact. Yet, 
there is a similar argument from the literature on the decay and persistence of teacher effect suggesting that teacher effect decays dramatically in the first few years and flattens out slowly afterward. Similarly, it is possible that principal turnover has a decreasing impact in the first three years after a principal turns over and then becomes indistinguishable. We only look ahead one year due to data availability. Three cohorts of students are included in the data panel: cohort 0607 , cohort 0708 , and cohort 0809. Estimation with $T U R N_{s, t+2}$ for equation (10) requires data for at least two cohorts because that equation includes school fixed effect. However, we have data for only one cohort so that we cannot estimate equation (10) with $T U R N_{s, t+2}$ and looking ahead one year is as far as the data permit. To illustrate, I list available data for estimating principal turnover at different timings for each cohort in the data panel in Appendix L.

\subsection{Analysis}

\subsubsection{Main Results}

Table 6.1 shows the estimated effects of principal turnover on student academic

achievement in math and reading. ${ }^{16}$ Columns (5) and (6) present the results from the main models, equations (10) and (12). Columns (1) through (4) show results from estimation with two variants of the main models. Model 1 includes time-variant school covariants; model 2 adds school fixed effect to model 1. Both OLS and IV results are presented within each model to facilitate comparison between biased OLS estimates and unbiased IV estimates. The Five-year analysis is also presented, with each row indicating different timing when a principal turns over.

\footnotetext{
${ }^{16}$ Estimates for other coefficients from the main model (model 3) are reported in Appendix M.
} 
Estimates in column (6) show that on average, principal turnover has no impact on student academic achievement in the reading model. There is weak evidence in the math model that if a principal turned over at the end of the school year two years ago, this turnover had a negative impact on student math scores.

Comparing column (5) and column (6) provides insights into the degree to which bias is caused by the endogenous problem. Though IV estimates in column (6) are in general greater in magnitude than OLS estimates in column (5), the standard errors of IV estimates are also greater than those of OLS estimates, which is why OLS and IV estimates have similar significance levels. In reading models, because OLS and IV estimates do not differ in significance level, there is no evidence that OLS estimates are biased. In math models, we found weak evidence that OLS estimates are biased upward. In other words, for a principal who turned over at the end of the school year three years ago, the OLS estimate in row 1 indicates that this turnover had a positive impact on student math score, whereas the IV estimate in row 1 shows that this turnover had no impact on student math score. For a principal who turned over at the end of the school year two years ago, the OLS estimate in row 2 shows that this turnover had no impact on student math score, whereas the IV estimate in row 2 indicates that this turnover had a negative impact on student math score. One reason that we find only weak evidence for biased OLS estimates is that model 3 is complex and controls for many factors that help reduce the bias caused by the endogenous principal turnover variable. More evidence for this argument can be found after examining the estimates from models 1 and 2 .

Columns (3) and (4) show results from estimating model 2, which does not include principal covariates. All estimates are insignificant, which suggests that principal 
turnover has no impact on student academic achievement. The fact that we can draw the same conclusion from the model 2 estimates and model 3 estimates suggests that principal covariates do not make a contribution to reducing endogenous bias.

Columns (1) and (2) show results from estimating model 1, which further excludes school fixed effects from model 2. We find strong evidence that OLS estimates are biased downward. Most of the IV estimates in column (2) are insignificant, which suggests that principal turnover has no impact on student academic achievement. However, many OLS estimates in column (1) are significantly negative, which suggests that principal turnover has significant negative impact on student academic achievement. The big discrepancy between OLS estimates and IV estimates suggests that the former are significantly biased downward in model 1 . Notice that this big discrepancy is not obserced in model 2, which controls for school fixed effect. This suggests that controlling for school fixed effects can significantly reduce endogenous bias. This finding is consistent with Beteille et al. (2011), where they sought to reduce the potential endogenous bias by controlling for percentage of new teachers and year fixed effects in addition to school fixed effect, and they found primary estimates of interest were not affected.

\subsubsection{Robustness Check for IV}

We first check the relevance of the IVs by testing their significance in the first stage of 2SLS. Table 6.2 shows the t-statistics and p-values of $\widehat{\alpha_{1}}$ from the first stage of 2SLS. All of the estimates are significant at the 1 percent significance level but one, which is the IV for the variable that indicates whether a principal will turn over at the end 
of current school year. Thus, we find strong evidence that the IV, which is distance from peak-value pension wealth, is strongly correlated with the principal turnover variable.

We then further address the issue by rerunning models with another variable that indicates whether a principal will leave the profession. We expect the IV to be stronger for this variable than the principal turnover variable because pension wealth is critical for making the decision to retire. Table 6.3 shows the estimation results when I replace the principal turnover variable with this new one. If the results in Table 6.3 present a very similar pattern to results in Table 6.1, it means the nonretiree group of principals captured in the principal turnover variable does not interfere with the strong candidacy of the IV. For brevity, we conduct a three-year instead of a five-year analysis.

In general, very similar patterns are observed in Table 6.3. Estimates in column (6) show that principal turnover has no impact on student reading score, which is the same conclusion drawn from Table 6.1. There is still weak evidence that if a principal turned over at the end of the school year two years ago, this turnover had a negative impact on student math scores. There are some differences in significance, but in general, these estimates provide supportive evidence for the strong candidacy of the IV.

\subsubsection{Time Trend}

We extract the OLS estimates and IV estimates from model 3 in Table 6.1 and plot them in a timeline. Figure 6.1 presents two graphs, one for math models and the other for reading models. We choose a different perspective when plotting these graphs. If the principal turns over now (point 0 on the horizontal-axis), what is the impact on student achievement one year ago (point -1 ), now (point 0 ), one year later (point 1 ), two 
years later (point 2), and three years later (point 3)? Though two relatively huge dips in both graphs can be observed, these estimates are insignificant from 0 . In general, OLS estimates do not fluctuate as much as IV estimates.

\subsubsection{High-income and Low-income Schools}

In our main analysis we estimate the average within-school impact of principal turnover for all types of schools. We find principal turnover has no impact on student academic achievement, but we also notice IV estimates are very noisy. By averaging the within-school estimates, the variants in IV estimates would be averaged also, which might be one reason the IV estimates are insignificant. Previous research has also indicated that principal turnover is especially harmful for disadvantaged schools, and interaction terms are usually included to capture this proportionality. We directly address this potential for different impacts by running regressions separately on high-income schools and low-income schools.

Table 6.4 shows the estimated impact of principal turnover for high-income and low-income schools. If different patterns in high-income school estimates and lowincome school estimates are observed, then it suggests principal turnover has different impacts for schools with different poverty levels and empirical studies should be conducted separately. Columns (5) and (6) present the results from the main models. We do not observe a different pattern for math models, and there is some evidence in reading models that principal turnover has a different impact for schools of different poverty levels. In particular, in reading models, we find principal turnover has a negative impact at low-income schools but no impact at high-income schools. Similarly, estimates in 
models 1 and 2 show no difference in pattern for math models and some evidence of a difference for reading models.

\subsection{Limitation}

Our data link students to principals through schools. We do not link students to their teachers in each school. Therefore, the impact of principal turnover that our model captured includes the teacher effect. To illustrate, we can write out the single-year impact of principal turnover for principal $p$ at school $s$ in year $t$ as the sum of three components from the main model (10):

$\widehat{\theta_{p, s, t}}=\theta_{p, s, t}+\lambda_{s, t}+v_{p s t}$

In equation (13), $\widehat{\theta_{p, s, t}}$ is the estimated impact of principal turnover, $\theta_{p, s, t}$ is the true impact of principal turnover, $\lambda_{s, t}$ is the average teacher effect, and $v_{p s t}$ is a noise term that includes other issues I am not addressing (i.e., student sorting into schools). To separate $\lambda_{j, s, t}$ from $\widehat{\theta_{p, s, t}}$, we need to be able to identify the teacher effect induced by principal turnover, which is not allowed in our data set.

Another concern is the reverse causality problem. In other words, it is possible that the poor performance of the school causes a principal to turn over. Our model allows us to compare principal effectiveness as measured by value-added for principals who turnover at the end of a school year to others who do not turnover. However, the model does not allow us to investigate the causality. 


\subsection{Discussions and Conclusion}

We estimate the impact of principal turnover on student academic achievement from school year 2005-2006 to school year 2008-2009. We find no evidence to suggest that a principal turning over at the end of the previous school year had any impact on student academic achievement. We find weak evidence to suggest that principals turning over at the end of the school year two years ago had a negative impact on student reading score for students in low-income schools. We also find some evidence to suggest that principal turnover has different impacts on schools with different poverty levels.

The principal turnover variable has a potential for endogenous bias. To our knowledge, our analysis is the first one to directly address the endogenous problem using an IV strategy. We compare traditional OLS estimates with IV estimates and find evidence to suggest that complex regressions models can effectively reduce the endogenous bias.

Though we find no evidence to suggest that principal turnover has immediate negative impact on student academic achievement, this does not necessarily imply principal turnover is not harmful. It might take two years to see this negative impact, as shown in our analysis.

The analysis also suggests that when principals turn over, their replacements have similar performance levels. In other words, low-performing principals are replaced with low-performing principals and high-performing principals are replaced with highperforming principals. This finding is consistent with the segregated sorting in the teacher 
labor market where we observe teachers move into schools with a similar socioeconomic status to their previous schools. 
Table 6.1 Regression results of math and reading test scores on principal turnover

\begin{tabular}{|c|c|c|c|c|c|c|}
\hline \multirow[b]{3}{*}{ Time leaving the school } & \multicolumn{2}{|c|}{ Model 1} & \multicolumn{2}{|c|}{ Model 2} & \multicolumn{2}{|c|}{ Model 3} \\
\hline & (1) & (2) & (3) & (4) & (5) & (6) \\
\hline & OLS & IV & OLS & IV & OLS & IV \\
\hline \multicolumn{7}{|l|}{ Math } \\
\hline \multirow[t]{2}{*}{ Three years ago } & -0.004 & -0.157 & 0.008 & -0.016 & 0.008 & -0.007 \\
\hline & $(0.005)$ & $(0.091) \dagger$ & $(0.005)$ & $(0.026)$ & $(0.005) \dagger$ & $(0.025)$ \\
\hline \multirow[t]{2}{*}{ Two years ago } & -0.018 & -0.128 & -0.002 & -0.044 & 0.000 & -0.040 \\
\hline & $(0.005) * *$ & $(0.079)$ & $(0.005)$ & $(0.021)$ & $(0.005)$ & $(0.023) \dagger$ \\
\hline \multirow[t]{2}{*}{ Previous school year } & -0.027 & -0.029 & -0.005 & -0.010 & -0.002 & -0.011 \\
\hline & $(0.005) * *$ & $(0.057)$ & $(0.005)$ & $(0.018)$ & $(0.006)$ & $(0.018)$ \\
\hline \multirow{2}{*}{ Current school year } & -0.017 & 0.035 & 0.001 & -0.003 & -0.002 & -0.672 \\
\hline & $(0.005)^{* *}$ & $(0.071)$ & $(0.005)$ & $(0.021)$ & $(0.005)$ & $(0.699)$ \\
\hline \multirow[t]{2}{*}{ Next school year } & -0.015 & 0.027 & -0.002 & -0.040 & -0.002 & -0.040 \\
\hline & $(0.006)^{*}$ & $(0.085)$ & $(0.007)$ & $(0.030)$ & $(0.008)$ & $(0.031)$ \\
\hline \multicolumn{7}{|l|}{ Reading } \\
\hline \multirow[t]{2}{*}{ Three years ago } & -0.002 & 0.000 & 0.005 & 0.008 & 0.005 & 0.013 \\
\hline & $(0.004)$ & $(0.067)$ & $(0.004)$ & $(0.024)$ & $(0.004)$ & $(0.024)$ \\
\hline \multirow[t]{2}{*}{ Two years ago } & -0.006 & -0.017 & 0.004 & -0.031 & 0.006 & -0.031 \\
\hline & $(0.004)$ & $(0.061)$ & $(0.005)$ & $(0.020)$ & $(0.005)$ & $(0.022)$ \\
\hline \multirow[t]{2}{*}{ Previous school year } & -0.015 & -0.001 & -0.004 & -0.017 & -0.003 & -0.019 \\
\hline & $(0.004)$ & $(0.048)$ & $(0.005)$ & $(0.017)$ & $(0.005)$ & $(0.017)$ \\
\hline \multirow[t]{2}{*}{ Current school year } & -0.015 & 0.040 & -0.000 & 0.010 & -0.002 & -0.307 \\
\hline & $(0.004) * *$ & $(0.058)$ & $(0.004)$ & $(0.019)$ & $(0.005)$ & $(0.327)$ \\
\hline \multirow[t]{2}{*}{ Next school year } & -0.019 & 0.062 & -0.008 & -0.004 & -0.007 & 0.000 \\
\hline & $(0.005)^{* *}$ & $(0.072)$ & $(0.006)$ & $(0.022)$ & $(0.006)$ & $(0.022)$ \\
\hline School covariates & \multirow{3}{*}{\multicolumn{2}{|c|}{$X$}} & \multicolumn{2}{|c|}{$X$} & \multicolumn{2}{|c|}{$\mathrm{X}$} \\
\hline School fixed effects & & & \multicolumn{2}{|c|}{$\mathrm{X}$} & \multirow{2}{*}{\multicolumn{2}{|c|}{$\begin{array}{l}X \\
X\end{array}$}} \\
\hline Principal covariates & & & & & & \\
\hline
\end{tabular}

Note: Standard errors are in parentheses and are clustered at the school level.

** Indicates statistical significance at the $1 \%$ level.

* Indicates statistical significance at the 5\% level.

$\dagger$ Indicates statistical significance at the $10 \%$ level. 
Table 6.2 T-statistics and p-values of $\widehat{\alpha_{1}}$ from the first stage of 2SLS

\begin{tabular}{|c|c|c|c|c|c|c|}
\hline \multirow[b]{2}{*}{ Time leaving the school } & \multicolumn{2}{|c|}{ Model 1} & \multicolumn{2}{|c|}{ Model 2} & \multicolumn{2}{|c|}{ Model 3} \\
\hline & T-stat & P-value & T-stat & P-value & T-stat & P-value \\
\hline Three years ago & -3.59 & 0 & -5.7 & 0 & -5.82 & 0 \\
\hline Two years ago & -3.78 & 0 & -7.7 & 0 & -7.19 & 0 \\
\hline Previous school year & -4.89 & 0 & -11.54 & 0 & -11.56 & 0 \\
\hline Current school year & -3.97 & 0 & -8.15 & 0 & -1.04 & 0.299 \\
\hline Next school year & -2.82 & 0.005 & -4.96 & 0 & -4.87 & 0 \\
\hline School covariates & \multirow{3}{*}{\multicolumn{2}{|c|}{$\mathrm{X}$}} & \multicolumn{2}{|c|}{$\mathrm{X}$} & \multicolumn{2}{|c|}{$\mathrm{X}$} \\
\hline School fixed effects & & & \multirow{2}{*}{\multicolumn{2}{|c|}{$\mathrm{X}$}} & \multirow{2}{*}{\multicolumn{2}{|c|}{$\begin{array}{l}X \\
X\end{array}$}} \\
\hline Principal covariates & & & & & & \\
\hline
\end{tabular}


Table 6.3 Regression results of math and reading test scores on principal leaving the profession

\begin{tabular}{lcccccc}
\hline \multirow{2}{*}{$\begin{array}{l}\text { Time leaving the } \\
\text { profession }\end{array}$} & $(1)$ & $(2)$ & $(3)$ & $(4)$ & $(5)$ & $(6)$ \\
\hline Math & OLS & IV & OLS & IV & OLS & IV \\
\hline Three years ago & -0.005 & -0.100 & 0.010 & -0.018 & 0.010 & -0.008 \\
& $(0.007)$ & $(0.054) \dagger$ & $(0.007)$ & $(0.028)$ & $(0.007)$ & $(0.028)$ \\
Two years ago & -0.015 & -0.081 & 0.001 & -0.057 & 0.003 & -0.049 \\
& $(0.007)^{*}$ & $(0.049) \dagger$ & $(0.009)$ & $(0.026)^{*}$ & $(0.009)$ & $(0.026) \dagger$ \\
Previous school year & -0.023 & -0.020 & -0.007 & -0.012 & -0.002 & -0.014 \\
& $(0.008)^{* *}$ & $(0.040)$ & $(0.009)$ & $(0.023)$ & $(0.010)$ & $(0.022)$ \\
& & & & & & \\
Reading & & & & & & \\
Three years ago & 0.002 & 0.000 & 0.008 & 0.009 & 0.009 & 0.015 \\
& $(0.006)$ & $(0.042)$ & $(0.006)$ & $(0.026)$ & $(0.006)$ & $(0.026)$ \\
Two years ago & 0.002 & -0.011 & 0.007 & -0.040 & 0.008 & -0.038 \\
& $(0.007)$ & $(0.039)$ & $(0.009)$ & $(0.024) \dagger$ & $(0.008)$ & $(0.024)$ \\
Previous school year & -0.011 & -0.000 & -0.009 & -0.022 & -0.006 & -0.023 \\
& $(0.006)$ & $(0.033)$ & $(0.008)$ & $(0.021)$ & $(0.009)$ & $(0.020)$ \\
School covariates & & & & & & X \\
School fixed effects & & & & $X$ & & $X$ \\
Principal covariates & & & & & \\
\hline
\end{tabular}

Note: Standard errors are in parentheses and are clustered at the school level.

** Indicates statistical significance at the 1\% level.

* Indicates statistical significance at the 5\% level.

$\dagger$ Indicates statistical significance at the $10 \%$ level. 
Figure 6.1 Time trends for OLS estimates and IV estimates from main models (1) Math

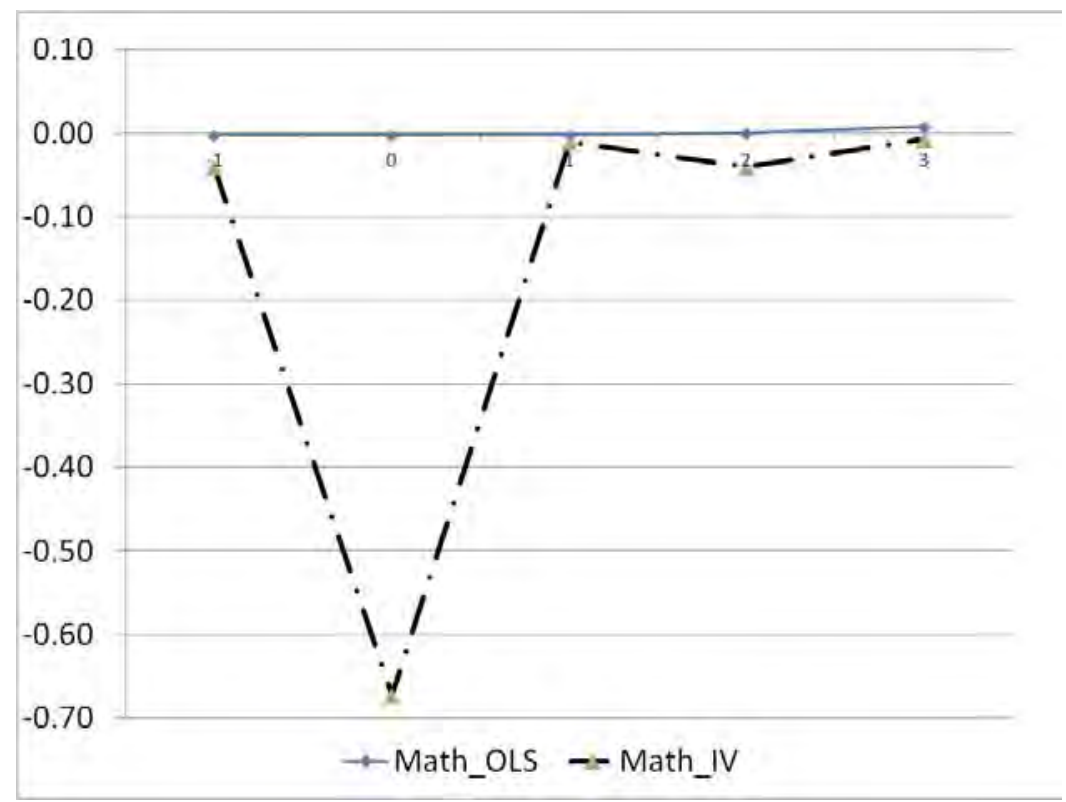

(2) Reading

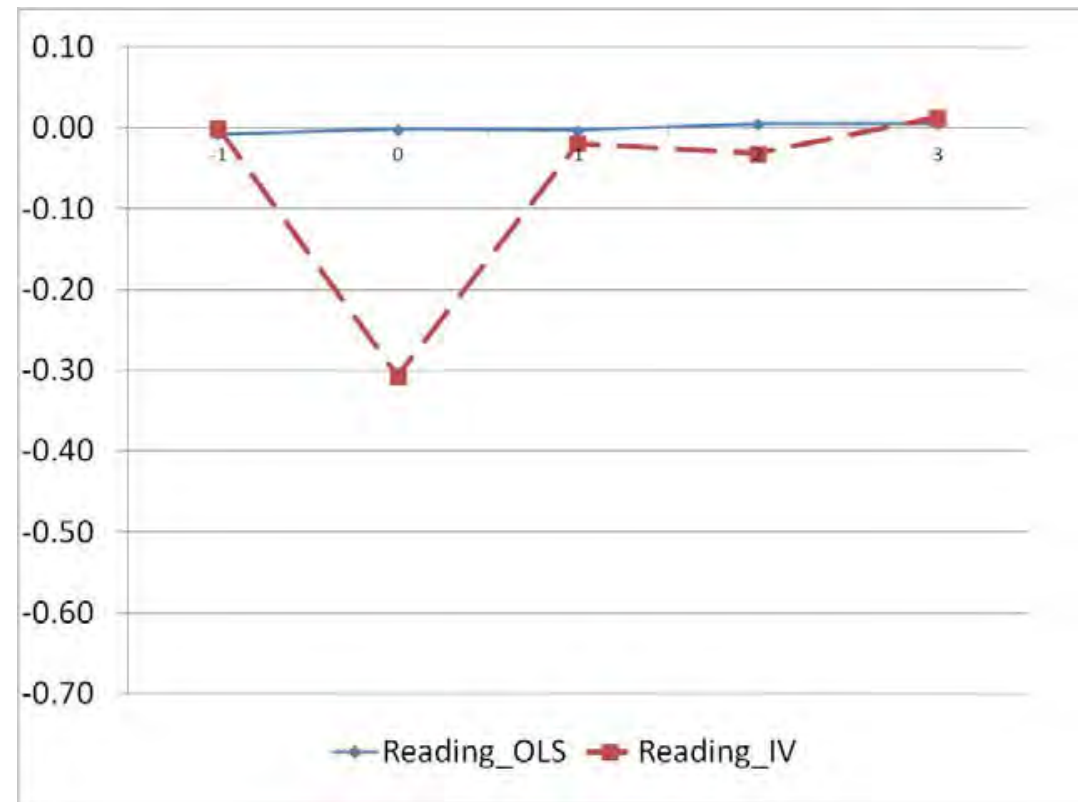


Table 6.4 Regressions of math and reading test scores on principal turnover for lowincome and high-income schools

\begin{tabular}{|c|c|c|c|c|c|c|}
\hline \multirow[b]{3}{*}{ Time leaving the school } & \multicolumn{2}{|c|}{ Model 1} & \multicolumn{2}{|c|}{ Model 2} & \multicolumn{2}{|c|}{ Model 3} \\
\hline & (1) & (2) & (3) & (4) & $(5)$ & $(6)$ \\
\hline & OLS & IV & OLS & IV & OLS & IV \\
\hline \multicolumn{7}{|l|}{ Low-income schools } \\
\hline \multicolumn{7}{|l|}{ Math } \\
\hline \multirow[t]{2}{*}{ Three years ago } & -0.005 & -0.129 & 0.012 & -0.016 & 0.012 & 0.006 \\
\hline & $(0.009)$ & $(0.123)$ & $(0.008)$ & $(0.035)$ & $(0.008)$ & $(0.035)$ \\
\hline \multirow[t]{2}{*}{ Two years ago } & -0.015 & -0.137 & -0.000 & -0.042 & 0.002 & -0.037 \\
\hline & $(0.007)^{*}$ & $(0.154)$ & $(0.007)$ & $(0.026)$ & $(0.007)$ & $(0.025)$ \\
\hline \multirow[t]{2}{*}{ Previous school year } & -0.035 & -0.061 & -0.013 & -0.029 & -0.006 & -0.028 \\
\hline & $(0.009)^{* *}$ & $(0.097)$ & $(0.009)$ & $(0.029)$ & $(0.009)$ & $(0.026)$ \\
\hline \multicolumn{7}{|l|}{ Reading } \\
\hline \multirow[t]{2}{*}{ Tree years ago } & 0.004 & -0.007 & 0.014 & 0.031 & 0.013 & 0.041 \\
\hline & $(0.007)$ & $(0.096)$ & $(0.007) \dagger$ & $(0.031)$ & $(0.007) \dagger$ & $(0.032)$ \\
\hline \multirow{2}{*}{ Two years ago } & -0.008 & -0.092 & 0.006 & -0.048 & 0.008 & -0.050 \\
\hline & $(0.007)$ & $(0.122)$ & $(0.008)$ & $(0.027) \dagger$ & $(0.008)$ & $(0.028) \dagger$ \\
\hline \multirow[t]{2}{*}{ Previous school year } & -0.027 & -0.029 & -0.017 & -0.029 & -0.015 & -0.029 \\
\hline & $(0.007)^{* *}$ & $(0.088)$ & $(0.007)^{*}$ & $(0.027)$ & $(0.008) \dagger$ & $(0.026)$ \\
\hline \multicolumn{7}{|l|}{ High-income schools } \\
\hline \multicolumn{7}{|l|}{ Math } \\
\hline \multirow[t]{2}{*}{ Three years ago } & -0.003 & -0.165 & 0.007 & -0.015 & 0.007 & -0.012 \\
\hline & $(0.006)$ & $(0.127)$ & $(0.006)$ & $(0.039)$ & $(0.006)$ & $(0.037)$ \\
\hline \multirow[t]{2}{*}{ Two years ago } & -0.019 & -0.118 & -0.004 & -0.045 & -0.003 & -0.047 \\
\hline & $(0.007)^{* *}$ & $(0.091)$ & $(0.007)$ & $(0.031)$ & $(0.007)$ & $(0.034)$ \\
\hline \multirow[t]{2}{*}{ Previous school year } & -0.021 & -0.012 & 0.000 & 0.005 & 0.004 & 0.003 \\
\hline & $(0.007)^{* *}$ & $(0.068)$ & $(0.006)$ & $(0.022)$ & $(0.007)$ & $(0.022)$ \\
\hline \multicolumn{7}{|l|}{ Reading } \\
\hline \multirow[t]{2}{*}{ Tree years ago } & -0.005 & 0.002 & 0.001 & -0.021 & 0.001 & -0.016 \\
\hline & $(0.005)$ & $(0.085)$ & $(0.005)$ & $(0.035)$ & $(0.005)$ & $(0.032)$ \\
\hline \multirow[t]{2}{*}{ Two years ago } & -0.002 & 0.013 & 0.002 & -0.021 & 0.002 & -0.020 \\
\hline & $(0.006)$ & $(0.067)$ & $(0.006)$ & $(0.026)$ & $(0.006)$ & $(0.028)$ \\
\hline \multirow[t]{2}{*}{ Previous school year } & -0.006 & 0.012 & 0.005 & -0.012 & 0.005 & -0.015 \\
\hline & $(0.005)$ & $(0.055)$ & $(0.006)$ & $(0.021)$ & $(0.006)$ & $(0.020)$ \\
\hline School covariates & \multirow{3}{*}{\multicolumn{2}{|c|}{$X$}} & \multicolumn{2}{|c|}{$X$} & \multicolumn{2}{|c|}{$\mathrm{X}$} \\
\hline \multirow{2}{*}{$\begin{array}{l}\text { School fixed effects } \\
\text { Principal covariates }\end{array}$} & & & \multicolumn{2}{|c|}{$X$} & \multicolumn{2}{|c|}{$X$} \\
\hline & & & & & & \\
\hline
\end{tabular}


Appendix A Creating neighboring school variables

For each school $j$ in year $t$, I created the following three variables measuring quartile ranking of all of its neighboring schools.

$N S_{\text {low-income }}$ : average school enrollment weighted top-quartile ranking

$N S_{\text {middle-income }}$ : average school enrollment weighted middle-quartile ranking

$N S_{\text {high-income }}$ : average school enrollment weighted bottom-quartile ranking

Assume a school $j$ in year $t$ has $r_{j}$ neighbor schools within radius $r$, let

enroll $_{l}$ : enrollment for each neighbor school $l, l=1 \ldots r_{j}$.

low - income $e_{l}: 1$ if neighbor school $l$ has FRL share ranking in the top quartile, 0 otherwise

middle - income $_{l}: 1$ if neighbor school $l$ has FRL share ranking in the middle two quartiles, 0 otherwise

high - income $e_{l}: 1$ if neighbor school $l$ FRL share ranking in the bottom quartile, 0 otherwise

$n_{\text {low-income }}$ : number of neighbor schools that have FRL share ranking in the top quartile

$n_{\text {middle-income }}$ : number of neighbor schools that have FRL share ranking in the middle two quartiles

$n_{\text {high-income }}$ : number of neighbor schools that have FRL share ranking in the bottom quartile

Thus, $n_{\text {low-income }}+n_{\text {middle-income }}+n_{\text {high-income }}=r_{j}$.

Then,

$$
\begin{aligned}
& N S_{\text {low-income }}=\frac{\sum_{l=1}^{n_{\text {low-income }} \text { enroll }_{l}}}{\sum_{l=1}^{r_{j}} \text { enroll }_{l}} \\
& N S_{\text {middle-income }}=\frac{\sum_{l=1}^{n_{\text {middle-income }} \text { enroll }_{l}}}{\sum_{l=1}^{r_{j}} \text { enroll }_{l}} \\
& N S_{\text {high-income }}=\frac{\sum_{l=1}^{n_{\text {high-income }} \text { enroll }_{l}}}{\sum_{l=1}^{r_{j}} \text { enroll }_{l}}
\end{aligned}
$$


Thus,

$$
\begin{aligned}
N S_{\text {low-income }} & +N S_{\text {middle-income }}+N S_{\text {high-income }} \\
& =\frac{\sum_{l=1}^{n_{\text {low-income }} \text { enroll }}+\sum_{l=1}^{n_{\text {middle-income }}} \text { enroll }_{l}+\sum_{l=1}^{n_{\text {high-income }}} \text { enroll }_{l}}{\sum_{l=1}^{r_{j}} \text { enroll }_{l}} \\
& =1
\end{aligned}
$$

For example, assume a teacher $i$ at school $j$ in year $t$, and school $j$ has 3 neighbor schools

\begin{tabular}{ccccccc}
\hline Teacher & School & Neighbor school & Enrollment & Low-income & Middle-income & High-income \\
\hline$i$ & $j$ & A & 1000 & 1 & 0 & 0 \\
& & B & 400 & 0 & 1 & 0 \\
& & C & 600 & 0 & 0 & 1 \\
\hline
\end{tabular}

Use the formulas described above,

$$
\begin{gathered}
N S_{\text {low-income }}=\frac{1000}{1000+400+600}=\frac{1}{2} \\
N S_{\text {middle-income }}=\frac{400}{1000+400+600}=\frac{1}{5} \\
N S_{\text {high-income }}=\frac{600}{1000+400+600}=\frac{3}{10}
\end{gathered}
$$

And the data become

\begin{tabular}{ccccc}
\hline Teacher & School & $N S_{\text {low-income }}$ & $N S_{\text {middle-income }}$ & $N S_{\text {high-income }}$ \\
\hline$i$ & $j$ & $\frac{1}{2}$ & $\frac{1}{5}$ & $\frac{3}{10}$ \\
\hline
\end{tabular}


Appendix B Ordered probit estimation results for elementary school transfers. Radius: 5, 10 , and 20 miles

\begin{tabular}{|c|c|c|c|c|c|c|}
\hline & \multicolumn{2}{|c|}{5 miles } & \multicolumn{2}{|c|}{10 miles } & \multicolumn{2}{|c|}{20 miles } \\
\hline & Estimate & $(\mathrm{SE})$ & Estimate & $(\mathrm{SE})$ & Estimate & $(\mathrm{SE})$ \\
\hline \multicolumn{7}{|l|}{ Teacher } \\
\hline$\overline{\text { Female }}$ & 0.071 & $(0.041) \dagger$ & 0.045 & $(0.037)$ & 0.042 & $(0.037)$ \\
\hline \multicolumn{7}{|l|}{ Race (versus White) } \\
\hline Asian/Pacific Islander & -0.169 & $(0.302)$ & -0.053 & $(0.284)$ & -0.034 & $(0.279)$ \\
\hline American Indian & 0.192 & $(0.313)$ & 0.321 & $(0.285)$ & 0.274 & $(0.277)$ \\
\hline Black & -0.725 & $(0.071)^{* *}$ & -0.760 & $(0.072)^{* *}$ & -0.784 & $(0.074)^{* *}$ \\
\hline Hispanic & -0.565 & $(0.240)^{*}$ & -0.539 & $(0.237)^{*}$ & -0.557 & $(0.238)^{*}$ \\
\hline Has a master's degree/Ph.D. & 0.105 & $(0.031)^{* *}$ & 0.112 & $(0.029)^{* *}$ & 0.110 & $(0.029)^{* *}$ \\
\hline Experience & -0.013 & $(0.002)^{* *}$ & -0.012 & $(0.002)^{* *}$ & -0.012 & $(0.002)^{* *}$ \\
\hline Salary premium & 0.020 & $(0.192)$ & -0.086 & $(0.187)$ & -0.130 & $(0.188)$ \\
\hline \multicolumn{7}{|l|}{ School } \\
\hline Low-income school & -0.180 & $(0.062)^{* *}$ & -0.266 & $(0.058)^{* *}$ & -0.318 & $(0.059)^{* *}$ \\
\hline $\begin{array}{l}\text { High-income school } \\
\text { Neighboring schools }\end{array}$ & 0.270 & $(0.077)^{* *}$ & 0.354 & $(0.077)^{* *}$ & 0.506 & $(0.082)^{* *}$ \\
\hline Low-income school & -0.642 & $(0.107)^{* *}$ & -0.452 & $(0.089)^{* *}$ & -0.273 & $(0.132)^{* *}$ \\
\hline \multicolumn{7}{|l|}{ District } \\
\hline $\begin{array}{l}\text { District enrollment } \\
\text { Neighborhood }\end{array}$ & -0.010 & $(0.037)$ & -0.016 & $(0.038)$ & -0.026 & $(0.038)$ \\
\hline $\begin{array}{l}\text { \% of Pop Living in Same House } 5 \\
\text { Yrs Ago }\end{array}$ & -0.167 & $(0.359)$ & -0.190 & $(0.296)$ & -0.456 & $(0.304)$ \\
\hline$\%$ of Pop Age $25+$ w/ Ed $>$ Bachelors & 0.294 & $(0.304)$ & 0.626 & $(0.329) \dagger$ & 0.405 & $(0.375)$ \\
\hline $\begin{array}{l}\% \text { of Households Married-Couple-w- } \\
\text { Kids }<18\end{array}$ & 0.182 & $(0.466)$ & 0.329 & $(0.415)$ & 0.869 & $(0.446) \dagger$ \\
\hline Median Family Income & 0.434 & $(0.149)^{* *}$ & 0.554 & $(0.146)^{* *}$ & 0.585 & $(0.160)^{* *}$ \\
\hline$\%$ of Pop Who Are Non-White & -0.352 & $(0.136)^{* *}$ & -0.551 & $(0.133)^{* *}$ & -0.842 & $(0.144)^{* *}$ \\
\hline Population Density & 0.163 & $(0.102)$ & 0.196 & $(0.103) \dagger$ & 0.280 & $(0.110)^{*}$ \\
\hline $\begin{array}{l}\% \text { of Housing Units that are Vacant } \\
\text { Urbanicity }\end{array}$ & -0.358 & $(0.412)$ & 0.274 & $(0.340)$ & 0.402 & $(0.346)$ \\
\hline City & -0.346 & $(0.073)^{* *}$ & -0.460 & $(0.075)^{* *}$ & -0.480 & $(0.077)^{* *}$ \\
\hline Rural & -0.108 & $(0.054) *$ & -0.100 & $(0.048)^{*}$ & -0.132 & $(0.048)^{* *}$ \\
\hline Cut1 & 3.535 & $(1.484)$ & 4.874 & $(1.474)$ & -7.845 & $(1.625)$ \\
\hline Cut2 & 5.014 & $(1.486)$ & 6.475 & $(1.475)$ & -6.037 & $(1.622)$ \\
\hline Log pseudolikelihood & $-6,5$ & 66.851 & $-7,7$ & 32.234 & $-8,0^{\prime}$ & 5.744 \\
\hline $\mathrm{N}$ & & 232 & & 589 & & 24 \\
\hline $\mathrm{P}$-value & & 0000 & & 000 & & 000 \\
\hline
\end{tabular}

Note: Standard errors are in parentheses and clustered at the school level.

** Indicates statistical significance at the $1 \%$ level.

* Indicates statistical significance at the 5\% level.

$\dagger$ Indicates statistical significance at the $10 \%$ level. 
Appendix C Ordered probit estimation results for MJH school transfers. Radius: 5, 10, and 20 miles

\begin{tabular}{|c|c|c|c|c|c|c|}
\hline & \multicolumn{2}{|c|}{5 miles } & \multicolumn{2}{|c|}{10 miles } & \multicolumn{2}{|c|}{20 miles } \\
\hline & Estimate & $(\mathrm{SE})$ & Estimate & $(\mathrm{SE})$ & Estimate & $(\mathrm{SE})$ \\
\hline \multicolumn{7}{|l|}{ Teacher } \\
\hline Female & 0.002 & $(0.028)$ & 0.000 & $(0.027)$ & 0.003 & $(0.026)$ \\
\hline \multicolumn{7}{|l|}{ Race (versus White) } \\
\hline Asian/Pacific Islander & -0.387 & $(0.164)^{*}$ & -0.394 & $(0.165)^{*}$ & -0.399 & $(0.166)^{*}$ \\
\hline American Indian & -0.119 & $(0.280)$ & -0.144 & $(0.268)$ & -0.190 & $(0.242)$ \\
\hline Black & -0.830 & $(0.080)^{* *}$ & -0.851 & $(0.082)^{* *}$ & -0.864 & $(0.082)^{* *}$ \\
\hline Hispanic & -0.101 & $(0.169)$ & -0.227 & $(0.170)$ & -0.277 & $(0.167) \dagger$ \\
\hline Has a master's degree/Ph.D. & 0.166 & $(0.033)^{* *}$ & 0.175 & $(0.032)^{* *}$ & 0.161 & $(0.031)^{* *}$ \\
\hline Experience & -0.014 & $(0.002)^{* *}$ & -0.013 & $(0.002)^{* *}$ & -0.012 & $(0.002)^{* *}$ \\
\hline Salary premium & 0.270 & $(0.229)$ & 0.275 & $(0.225)$ & 0.185 & $(0.226)$ \\
\hline \multicolumn{7}{|l|}{ School } \\
\hline Low-income school & -0.308 & $(0.086)^{* *}$ & -0.314 & $(0.078)^{* *}$ & -0.281 & $(0.078) * *$ \\
\hline High-income school & 0.294 & $(0.070)^{* *}$ & 0.304 & $(0.072)^{* *}$ & 0.362 & $(0.071)^{* *}$ \\
\hline Low-income school & -0.340 & $(0.117)^{* *}$ & -0.301 & $(0.114)^{* *}$ & -0.273 & $(0.167)$ \\
\hline $\begin{array}{l}\text { High-income school } \\
\text { District }\end{array}$ & 0.498 & $(0.078)^{* *}$ & 0.408 & $(0.086)^{* *}$ & 0.590 & $(0.113)^{* *}$ \\
\hline $\begin{array}{l}\text { District enrollment } \\
\text { Neighborhood }\end{array}$ & 0.020 & $(0.039)$ & 0.028 & $(0.040)$ & 0.014 & $(0.040)$ \\
\hline $\begin{array}{l}\% \text { of Pop Living in Same House } 5 \\
\text { Yrs Ago }\end{array}$ & -0.385 & $(0.382)$ & -0.096 & $(0.343)$ & -0.154 & $(0.331)$ \\
\hline $\begin{array}{l}\% \text { of Pop Age } 25+w / \\
\text { Ed }>\text { Bachelors }\end{array}$ & -0.036 & $(0.268)$ & 0.334 & $(0.269)$ & 0.441 & $(0.277)$ \\
\hline $\begin{array}{l}\% \text { of Households Married-Couple- } \\
\text { w-Kids }<18\end{array}$ & -0.418 & $(0.664)$ & 0.159 & $(0.660)$ & 0.559 & $(0.680)$ \\
\hline Median Family Income & 0.759 & $(0.138)^{* *}$ & 0.715 & $(0.136)^{* *}$ & 0.627 & $(0.140)^{* *}$ \\
\hline$\%$ of Pop Who Are Non-White & -0.368 & $(0.214) \dagger$ & -0.534 & $(0.212)^{*}$ & -0.819 & $(0.221)^{* *}$ \\
\hline Population Density & 0.205 & $(0.135)$ & 0.221 & $(0.134)$ & 0.258 & $(0.137) \dagger$ \\
\hline $\begin{array}{l}\% \text { of Housing Units that are Vacant } \\
\text { Urbanicity }\end{array}$ & -0.064 & $(0.362)$ & -0.012 & $(0.334)$ & 0.254 & $(0.338)$ \\
\hline City & -0.289 & $(0.080)^{* *}$ & -0.303 & $(0.079)^{* *}$ & -0.343 & $(0.079)^{* *}$ \\
\hline Rural & -0.034 & $(0.052)$ & -0.026 & $(0.051)$ & -0.058 & $(0.052)$ \\
\hline Cut1 & 6.427 & $(1.328)$ & 5.639 & $(1.360)$ & 5.639 & $(1.360)$ \\
\hline Cut2 & 7.919 & $(1.328)$ & 7.218 & (1.361) & 7.218 & $(1.361)$ \\
\hline Log pseudolikelihood & $-6,0$ & 0.916 & $-6,7$ & 64.181 & $-6,9$ & 57.962 \\
\hline $\mathrm{N}$ & & 373 & & 156 & & 402 \\
\hline P-value & & 000 & & 0000 & & 000 \\
\hline
\end{tabular}

Note: Standard errors are in parentheses and clustered at the school level.

** Indicates statistical significance at the $1 \%$ level.

* Indicates statistical significance at the 5\% level.

$\dagger$ Indicates statistical significance at the $10 \%$ level. 
Appendix D Cross-tabulation for transfers with randomly assigned school types

To create a benchmark table for comparison, I create the following table with randomly assigning a school type (i.e., high-income, middle-income, and low-income schools) to each school in Missouri using the $25 \%, 50 \%$, and $25 \%$ distribution.

\begin{tabular}{|c|c|c|c|}
\hline Exporting school & High-income (\%) & $\begin{array}{l}\text { Importing school } \\
\text { Middle-income }(\%)\end{array}$ & Low-income $(\%)$ \\
\hline \multicolumn{4}{|c|}{ Elementary school transfers } \\
\hline High-income & 23.37 & 51.24 & 25.39 \\
\hline Middle-income & 25.55 & 50.05 & 24.40 \\
\hline Low-income & 25.99 & 51.10 & 22.92 \\
\hline \multicolumn{4}{|c|}{ MJH school transfers } \\
\hline High-income & 25.62 & 49.18 & 25.20 \\
\hline Middle-income & 25.01 & 50.28 & 24.72 \\
\hline Low-income & 23.63 & 50.71 & 25.66 \\
\hline
\end{tabular}


Appendix E Percentages of correctly predicted teacher moves based on ordered probit estimates

\begin{tabular}{lccc}
\hline & \multicolumn{3}{c}{ Importing school } \\
& High-income (\%) & Middle-income (\%) & Low-income (\%) \\
\hline Elementary & 60.35 & 76.71 & 55 \\
MJH & 61.40 & 73.77 & 45.80 \\
\hline
\end{tabular}

Note: All schools in the sample are divided into three groups based on their shares of free or reduced-price lunch-eligible students (FRL). Low-income schools are schools in the top quartile in terms of their FRL shares, middle-income schools are schools in the middle two quartiles, and high-income schools are schools in the bottom quartile. 
Appendix F Distance between two schools for inter-district transfers (mile)

\begin{tabular}{lcc}
\hline Percentiles & Elementary school transfers & MJH school transfers \\
\hline $10^{\text {th }}$ & 6 & 8 \\
$25^{\text {th }}$ & 11 & 13 \\
$50^{\text {th }}$ & 21 & 25 \\
$70^{\text {th }}$ & 35 & 41 \\
$80^{\text {th }}$ & 56 & 64 \\
$85^{\text {th }}$ & 82 & 85 \\
$90^{\text {th }}$ & 116 & 112 \\
$100^{\text {th }}$ & 310 & 316 \\
\hline
\end{tabular}


Appendix G Ordered probit estimation results for intra-district elementary school transfers. Radius: 5, 10, and 20 miles

\begin{tabular}{|c|c|c|c|c|c|c|}
\hline & \multicolumn{2}{|c|}{5 miles } & \multicolumn{2}{|c|}{10 miles } & \multicolumn{2}{|c|}{20 miles } \\
\hline & Estimate & $(\mathrm{SE})$ & Estimate & $(\mathrm{SE})$ & Estimate & $(\mathrm{SE})$ \\
\hline \multicolumn{7}{|l|}{ Teacher } \\
\hline$\overline{\text { Female }}$ & 0.113 & $(0.060) \dagger$ & 0.082 & $(0.060)$ & 0.079 & $(0.060)$ \\
\hline \multicolumn{7}{|l|}{ Race (versus White) } \\
\hline Asian/Pacific Islander & 0.287 & $(0.308)$ & 0.255 & $(0.291)$ & 0.212 & $(0.294)$ \\
\hline American Indian & -0.257 & $(0.442)$ & -0.420 & $(0.452)$ & -0.393 & $(0.450)$ \\
\hline Black & -0.332 & $(0.087)^{* *}$ & -0.298 & $(0.091)^{* *}$ & -0.272 & $(0.096) * *$ \\
\hline Hispanic & -0.772 & $(0.324)^{*}$ & -0.769 & $(0.363)^{*}$ & -0.805 & $(0.372)^{*}$ \\
\hline Has a master's degree/Ph.D. & 0.149 & $(0.043)^{* *}$ & 0.108 & $(0.041)^{* *}$ & 0.097 & $(0.041)^{*}$ \\
\hline Experience & -0.005 & $(0.003) \dagger$ & -0.004 & $(0.003)$ & -0.005 & $(0.003) \dagger$ \\
\hline Salary premium & 0.063 & $(0.266)$ & -0.146 & $(0.254)$ & -0.304 & $(0.254)$ \\
\hline \multicolumn{7}{|l|}{ School } \\
\hline Low-income school & -0.096 & $(0.082)$ & -0.191 & $(0.080)^{*}$ & -0.157 & $(0.086) \dagger$ \\
\hline High-income school & 0.203 & $(0.107) \dagger$ & 0.325 & $(0.100)^{* *}$ & 0.499 & $(0.093)^{* *}$ \\
\hline \multicolumn{7}{|l|}{ Neighboring schools } \\
\hline Inside-district low-income school & -1.325 & $(0.267)^{* *}$ & -2.161 & $(0.323)^{* *}$ & -2.714 & $(0.465)^{* *}$ \\
\hline Inside-district high-income school & 2.215 & $(0.233)^{* *}$ & 3.264 & $(0.344)^{* *}$ & 5.906 & $(0.587)^{* *}$ \\
\hline Outside-district low-income school & -0.143 & $(0.234)$ & 0.114 & $(0.269)$ & 1.369 & $(0.369)^{* *}$ \\
\hline $\begin{array}{l}\text { Outside-district high-income school } \\
\text { District }\end{array}$ & 0.756 & $(0.224)^{* *}$ & 0.685 & $(0.232)^{* *}$ & 0.237 & $(0.264)$ \\
\hline $\begin{array}{l}\text { District enrollment } \\
\text { Neighborhood }\end{array}$ & -0.092 & $(0.060)$ & -0.072 & $(0.058)$ & -0.109 & $(0.059) \dagger$ \\
\hline $\begin{array}{l}\text { \% of Pop Living in Same House } 5 \\
\text { Yrs Ago }\end{array}$ & -0.584 & $(0.669)$ & -0.869 & $(0.634)$ & -1.129 & $(0.630) \dagger$ \\
\hline$\%$ of Pop Age $25+$ w/ Ed $>$ Bachelors & -0.876 & $(0.425)^{*}$ & -1.196 & $(0.502)^{*}$ & -2.443 & $(0.536)^{* *}$ \\
\hline $\begin{array}{l}\% \text { of Households Married-Couple- } \\
\text { w-Kids }<18\end{array}$ & 0.504 & $(0.760)$ & 0.423 & $(0.797)$ & 0.965 & $(0.799)$ \\
\hline Median Family Income & 0.161 & $(0.297)$ & 0.618 & $(0.319) \dagger$ & 1.043 & $(0.359)^{* *}$ \\
\hline$\%$ of Pop Who Are Non-White & -0.906 & $(0.199)^{* *}$ & -0.871 & $(0.198)^{* *}$ & -1.121 & $(0.209)^{* *}$ \\
\hline Population Density & 0.404 & $(0.171)^{*}$ & 0.108 & $(0.160)$ & 0.089 & $(0.165)$ \\
\hline $\begin{array}{l}\% \text { of Housing Units that are Vacant } \\
\text { Urbanicity }\end{array}$ & 0.455 & $(0.556)$ & 0.437 & $(0.617)$ & 0.791 & $(0.599)$ \\
\hline City & -0.310 & $(0.090)^{* *}$ & -0.488 & $(0.096)^{* *}$ & -0.445 & $(0.098)^{* *}$ \\
\hline Rural & -0.162 & $(0.108)$ & -0.217 & $(0.098)^{*}$ & -0.293 & $(0.097)^{* *}$ \\
\hline Cut1 & 0.659 & $(2.755)$ & 5.101 & $(2.969)$ & 9.585 & $(3.375)$ \\
\hline Cut2 & 2.255 & $(2.755)$ & 6.730 & $(2.970)$ & 11.167 & $(3.382)$ \\
\hline Log pseudolikelihood & $-2,8$ & 53.076 & $-2,9$ & 11.642 & -29 & 5.389 \\
\hline $\mathrm{N}$ & & 109 & & 190 & & 00 \\
\hline P-value & & 000 & & 000 & & 00 \\
\hline
\end{tabular}

Note: Standard errors are in parentheses and clustered at the school level.

** Indicates statistical significance at the $1 \%$ level.

* Indicates statistical significance at the 5\% level.

$\dagger$ Indicates statistical significance at the $10 \%$ level. 
Appendix H Ordered probit estimation results for inter-district elementary school transfers. Radius: 5, 10, and 20 miles

\begin{tabular}{|c|c|c|c|c|c|c|}
\hline & \multicolumn{2}{|c|}{5 miles } & \multicolumn{2}{|c|}{10 miles } & \multicolumn{2}{|c|}{20 miles } \\
\hline & Estimate & $(\mathrm{SE})$ & Estimate & $(\mathrm{SE})$ & Estimate & $(\mathrm{SE})$ \\
\hline \multicolumn{7}{|l|}{ Teacher } \\
\hline$\overline{\text { Female }}$ & 0.036 & $(0.075)$ & 0.026 & $(0.062)$ & 0.027 & $(0.059)$ \\
\hline \multicolumn{7}{|l|}{ Race (versus White) } \\
\hline Asian/Pacific Islander & -0.476 & $(0.710)$ & -0.100 & $(0.625)$ & -0.127 & $(0.638)$ \\
\hline American Indian & 0.480 & $(0.401)$ & 0.424 & $(0.307)$ & 0.293 & $(0.324)$ \\
\hline Black & -1.159 & $(0.115)^{* *}$ & -1.228 & $(0.119)^{* *}$ & -1.271 & $(0.119)^{* *}$ \\
\hline Hispanic & -0.731 & $(0.333)^{*}$ & -0.669 & $(0.340)^{*}$ & -0.716 & $(0.345)^{*}$ \\
\hline Has a master's degree/Ph.D. & 0.109 & $(0.062) \dagger$ & 0.113 & $(0.053)^{*}$ & 0.108 & $(0.052)^{*}$ \\
\hline Experience & -0.017 & $(0.004)^{* *}$ & -0.012 & $(0.004)^{* *}$ & -0.011 & $(0.004)^{* *}$ \\
\hline Salary premium & 0.342 & $(0.366)$ & 0.212 & $(0.341)$ & 0.285 & $(0.338)$ \\
\hline \multicolumn{7}{|l|}{ School } \\
\hline Low-income school & -0.232 & $(0.095)^{*}$ & -0.213 & $(0.082)^{* *}$ & -0.204 & $(0.075)^{* *}$ \\
\hline High-income school & -0.120 & $(0.108)$ & -0.076 & $(0.093)$ & 0.011 & $(0.089)$ \\
\hline \multicolumn{7}{|l|}{ Neighboring schools } \\
\hline Inside-district low-income school & -0.169 & $(0.207)$ & -0.026 & $(0.309)$ & 0.395 & $(0.513)$ \\
\hline Inside-district high-income school & 0.382 & $(0.196) \dagger$ & 0.860 & $(0.389)^{*}$ & 1.190 & $(0.709) \dagger$ \\
\hline Outside-district low-income school & -0.174 & $(0.146)$ & -0.209 & $(0.100)^{*}$ & -0.434 & $(0.157)^{* *}$ \\
\hline $\begin{array}{l}\text { Outside-district high-income school } \\
\text { District }\end{array}$ & 0.097 & $(0.104)$ & 0.347 & $(0.118)^{* *}$ & 0.798 & $(0.179)^{* *}$ \\
\hline $\begin{array}{l}\text { District enrollment } \\
\text { Neighborhood }\end{array}$ & 0.050 & $(0.057)$ & 0.023 & $(0.057)$ & 0.010 & $(0.054)$ \\
\hline $\begin{array}{l}\text { \% of Pop Living in Same House } 5 \\
\text { Yrs Ago }\end{array}$ & 0.191 & $(0.511)$ & 0.059 & $(0.376)$ & -0.021 & $(0.362)$ \\
\hline$\%$ of Pop Age $25+w /$ Ed $>$ Bachelors & -0.557 & $(0.481)$ & -0.376 & $(0.475)$ & -0.016 & $(0.507)$ \\
\hline $\begin{array}{l}\% \text { of Households Married-Couple- } \\
\text { w-Kids }<18\end{array}$ & -2.454 & $(0.876)^{* *}$ & -2.284 & $(0.707)^{* *}$ & -1.821 & $(0.666)^{* *}$ \\
\hline Median Family Income & 0.945 & $(0.197)^{* *}$ & 0.958 & $(0.174)^{* *}$ & 0.684 & $(0.197)^{* *}$ \\
\hline$\%$ of Pop Who Are Non-White & -0.497 & $(0.245)^{*}$ & -0.473 & $(0.216)^{*}$ & -0.660 & $(0.226)^{* *}$ \\
\hline Population Density & 0.115 & $(0.147)$ & 0.171 & $(0.154)$ & 0.225 & $(0.156)$ \\
\hline $\begin{array}{l}\% \text { of Housing Units that are Vacant } \\
\text { Urbanicity }\end{array}$ & -1.164 & $(0.507)^{*}$ & -0.663 & $(0.358) \dagger$ & -0.529 & $(0.347)$ \\
\hline City & -0.049 & $(0.114)$ & -0.102 & $(0.117)$ & -0.215 & $(0.121) \dagger$ \\
\hline Rural & -0.112 & $(0.070)$ & -0.126 & $(0.065) \dagger$ & -0.132 & $(0.064)^{*}$ \\
\hline Cut1 & 7.801 & $(1.906)$ & 7.992 & $(1.685)$ & 5.364 & $(1.898)$ \\
\hline Cut2 & 9.180 & $(1.912)$ & 9.598 & $(1.690)$ & 7.031 & $(1.898)$ \\
\hline Log pseudolikelihood & $-2,2$ & 28.427 & $-3,0$ & 53.960 & $-3,2$ & 2.323 \\
\hline $\mathrm{N}$ & & 354 & & 332 & & 570 \\
\hline P-value & & 000 & & 000 & & 00 \\
\hline
\end{tabular}

Note: Standard errors are in parentheses and clustered at the school level.

** Indicates statistical significance at the $1 \%$ level.

* Indicates statistical significance at the 5\% level.

$\dagger$ Indicates statistical significance at the $10 \%$ level. 
Appendix I Ordered probit estimation results for intra-district MJH school transfers. Radius: 5,10 , and 20 miles

\begin{tabular}{|c|c|c|c|c|c|c|}
\hline & \multicolumn{2}{|c|}{$5 \mathrm{~m}$} & \multicolumn{2}{|c|}{$10 \mathrm{~m}$} & \multicolumn{2}{|c|}{$20 \mathrm{~m}$} \\
\hline & Estimate & $(\mathrm{SE})$ & Estimate & $(\mathrm{SE})$ & Estimate & $(\mathrm{SE})$ \\
\hline \multicolumn{7}{|l|}{ Teacher } \\
\hline Female & 0.006 & $(0.059)$ & 0.036 & $(0.058)$ & 0.027 & $(0.058)$ \\
\hline \multicolumn{7}{|l|}{ Race (versus White) } \\
\hline Asian/Pacific Islander & -0.245 & $(0.312)$ & -0.199 & $(0.296)$ & -0.184 & $(0.293)$ \\
\hline American Indian & 0.306 & $(0.740)$ & 0.139 & $(0.670)$ & 0.160 & $(0.651)$ \\
\hline Black & -0.259 & $(0.122)^{*}$ & -0.202 & $(0.121) \dagger$ & -0.174 & $(0.122)$ \\
\hline Hispanic & -0.109 & $(0.266)$ & -0.219 & $(0.286)$ & -0.126 & $(0.290)$ \\
\hline Has a master's degree/Ph.D. & 0.207 & $(0.061)^{* *}$ & 0.181 & $(0.061)^{* *}$ & 0.189 & $(0.062)^{* *}$ \\
\hline Experience & -0.003 & $(0.004)$ & -0.003 & $(0.004)$ & -0.002 & $(0.004)$ \\
\hline Salary premium & -0.459 & $(0.386)$ & -0.670 & $(0.395) \dagger$ & -0.871 & $(0.380)^{*}$ \\
\hline \multicolumn{7}{|l|}{ School } \\
\hline Low-income school & -0.249 & $(0.165)$ & -0.340 & $(0.169)^{*}$ & -0.534 & $(0.170)^{* *}$ \\
\hline High-income school & 0.345 & $(0.144)^{*}$ & 0.416 & $(0.169)^{*}$ & 0.370 & $(0.169)^{*}$ \\
\hline \multicolumn{7}{|l|}{ Neighboring schools } \\
\hline Inside-district low-income school & -3.129 & $(0.495)^{* *}$ & -5.425 & $(1.762)^{* *}$ & -16.316 & $(2.641)^{* *}$ \\
\hline Inside-district high-income school & 1.623 & $(0.247)^{* *}$ & 2.498 & $(0.453)^{* *}$ & 2.135 & $(0.595)^{* *}$ \\
\hline Outside-district low-income school & -0.186 & $(0.587)$ & -0.087 & $(0.601)$ & 0.248 & $(0.665)$ \\
\hline $\begin{array}{l}\text { Outside-district high-income school } \\
\text { District }\end{array}$ & 1.133 & $(0.355)^{* *}$ & 0.647 & $(0.325)^{*}$ & -0.096 & $(0.402)$ \\
\hline $\begin{array}{l}\text { District enrollment } \\
\text { Neighborhood }\end{array}$ & 0.232 & $(0.100)^{*}$ & 0.141 & $(0.131)$ & 0.328 & $(0.118)^{* *}$ \\
\hline $\begin{array}{l}\text { \% of Pop Living in Same House } 5 \\
\text { Yrs Ago }\end{array}$ & -0.462 & $(0.907)$ & 0.868 & $(1.000)$ & 0.670 & $(1.030)$ \\
\hline$\%$ of Pop Age $25+w /$ Ed $>$ Bachelors & -0.314 & $(0.533)$ & -0.958 & $(0.648)$ & -1.140 & $(0.699)$ \\
\hline $\begin{array}{l}\% \text { of Households Married-Couple- } \\
\text { w-Kids }<18\end{array}$ & -0.979 & $(1.616)$ & -1.383 & $(1.731)$ & -0.831 & $(1.753)$ \\
\hline Median Family Income & 0.190 & $(0.440)$ & 0.703 & $(0.514)$ & 0.955 & $(0.528) \dagger$ \\
\hline$\%$ of Pop Who Are Non-White & -0.913 & $(0.476) \dagger$ & -1.230 & $(0.429)^{* *}$ & -1.600 & $(0.434)^{* *}$ \\
\hline Population Density & -0.205 & $(0.281)$ & -0.254 & $(0.269)$ & -0.282 & $(0.299)$ \\
\hline $\begin{array}{l}\% \text { of Housing Units that are Vacant } \\
\text { Urbanicity }\end{array}$ & 1.981 & $(2.078)$ & 2.128 & $(2.292)$ & 4.911 & $(2.025)^{*}$ \\
\hline City & -0.313 & $(0.137)^{*}$ & -0.193 & $(0.149)$ & -0.060 & $(0.154)$ \\
\hline Rural & -0.048 & $(0.165)$ & 0.058 & $(0.167)$ & -0.015 & $(0.197)$ \\
\hline Cut1 & 0.493 & $(4.200)$ & 6.196 & $(4.928)$ & 8.776 & $(5.030)$ \\
\hline Cut2 & 2.466 & $(4.195)$ & 8.134 & $(4.932)$ & 10.661 & $(5.041)$ \\
\hline Log pseudolikelihood & $-1,3$ & 07.551 & $-1,3$ & 35.985 & $-1,3$ & 64.976 \\
\hline $\mathrm{N}$ & & 066 & & 071 & & 071 \\
\hline P-value & & 000 & & 000 & & 000 \\
\hline
\end{tabular}

Note: Standard errors are in parentheses and clustered at the school level.

** Indicates statistical significance at the $1 \%$ level.

* Indicates statistical significance at the 5\% level.

$\dagger$ Indicates statistical significance at the $10 \%$ level. 
Appendix J Ordered probit estimation results for inter-district MJH school transfers. Radius: 5, 10, and 20 miles

\begin{tabular}{|c|c|c|c|c|c|c|}
\hline & \multicolumn{2}{|c|}{5 miles } & \multicolumn{2}{|c|}{10 miles } & \multicolumn{2}{|c|}{20 miles } \\
\hline & Estimate & $(\mathrm{SE})$ & Estimate & $(\mathrm{SE})$ & Estimate & $(\mathrm{SE})$ \\
\hline \multicolumn{7}{|l|}{ Teacher } \\
\hline$\overline{\text { Female }}$ & -0.002 & $(0.041)$ & -0.010 & $(0.038)$ & -0.004 & $(0.037)$ \\
\hline \multicolumn{7}{|l|}{ Race (versus White) } \\
\hline Asian/Pacific Islander & -0.114 & $(0.340)$ & -0.106 & $(0.356)$ & -0.130 & $(0.363)$ \\
\hline American Indian & 0.012 & $(0.283)$ & 0.025 & $(0.269)$ & 0.028 & $(0.247)$ \\
\hline Black & -1.241 & $(0.114)^{* *}$ & -1.271 & $(0.117)^{* *}$ & -1.301 & $(0.118)^{* *}$ \\
\hline Hispanic & -0.299 & $(0.254)$ & -0.357 & $(0.240)$ & -0.491 & $(0.229) *$ \\
\hline Has a master's degree/Ph.D. & 0.199 & $(0.047)^{* *}$ & 0.199 & $(0.044)^{* *}$ & 0.188 & $(0.043)^{* *}$ \\
\hline Experience & -0.017 & $(0.004)^{* *}$ & -0.016 & $(0.003)^{* *}$ & -0.015 & $(0.003)^{* *}$ \\
\hline Salary premium & 0.432 & $(0.372)$ & 0.561 & $(0.349)$ & 0.506 & $(0.344)$ \\
\hline \multicolumn{7}{|l|}{ School } \\
\hline Low-income school & -0.388 & $(0.088)^{* *}$ & -0.345 & $(0.078)^{* *}$ & -0.235 & $(0.076)^{* *}$ \\
\hline High-income school & 0.125 & $(0.073) \dagger$ & 0.096 & $(0.071)$ & 0.061 & $(0.065)$ \\
\hline \multicolumn{7}{|l|}{ Neighboring schools } \\
\hline Inside-district low-income school & -0.226 & $(0.122) \dagger$ & -0.306 & $(0.131)^{*}$ & -0.773 & $(0.544)$ \\
\hline Inside-district high-income school & 0.062 & $(0.086)$ & 0.354 & $(0.152)^{*}$ & 0.684 & $(0.344)^{*}$ \\
\hline Outside-district low-income school & -0.047 & $(0.135)$ & -0.204 & $(0.136)$ & -0.586 & $(0.183)^{* *}$ \\
\hline $\begin{array}{l}\text { Outside-district high-income school } \\
\text { District }\end{array}$ & 0.065 & $(0.131)$ & 0.108 & $(0.097)$ & 0.636 & $(0.114)^{* *}$ \\
\hline $\begin{array}{l}\text { District enrollment } \\
\text { Neighborhood }\end{array}$ & 0.109 & $(0.047)^{*}$ & 0.094 & $(0.046)^{*}$ & 0.090 & $(0.051) \dagger$ \\
\hline $\begin{array}{l}\text { \% of Pop Living in Same House } 5 \\
\text { Yrs Ago }\end{array}$ & 0.262 & $(0.407)$ & 0.683 & $(0.338)^{*}$ & 0.719 & $(0.319)^{*}$ \\
\hline$\%$ of Pop Age $25+w /$ Ed $>$ Bachelors & -0.903 & $(0.395)^{*}$ & -0.710 & $(0.399) \dagger$ & -0.257 & $(0.406)$ \\
\hline $\begin{array}{l}\% \text { of Households Married-Couple- } \\
\text { w-Kids }<18\end{array}$ & -2.153 & $(0.702)^{* *}$ & -1.887 & $(0.670)^{* *}$ & -1.586 & $(0.678)^{*}$ \\
\hline Median Family Income & 0.989 & $(0.158)^{* *}$ & 0.909 & $(0.147)^{* *}$ & 0.600 & $(0.149)^{* *}$ \\
\hline$\%$ of Pop Who Are Non-White & -0.248 & $(0.246)$ & -0.227 & $(0.227)$ & -0.522 & $(0.236)^{*}$ \\
\hline Population Density & 0.143 & $(0.162)$ & 0.169 & $(0.158)$ & 0.238 & $(0.162)$ \\
\hline $\begin{array}{l}\% \text { of Housing Units that are Vacant } \\
\text { Urbanicity }\end{array}$ & -0.356 & $(0.427)$ & -0.277 & $(0.394)$ & -0.149 & $(0.360)$ \\
\hline City & 0.057 & $(0.106)$ & 0.040 & $(0.108)$ & -0.066 & $(0.111)$ \\
\hline Rural & -0.064 & $(0.058)$ & -0.086 & $(0.056)$ & -0.096 & $(0.056) \dagger$ \\
\hline Cut1 & 8.338 & $(1.518)$ & 7.809 & $(1.406)$ & 4.857 & $(1.408)$ \\
\hline Cut2 & 9.714 & $(1.523)$ & 9.294 & $(1.409)$ & 6.397 & $(1.411)$ \\
\hline Log pseudolikelihood & $-3,1$ & 85.426 & $-3,7$ & 26.689 & $-3,8$ & 5.400 \\
\hline $\mathrm{N}$ & & 458 & & 083 & & 266 \\
\hline P-value & & 000 & & 000 & & 00 \\
\hline
\end{tabular}

Note: Standard errors are in parentheses and clustered at the school level.

** Indicates statistical significance at the $1 \%$ level.

* Indicates statistical significance at the 5\% level.

$\dagger$ Indicates statistical significance at the $10 \%$ level. 
Appendix K Percentages of correctly predicted teacher moves based on ordered probit estimates

\begin{tabular}{|c|c|c|c|c|}
\hline & \multicolumn{3}{|c|}{ Importing school } \\
\hline & & High-income $(\%)$ & Middle-income (\%) & Low-income $(\%)$ \\
\hline \multirow[t]{2}{*}{ Elementary } & Intra-district & 69.82 & 60.92 & 75.84 \\
\hline & Inter-district & 25.68 & 91.02 & 24.23 \\
\hline \multirow[t]{2}{*}{$\mathrm{MJH}$} & Intra-district & 60.84 & 66.84 & 84.47 \\
\hline & Inter-district & 52.84 & 76.76 & 21.87 \\
\hline
\end{tabular}


Appendix L Available data for estimating principal turnover at different timing for each cohort in the analytical sample

\begin{tabular}{lccc}
\hline $\begin{array}{l}\text { Timing of principal } \\
\text { turnover }\end{array}$ & Cohort 2006-2007 & Cohort 2007-2008 & Cohort 2008-2009 \\
\hline Three years ago & School year & School year & School year \\
& $2003-2004$ & $2004-2005$ & $2005-2006$ \\
Two years ago & School year & School year & School year \\
& $2004-2005$ & $2005-2006$ & $2006-2007$ \\
Previous & School year & School year & School year \\
& $2005-2006$ & $2006-2007$ & $2007-2008$ \\
Current & School year & School year & School year \\
& $2006-2007$ & $2007-2008$ & $2008-2009$ \\
One year later & School year & School year & \\
& $2007-2008$ & $2008-2009$ & \\
Two years later & School year & & \\
& $2008-2009$ & & \\
\hline
\end{tabular}


Appendix M Estimates for the other coefficients from equation (10) and (12)

\begin{tabular}{|c|c|c|c|c|}
\hline & \multicolumn{2}{|c|}{ Math } & \multicolumn{2}{|c|}{ Reading } \\
\hline & OLS & IV & OLS & IV \\
\hline \multirow{2}{*}{ Lagged math score } & 0.624 & 0.624 & 0.239 & 0.239 \\
\hline & $(0.002)^{* *}$ & $(0.002)^{* *}$ & $(0.002)^{* *}$ & $(0.002)^{* *}$ \\
\hline \multirow{2}{*}{ Lagged reading score } & 0.212 & 0.212 & 0.597 & 0.597 \\
\hline & $(0.002)^{* *}$ & $(0.002)^{* *}$ & $(0.002)^{* *}$ & $(0.002)^{* *}$ \\
\hline \multirow{2}{*}{ Student is black } & -0.102 & -0.102 & -0.033 & -0.033 \\
\hline & $(0.003)^{* *}$ & $(0.003)^{* *}$ & $(0.003)^{* *}$ & $(0.003)^{* *}$ \\
\hline \multirow{2}{*}{ Student is Hispanic } & -0.016 & -0.016 & -0.001 & -0.001 \\
\hline & $(0.004)^{* *}$ & $(0.004)^{* *}$ & $(0.004)$ & $(0.004)$ \\
\hline \multirow{2}{*}{ Student is female } & -0.049 & -0.049 & 0.116 & 0.116 \\
\hline & $(0.001)^{* *}$ & $(0.001)^{* *}$ & $(0.002)^{* *}$ & $(0.002)^{* *}$ \\
\hline \multirow{2}{*}{ Student is free-lunch eligible } & -0.067 & -0.067 & -0.075 & -0.075 \\
\hline & $(0.002)^{* *}$ & $(0.002)^{* *}$ & $(0.002)^{* *}$ & $(0.002)^{* *}$ \\
\hline \multirow{2}{*}{ Student is in $4^{\text {th }}$ grade } & -0.139 & -0.139 & -0.129 & -0.129 \\
\hline & $(0.012)^{* *}$ & $(0.012)^{* *}$ & $(0.010)^{* *}$ & $(0.010)^{* *}$ \\
\hline \multirow{2}{*}{ Student is in $5^{\text {th }}$ grade } & -0.119 & -0.119 & -0.111 & -0.111 \\
\hline & $(0.011)^{* *}$ & $(0.011)^{* *}$ & $(0.010)^{* *}$ & $(0.010)^{* *}$ \\
\hline \multirow{2}{*}{ Student is in $6^{\text {th }}$ grade } & -0.048 & -0.047 & -0.045 & -0.045 \\
\hline & $(0.009)^{* *}$ & $(0.009)^{* *}$ & $(0.008)^{* *}$ & $(0.008)^{* *}$ \\
\hline \multirow{2}{*}{ Student is in $7^{\text {th }}$ grade } & -0.004 & -0.004 & -0.002 & -0.002 \\
\hline & $(0.007)$ & $(0.007)$ & $(0.006)$ & $(0.006)$ \\
\hline \multirow{2}{*}{ Principal's age } & 0.010 & 0.011 & 0.013 & 0.013 \\
\hline & $(0.006)$ & $(0.006)$ & $(0.006)^{*}$ & $(0.006)^{*}$ \\
\hline \multirow{2}{*}{ Principal's age squared } & -0.000 & 0.000 & 0.000 & 0.000 \\
\hline & $(0.000$ & $(0.000)$ & $(0.000)^{*}$ & $(0.000)^{*}$ \\
\hline \multirow{2}{*}{ Principal's experience } & -0.005 & -0.005 & -0.006 & -0.006 \\
\hline & $(0.002) \dagger$ & $(0.002)^{*}$ & $(0.002)^{*}$ & $(0.002)^{*}$ \\
\hline \multirow{2}{*}{ Principal's experience squared } & 0.000 & 0.000 & 0.000 & 0.000 \\
\hline & $(0.000) \dagger$ & $(0.000)^{*}$ & $(0.000)^{* *}$ & $(0.000)^{* *}$ \\
\hline \multirow{2}{*}{ Principal's highest degree is master's } & 0.002 & 0.002 & 0.004 & 0.003 \\
\hline & $(0.024)$ & $(0.024)$ & $(0.017)$ & $(0.016)$ \\
\hline \multirow{2}{*}{ Principal's highest degree is education specialist } & -0.002 & -0.003 & 0.011 & 0.010 \\
\hline & $(0.025)$ & $(0.025)$ & $(0.018)$ & $(0.018)$ \\
\hline \multirow{2}{*}{ Principal's highest degree is Ph.D. } & -0.007 & -0.009 & 0.008 & 0.005 \\
\hline & $(0.026)$ & $(0.026)$ & $(0.019)$ & $(0.019)$ \\
\hline & -0.010 & -0.011 & 0.011 & 0.008 \\
\hline Principal is black & $(0.029)$ & $(0.029)$ & $(0.028)$ & $(0.028)$ \\
\hline Princinal is Hisnanic & 0.004 & 0.004 & 0.049 & 0.048 \\
\hline & $(0.059)$ & $(0.057)$ & $(0.071)$ & $(0.069)$ \\
\hline & -0.006 & -0.005 & -0.002 & 0.000 \\
\hline Principal is temale & $(0.009)$ & $(0.009)$ & $(0.007)$ & $(0.008)$ \\
\hline Princinal's salary & 0.000 & 0.000 & 0.000 & 0.000 \\
\hline Principal s sarary & $(0.000)$ & $(0.000)$ & $(0.000) \dagger$ & $(0.000)$ \\
\hline Percentage of hlack students at the school & 0.001 & 0.000 & 0.000 & -0.001 \\
\hline Percentage or biack students at the scnoor & $(0.001)$ & $(0.001)$ & $(0.001)$ & $(0.001)$ \\
\hline & 0.002 & 0.002 & 0.001 & 0.001 \\
\hline Percentage of Hispanic students at the school & $(0.002)$ & $(0.002)$ & $(0.002)$ & $(0.002)$ \\
\hline Percentage of free-lunch eligible students at the school & -0.000 & 0.000 & -0.001 & -0.001 \\
\hline 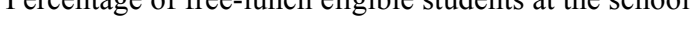 & $(0.000)$ & $(0.000)$ & $(0.000)^{*}$ & $(0.000)^{*}$ \\
\hline & -0.000 & 0.000 & 0.000 & 0.000 \\
\hline Enrollment at the school & $(0.000)^{*}$ & $(0.000)$ & $(0.000)^{*}$ & $(0.000)^{*}$ \\
\hline $\mathrm{N}$ & 816,493 & 816,493 & 816,493 & 816,493 \\
\hline R-squared & 0.713 & 0.713 & 0.687 & 0.687 \\
\hline
\end{tabular}

Note: Standard errors are clustered at the school level. ${ }^{* *}$ Indicates statistical significance at the $1 \%$ level.

$*$ Indicates statistical significance at the $5 \%$ level. $\uparrow$ Indicates statistical significance at the $10 \%$ level. 


\section{References}

Aaronson, Daniel, Lisa Barrow, and William Sander. 2007. "Teachers and Student Achievement in the Chicago Public High Schools." Journal of Labor Economics 25(1): 95- 135.

Adams, Gerald J. 1996. "Using a Cox Regression Model to Examine Voluntary Teacher Turnover.” Journal of Experimental Education 64(3): 267-285.

Aud, Susan, Hussar, William, Kena, Grace, Bianco, Kevin, Frohlich, Lauren, Kemp, Jana, Tahan, Kim (2011). The Condition of Education 2011 (NCES 2011-033). U.S. Department of Education, National Center for Education Statistics. Washington, DC: U.S. Government Printing Office.

Audas, Rick, Stephen Dobson, and John Goddard. 2002. "The Impact of Managerial Change on Team Performance in Professional Sports." Journal of Economics and Business 54: 633-650.

Ballou, Dale, and Michael J. Podgursky.1993. "What Makes a Good Principal? How Teachers Assess the Performance of Principals." Economics of Education Review 14(3): $243-252$.

Beteille, Tara, Demetra Kalogrides, and Susanna Loeb. 2011.“Stepping Stones: Principal Career Paths and School Outcomes." National Bureau of Economic Research Working Paper \#17243.

Blank, Rolf K. 1987. "The Role of Principal as Leader: Analysis of Variation in Leadership of Urban High Schools." Journal of Educational Research 81(2): 69-80.

Boyd, Donald, Hamilton Lankford, Susanna Loeb, Mathew Ronfeldt, and James Wyckoff. 2011. "The Role of Teacher Quality in Retention and Hiring: Using Applications-to-Transfer to Uncover Preferences of Teachers and Schools." Journal of Policy Analysis and Management 30(1): 88-110.

Boyd, Donald, Hamilton Lankford, Susanna Loeb, and James Wyckoff. 2005a. "The Draw of Home: How Teachers' Preferences for Proximity Disadvantage Urban Schools." Journal of Policy Analysis and Management 24(1): 113-132.

_. 2005b. "Explaining the Short Careers of High-Achieving Teachers in Schools with Low-Performing Students." American Economic Review 95(2): 166-171.

Brewer, Dominic J. 1993. "Principals and Student Outcomes: Evidence from U.S. High Schools." Economics of Education Review 12(4): 281-293.

Clark, Damon, Paco Martorell, and Jonah Rockoff. 2009. "School Principals and School Performance." National Center for Analysis of Longitudinal Data in Education Research. CALDER Working Paper \#38. 
Clotfelter, Charles T., Helen F. Ladd, and Jacob Vigdor. 2005. "Who Teaches Whom? Race and the Distribution of Novice Teachers." Economics of Education Review 24 (4): 377-392.

. 2006. "Teacher-Student Matching and the Assessment of Teacher Effectiveness." Journal of Human Resources 41(4): 778-820.

- 2007. "How and Why Do Teacher Credentials Matter for Student Achievement?" National Bureau of Economic Research Working Paper \#12828.

Denis, David J., and Diane K. Denis. 1995. "Performance Changes Following Top Management Dismissals." The Journal of Finance 50:1029-1057.

Eberts, Randall W., and Joe A. Stone. 1988. "Student Achievement in Public Schools: Do Principals Make a Difference?" Economics of Education Review 7(3): 291-299.

Edmonds, Ronald R. 1979. "Effective schools for the urban poor." Educational Leadership 37(1): 15-24.

Education Week. 2003. "Quality Counts 2003. If I Can't Learn from You: Ensuring a Highly Qualified Teacher for Every Classroom.” Education Week 22(17): 1-182.

Gates, Susan M., Jeanne S. Ringel, Lucrecia Santibanez, Cassandra Guarino, Bonnie Ghosh-Dastidar, and Abigail Brown. 2006. "Mobility and Turnover Among School Principals.” Economics of Education Review 25: 289-302.

Glazerman, Steven, Ali Protik, Bing-ru Teh, Julie Bruch, and Neil Seftor. 2012. "Moving High-Performing Teachers: Implementation of Transfer Incentives in Seven Districts." NCEE 2012-4051. Washington, DC: National Center for Education Evaluation and Regional Assistance, Institute of Education Sciences, U.S. Department of Education.

Goldhaber, Dan, Betheny Gross, and Daniel Player. 2007. “Are Public Schools Really Losing Their "Best"? Assessing The Career Transitions of Teachers and Their Implications for the Quality of the Teacher Workforce." University of Washington, Center for Education Data \& Research Working Paper 20007-2.

Gritz, R. Mark, and Neil D. Theobald. 1996. "The Effects of School District Spending Priorities on Length of Stay in Teaching." Journal of Human Resources 31(3): 477512.

Hanushek, Eric A, John F. Kain, and Steven G. Rivkin. 2004. "Why Public Schools Lose Teachers." Journal of Human Resources 39(2): 326-354.

Hanushek, Eric A., John F. Kain, Daniel M. O'Brien, and Steven G. Rivkin. 2005. "The Market for Teacher Quality.” National Bureau of Economic Research Working Paper \#11154. 
Henke, Robin R., Xianglei Chen, Sonya Geis, and Paula Knepper. 2000. "Progress

Through the Teacher Pipeline: 1992-93 College Graduates and Elementary/Secondary Teaching as of 1997." National Center for Education Statistics 2000-152.

Henke, Robin R., Lisa Zahn, and C. Dennis Carroll. 2001. "Attrition of new teachers among recent college graduates: Comparing occupational stability among 1992-1993 college graduates who taught and those who worked in other occupations." National Center for Education Statistics 2001-189.

Ingersoll, Richard. 2001. "Teacher Turnover and Teacher Shortages: An Organizational Analysis.” American Educational Research Journal 38(3): 499-534.

Ingersoll, Richard, and Nabeel Alsalam. 1997. "Teacher Professionalization and Teacher Commitment: A Multilevel Analysis.” National Center for Education Statistics 97-069.

Jacob, Brian. 2007. "The Challenges of Staffing Urban Schools with Effective Teachers." The Future of Children 17(1): 129-53.

Kane, Thomas J., Jonah E. Rockoff, and Douglas O. Staiger. 2006. "What Does Certification Tell Us About Teacher Effectiveness? Evidence from New York City." Cambridge: National Bureau of Economic Research Working Paper \#12155.

Kirby, Sheila Nataraj, Mark Berends, and Scott Naftel. 1999. "Supply and Demand of Minority Teachers in Texas: Problems and Prospects." Educational Evaluation and Policy Analysis 21(1): 47-66.

Koedel, Cory, and Julian R. Betts. 2007. "Re-Examining the Role of Teacher Quality in the Educational Production Function." University of Missouri Working Paper 0708 .

- 2011. "Does Student Sorting Invalidate Value-Added Models of Teacher Effectiveness? An Extended Analysis of the Rothstein Critique." Education Finance and Policy 6(1): 18-42.

Koedel, Cory, Shawn Ni, and Michael Podgursky. 2012. "Who Benefits from Pension Enhancements?” University of Missouri Working Paper 12-07.

Krieg, John M. 2006. “Teacher Quality and Attrition.” Economics of Education Review 25(1): $13-27$.

Lankford, Hamilton, Susanna Loeb, and James Wyckoff. 2002. "Teacher Sorting and the Plight of Urban Schools: A Descriptive Analysis." Educational Evaluation and Policy Analysis 24(1): 37-62.

Li, Feng and Tim Sass. 2010. "Teacher Quality and Teacher Mobility.” CALDER, The Urban Institute Working Paper 57. 
Loeb, Susanna, Demetra Kalogrides, and Eileen Horng. 2010. "Principal Preferences and the Unequal Distribution of Principals Across Schools." Education Evaluation and Policy Analysis 32: 205-229.

Miller, Ashley. 2009. "Principal Turnover, Student Achievement and Teacher Retention." Unpublished manuscript. Retrieved on March 1, 2013, from http://www.ers.princeton.edu/Miller.pdf

Podgursky, Michael. 2007. "Teams Versus Bureaucracies: Personnel Policy, WageSetting, and Teacher Quality in Traditional Public, Charter, and Private Schools." In M. Berends, M. G. Springer, \& H. Walberg (Eds.), Charter School Outcomes. Mahwah, NJ: Lawrence Erlbaum Associates.

Podgursky, Michael, Ryan Monroe, and Donald Watson. 2004. "The Academic Quality of Public School Teachers: An Analysis of Entry and Exit Behavior." Economics of Education Review 23(5): 507-518.

Podgursky, Michael, Donald Watson, Mark Ehlert, Michael Walker, and William Foster. 2004. "A Statistical Analysis of the Labor Market for Missouri Public School Teachers: 1994-95 to 1998-99." Retrieved on September 23, 2012 http://web.missouri.edu/\%7Epodgurskym/papers_presentations/reports/final99c.pdf

Purkey, Stewart C., and Marshall S. Smith. 1983. "Effective Schools: A Review." The Elementary School Journal 83(4): 427-452.

Reininger, Michelle. 2012. "Hometown Disadvantage? It Depends on Where You're From: Teachers' Location Preference and the Implications for Staffing Schools." Educational Evaluation and Policy Analysis 34(2): 127-145.

Rivkin, Steven G., Eric A. Hanushek, and John F. Kain. 2005. "Teachers, Schools and Academic Achievement." Econometrica 73(2): 417-458.

Rockoff, Jonah E. 2004. "The Impact of Individual Teachers on Student Achievement: Evidence from Panel Data," American Economic Review 94(2): 247-252.

Sass, Tim R., Jane Hannaway, Zeyu Xu, David N. Figlio, and Li Feng. 2012. "Value Added of Teachers in High-Poverty Schools and Lower Poverty Schools." Journal of Urban Economics 72(2-3): 104-22.

West, Martin R., and Matthew M. Chingos. 2009. “Teacher Effectiveness, Mobility, and Attrition in Florida." In M. G. Springer (Ed.), Performance Incentives: Their Growing Impact on American K-12 Education (pp. 251-271): Brookings Institution Press.

Wooldridge, Jeffrey M. 2002. Econometric Analysis of Cross Section and Panel Data. Cambridge, MA: The MIT Press. 


\section{VITA}

Shishan Shi received a B.A. in Economics from University of Colorado at Denver and China Agricultural University in 2004, and a Ph.D. in Economics from the University of Missouri in 2013. She is an applied econometrician specializing in panel data modeling. Her primary research interests are discrete choice modeling, spatial analysis and survival analysis. She also has a variety of other research interests, such as labor economics, value-added modeling, time series analysis, and Bayesian analysis.

She was a research assistant for Education and Policy Analysis Research Center from January 2010 to May 2013. She is experienced with large data sets that have millions of records in both Linux and PC environment. She has worked with various data sets, such as the U.S. Census, Common Core Data, survey data and restricted administrative data sets (e.g., student level statewide records, teacher employment history). She is currently working on several projects on teacher labor markets. 